\title{
Results of Pressure Locking and Thermal Binding Tests of Gate Valves
}

Prepared by

K. G. DeWall, J. C. Watkins,

M. G. McKellar, D. Bramwell

Idaho National Engineering and Environmental Laboratory

Lockheed Martin Idaho Technologies Company

\author{
RECEIVED
JUN 081998 \\ OSTI
}

Prepared for

U.S. Nuclear Regulatory Commission

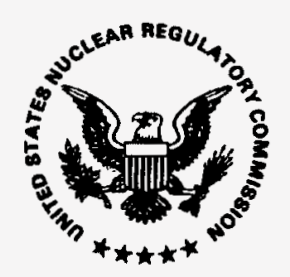




\section{AVAILABILITY NOTICE}

Availability of Reference Materials Cited in NRC Publications

Most documents cited in NRC publications will be avallable from one of the following sources:

1. The NRC Public Document Room, 2120 L Street, NW., Lower Level. Washington. DC 20555-0001

2. The Superintendent of Documents, U.S. Government Printing Office. P. O. B0x 37082, Washington, DC 20402-9328

3. The National Technical Information Service, Springfield, VA 22161-0002

Although the listing that follows represents the majority of documents cited in NRC publications, it is not intended to be exhaustive.

Referenced documents avallable for inspection and copying for a fee from the NRC Public Document Room Include NRC correspondence and internal NRC memoranda: NRC bulletins, circulars, information notices, inspection and investigation notices; licensee event reports; vendor reports and correspondence: Commission papers; and applicant and licensee documents and correspondence.

The following documents in the NUREG serles are available for purchase from the Government Printing Office: formal NRC staff and contractor reports. NRC-sponsored conference proceedings, international agreement reports, grantee reports, and NRC booklets and brochures. Also available are regulatory guides, NRC regulations in the Code of Federal Regulations, and Nuclear Regulatory Commission Issuances.

Documents avallable from the National Technical Information Service include NUREG-series reports and technical reports prepared by other Federal agencles and reports prepared by the Atomic Energy Commission. forerunner agency to the Nuclear Regulatory Commission.

Documents avallable from public and special technical libraries include all open literature items, such as books. journal articles, and transactions. Federal Register notices. Federal and State legislation, and congressional reports can usually be obtained from these libraries.

Documents such as theses, dissertations, foreign reports and translations, and non-NRC conference proceedings are avallable for purchase from the organization sponsoring the publication cited.

Single coples of NAC draft reports are available free. to the extent of supply. upon written request to the Office of Administration, Distribution and Mall Services Section, U.S. Nuclear Regulatory Commission, Washington, DC 20555-0001.

Coples of industry codes and standards used in a substantive manner in the NRC regulatory process are maintalned at the NRC Lbrary. Two White Filnt North, 11545 Rockville Pike. Rockville. MD 20852-2738, for use by the public. Codes and standards are usually copyrighted and may be purchased from the originating organization or, If they are Amerlcan National Standards. from the American National Standards Institute. 1430 Broadway, Now York, NY 10018-3308.

\section{DISCLAIMER NOTICE}

This report was prepared as an account of work sponsored by an agency of the United States Govemment. Neither the United States Government nor any agency thereol, nor any of their employees, makes any warranty, expressed or implied, or assumes any legal liability or responsibility for any third party's use, or the results of such use, of any information, apparatus, product, or process disclosed in this report, or represents that its use by such third party would not infringe privately owned rights. 


\section{DISCLAIMER}

This report was prepared as an account of work sponsored by an agency of the United States Government. Neither the United States Government nor any agency thereof, nor any of their employees, makes any warranty, express or implied, or assumes any legal liability or responsibility for the accuracy, completeness, or usefulness of any information, apparatus, product, or process disclosed, or represents that its use would not infringe privately owned rights. Reference herein to any specific commercial product, process, or service by trade name, trademark, manufacturer, or otherwise does not necessarily constitute or imply its endorsement, recommendation, or favoring by the United States Government or any agency thereof. The views and opinions of authors expressed herein do not necessarily state or reflect those of the United States Government or any agency thereof. 


\section{Results of Pressure Locking and Thermal Binding Tests of Gate Valves}

Manuscript Completed: April 1998

Date Published: May 1998

Prepared by

K. G. DeWall, J. C. Watkins,

M. G. McKellar, D. Bramwell

Idaho National Engineering and Environmental Laboratory Lockheed Martin Idaho Technologies Company Idaho Falls, ID 83415

G. H. Weidenhamer, NRC Project Manager

\section{Prepared for}

Division of Engineering Technology

Office of Nuclear Regulatory Research

U.S. Nuclear Regulatory Commission

Washington, DC 20555-0001

NRC Job Code W6598

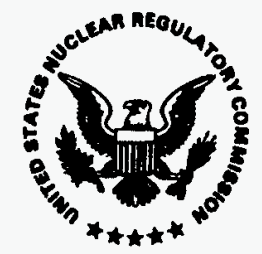




\begin{abstract}
The U.S. Nuclear Regulatory Commission (NRC), Office of Nuclear Regulatory Research, is funding the Idaho National Engineering and Environmental Laboratory (INEEL) in performing research investigating the performance of gate valves subjected to pressure locking and thermal binding conditions. Pressure locking and thermal binding are phenomena that make a closed gate valve difficult to open. Pressure locking can occur when operating sequences or temperature changes cause the pressure of the fluid in the bonnet (and, in most gate valves, between the discs) to be higher than the pressure on the upstream and downstream sides of the disc assembly. Thermal binding can occur when thermal expansion/contraction effects cause the disc to be squeezed between the valve body seats. If the loads associated with pressure locking or thermal binding are very high, the actuator might not have the capacity to open the valve. We tested a flexible-wedge gate valve and a double-disc gate valve under pressure locking and thermal binding conditions. The results show that these valves are susceptible to pressure locking; however, they are not significantly affected by thermal binding. For the flexible-wedge gate valve, pressure locking loads (in terms of stem thrust) were higher than corresponding hydrostatic opening loads by a factor of 1.1 to 1.5 . For the parallel disc gate valve, pressure locking loads were higher by a factor of 2.05 to 2.4 . The results also show that seat leakage affects the bonnet pressurization rate when the valve is subjected to thermally induced pressure locking conditions.
\end{abstract}




\section{CONTENTS}

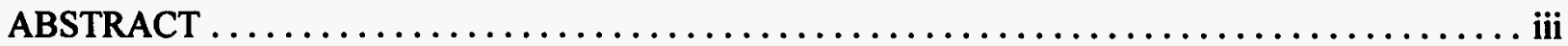

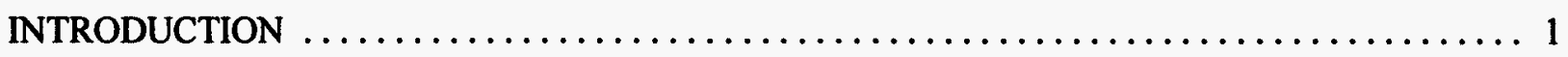

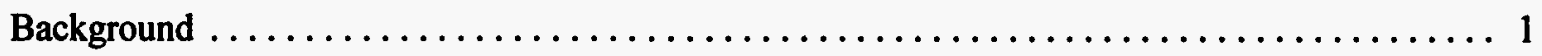

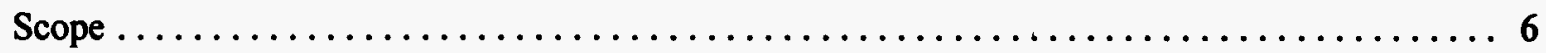

TEST EQUIPMENT $\ldots \ldots \ldots \ldots \ldots \ldots \ldots \ldots \ldots \ldots \ldots \ldots \ldots \ldots \ldots \ldots \ldots \ldots \ldots \ldots$

Walworth Gate Valve $\ldots \ldots \ldots \ldots \ldots \ldots \ldots \ldots \ldots \ldots \ldots \ldots \ldots \ldots \ldots \ldots \ldots, 8$

Anchor/Darling Gate Valve $\ldots \ldots \ldots \ldots \ldots \ldots \ldots \ldots \ldots \ldots \ldots \ldots \ldots \ldots \ldots$

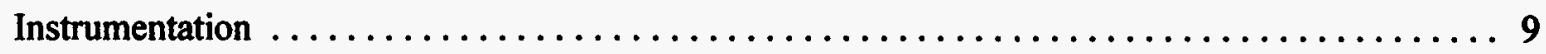

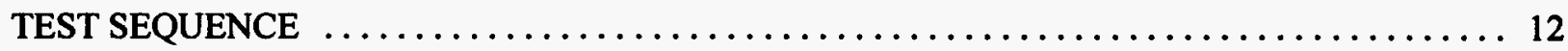

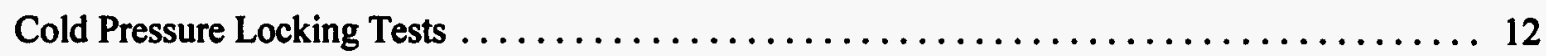

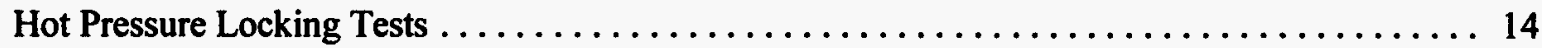

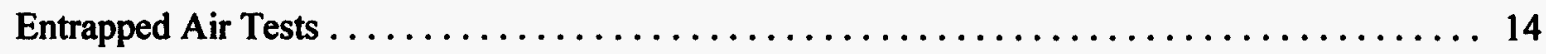

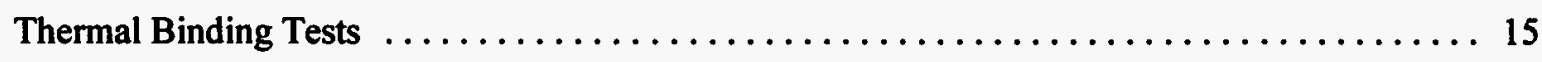

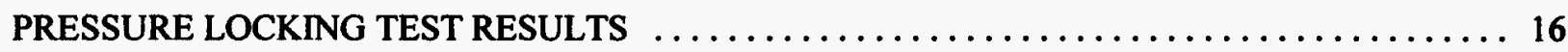

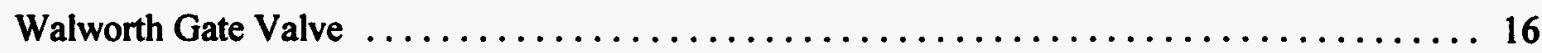

Cold Pressure Locking Tests $\ldots \ldots \ldots \ldots \ldots \ldots \ldots \ldots \ldots \ldots \ldots \ldots \ldots \ldots, \ldots \ldots \ldots$

Hot Pressure Locking Tests $\ldots \ldots \ldots \ldots \ldots \ldots \ldots \ldots \ldots \ldots \ldots \ldots \ldots \ldots \ldots \ldots \ldots \ldots \ldots, 16$

Effects of Valve Leakage $\ldots \ldots \ldots \ldots \ldots \ldots \ldots \ldots \ldots \ldots \ldots \ldots \ldots \ldots, 20$

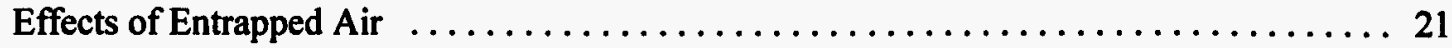

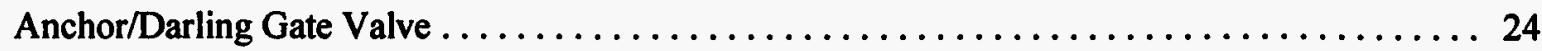

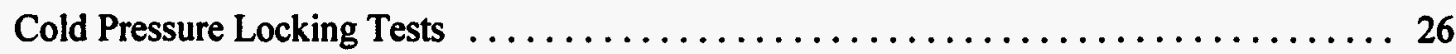

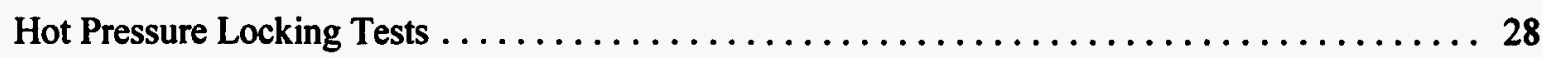

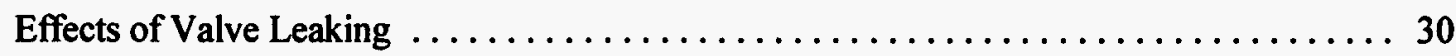

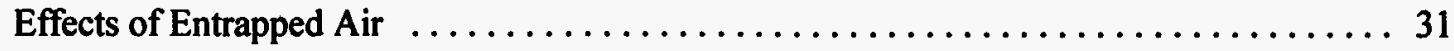

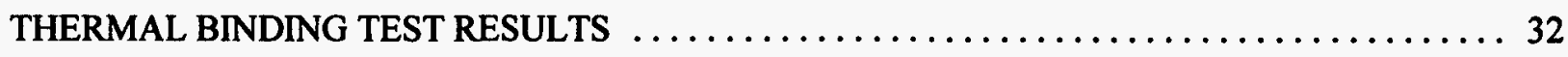

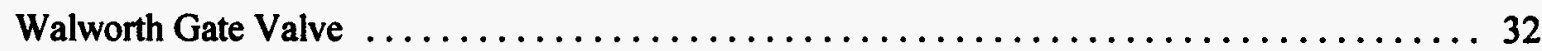




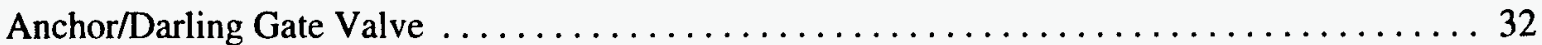

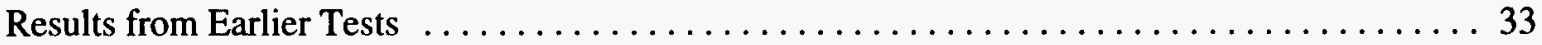

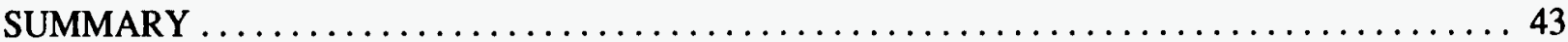

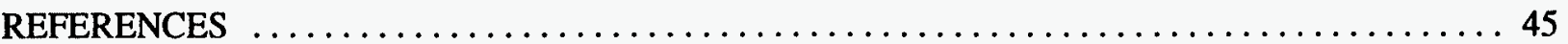

Appendix A-Tabulated Data Presented in U.S. Customary Units of Measurement

Appendix B-Disc Factor Equations

Appendix C-Friction Factor Equation

\section{LIST OF FIGURES}

1. Diagram of a typical motor-operated gate valve $\ldots \ldots \ldots \ldots \ldots \ldots \ldots \ldots \ldots \ldots \ldots \ldots$

2. Diagram of a gate valve, showing the various forces involved when pressure locking occurs ... 3

3. Sketch showing some of the forces affecting a pressure locking load $\ldots \ldots \ldots \ldots \ldots \ldots$

4. Diagram of a gate valve, showing the various forces involved when thermal binding occurs $\ldots \ldots 7$

5. Test setup and instrumentation for the pressure locking tests $\ldots \ldots \ldots \ldots \ldots \ldots \ldots \ldots \ldots 11$

6. Opening thrust measurements from pressure locking tests at five different pressures $\ldots \ldots \ldots 17$

7. Pressure versus temperature with no entrapped air $\ldots \ldots \ldots \ldots \ldots \ldots \ldots \ldots \ldots \ldots \ldots \ldots \ldots \ldots \ldots \ldots \ldots \ldots$

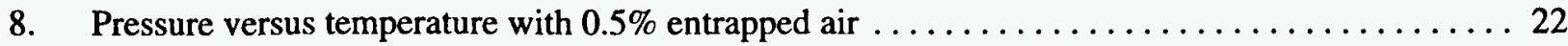

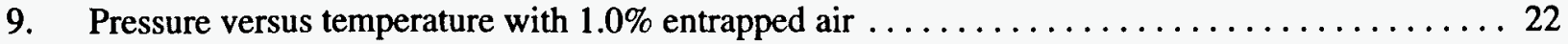

10. Pressure versus temperature with $2.0 \%$ entrapped air $\ldots \ldots \ldots \ldots \ldots \ldots \ldots \ldots \ldots \ldots \ldots \ldots \ldots$

11. Predicted pressure/temperature relationship for a valve with air pockets of various initial volumes, assuming no valve leakage and no valve expansion due to temperature and

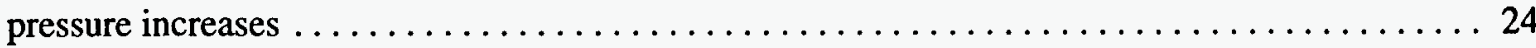

12. Predicted pressure/temperature relationship assuming very small valve leakage and very small expansion of valve body with the increase in temperature and pressure $\ldots \ldots \ldots \ldots \ldots \ldots 25$

13. Entrapped air remaining in the valve bonnet with flow over time $\ldots \ldots \ldots \ldots \ldots \ldots \ldots \ldots$

14. Pressure versus temperature for heatup tests performed at three different initial pressures ..... 30

15. Pressure versus temperature in three heatup tests, comparing the effects of entrapped air

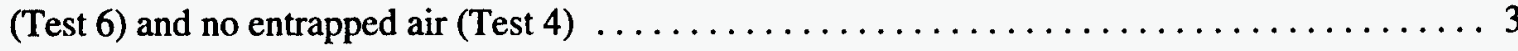


16. Stem thrust measured in a thermal binding test (Test 351) of the Walworth valve, compared with results from unloaded (static) opening strokes

17. Stem thrust measured in the thermal binding test (Test 310) of the Anchor/Darling valve, compared to the results of unloaded (static) tests

18. Thermal binding data from GI-87 tests; unwedging/wedging ratio versus temperature change for Valve 1

19. Thermal binding data from GI-87 tests; unwedging/wedging ratio versus pressure change for Valve 1

20. Thermal binding data from GI-87 tests; unwedging/wedging ratio versus temperature change for Valve 2

21. Thermal binding data from GI-87 tests; unwedging/wedging ratio versus pressure change for Valve 2

22. Thermal binding data from GI-87 tests; unwedging/wedging ratio versus temperature change for Valve 3

23. Thermal binding data from GI-87 tests; unwedging/wedging ratio versus pressure change for Valve 3

24. Thermal binding data from GI-87 tests; unwedging/wedging ratio versus temperature change for Valve 4

25. Thermal binding data from GI-87 tests; unwedging/wedging ratio versus pressure change for Valve 4

26. Thermal binding data from GI-87 tests; unwedging/wedging ratio versus temperature change for Valve 5

27. Thermal binding data from GI-87 tests; unwedging/wedging ratio versus pressure change for Valve 5

28. Thermal binding data from GI-87 tests; unwedging/wedging ratio versus temperature change for Valve 6

29. Thermal binding data from GI-87 tests; unwedging/wedging ratio versus pressure change for Valve 6

\section{LIST OF TABLES}

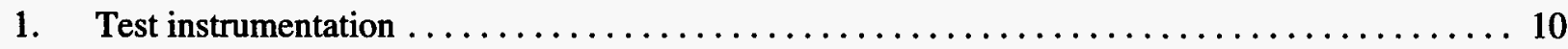

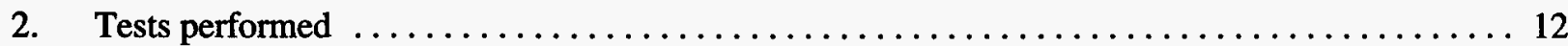


3. Matrix of test pressures for first pressurization method $\ldots \ldots \ldots \ldots \ldots \ldots \ldots \ldots \ldots$

4. Matrix of test pressures for second pressurization method $\ldots \ldots \ldots \ldots \ldots \ldots \ldots \ldots \ldots$

5. Walworth gate valve, cold pressure locking test results $\ldots \ldots \ldots \ldots \ldots \ldots \ldots \ldots \ldots$

6. Walworth gate valve, cold pressure locking test results (low friction tests) $\ldots \ldots \ldots \ldots \ldots$

7. Walworth gate valve thermally induced pressure locking test results $\ldots \ldots \ldots \ldots \ldots$

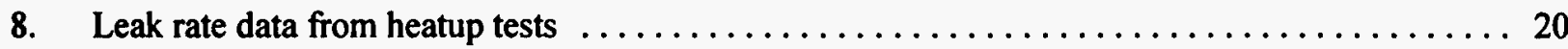

9. Leak rate data from cold differential pressure tests $\ldots \ldots \ldots \ldots \ldots \ldots \ldots \ldots \ldots \ldots \ldots \ldots$

10. Anchor/Darling gate valve, cold pressure locking test results $\ldots \ldots \ldots \ldots \ldots \ldots \ldots \ldots \ldots$

11. Anchor/Darling gate valve, thermally induced pressure locking test results $\ldots \ldots \ldots \ldots \ldots$

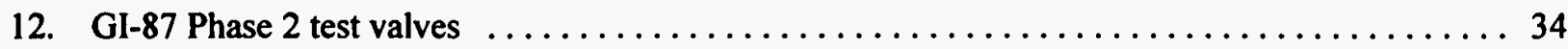

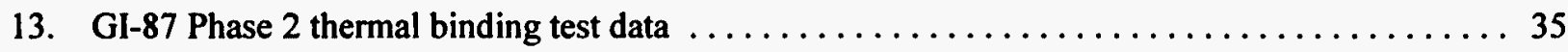




\section{Results of Pressure Locking and Thermal Binding Tests of Gate Valves}

\section{INTRODUCTION}

Since the mid-1980s, the Idaho National Engineering and Environmental Laboratory (INEEL) has been conducting valve research sponsored by the U.S. Nuclear Regulatory Commission (NRC). In general, the purpose of the research has been to provide technical information and test data to the NRC to help address NRC concerns regarding the performance of gate valves and other motor-operated valves (MOVs) installed in nuclear power plants. (Figure 1 shows the main components of a typical gate valve.) Earlier research addressed the performance of valves subjected to containment displacement loadings, earthquake loadings, and blowdown flow loadings. Some of this earlier research also investigated friction at the disc/seat interface in gate valves, friction at the stem/stem-nut interface in rising stem valves, the torque output of the electric motor at various conditions for MOVs, and friction in the valve actuator gearbox.

The tests described in this report investigate the effects of pressure locking and thermal binding on the performance of motor-operated gate valves. Pressure locking occurs when the high pressure of fluid trapped in the valve bonnet causes the valve to be difficult to open. Thermal binding occurs when thermal expansion/contraction effects squeeze the valve disc between the two seats, likewise causing the valve to be difficult to open. This report describes the tests and presents the results.

\section{Background}

In general, when a gate valve opens against an ordinary differential pressure load, the actuator must provide enough force to unwedge the disc from the seats and to overcome the resistance created by friction at the downstream disc/seat interface. (Other loads, such as the packing load, the stem rejection load, and the vertical pressure load on the disc also contribute to the total load on the valve stem, by either assisting or resisting stem movement.) Under differential pressure conditions, the upstream pressure tends to decrease the disc load at the upstream disc/seat interface and increase the load at the downstream disc/seat interface. Typical formulas for estimating valve operating requirements are based on differential pressure across only one disc/seat interface.

Pressure locking occurs when the valve bonnet pressure is higher than both the upstream and downstream pressures. In most gate valves, including most flexible wedge gate valves, split wedge gate valves, and double-disc gate valves, the bonnet cavity communicates with the area between the disc faces. The effect is that the pressure of the fluid between the discs acts on both the upstream and the downstream discs, introducing resistance to motion at both disc/seat interfaces rather than just one. This adds to the total force necessary to unwedge/unseat the valve disc. The various forces involved (in a flexible-wedge gate valve) are indicated in Figure 2; notice in particular the pressure forces between the two disc halves. At its worst, pressure locking causes the valve to be locked in the closed position, such that the actuator does not have sufficient output capacity to open it.

Pressure locking loads are much more difficult to predict than ordinary differential pressure loads (mentioned above), especially with flex-wedge gate designs. (The flex-wedge design is the most widely used of all gate valve disc designs.) With double-disc and split wedge gate valves, both discs respond 

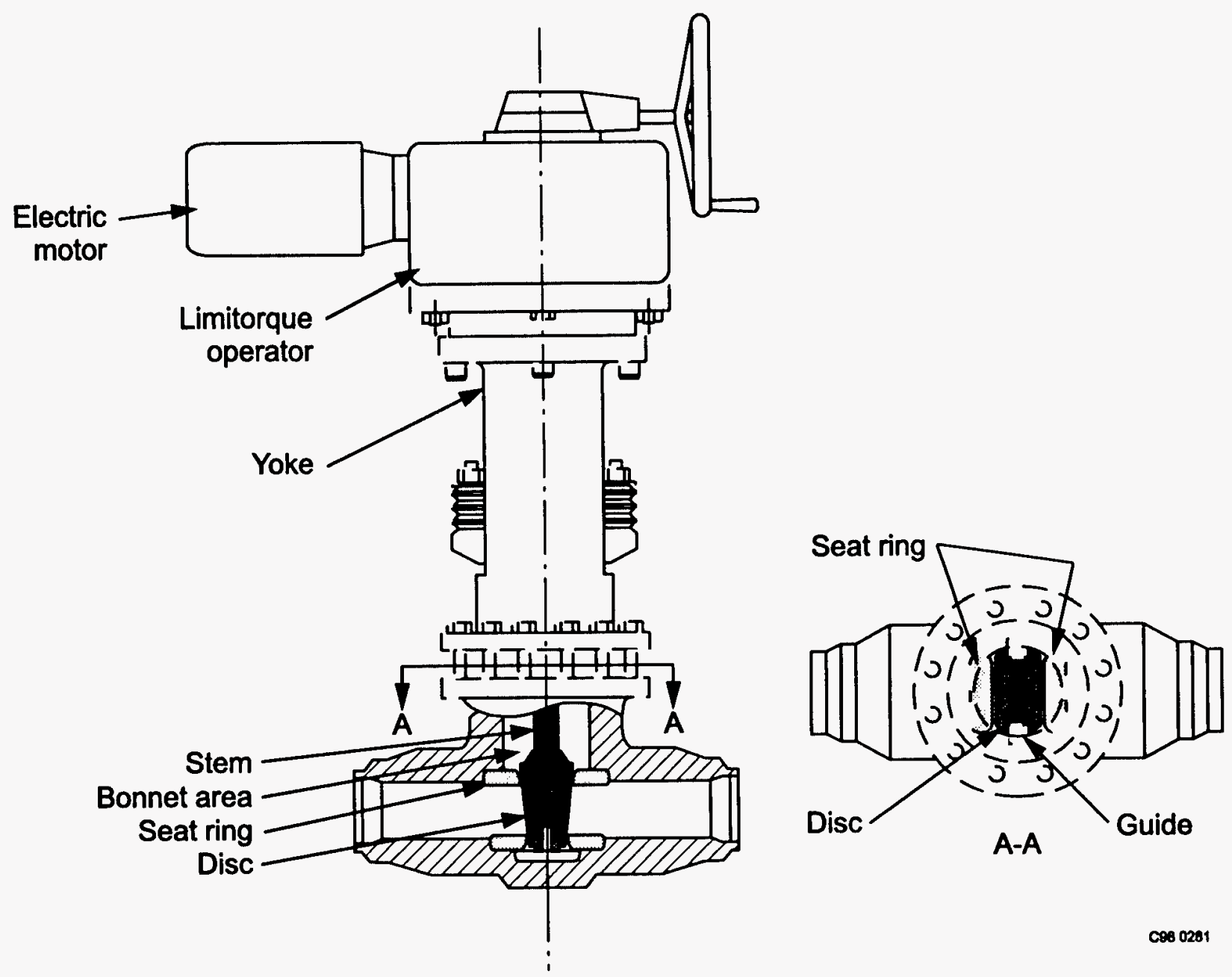

Figure 1. Diagram of a typical motor-operated gate valve. 
Introduction

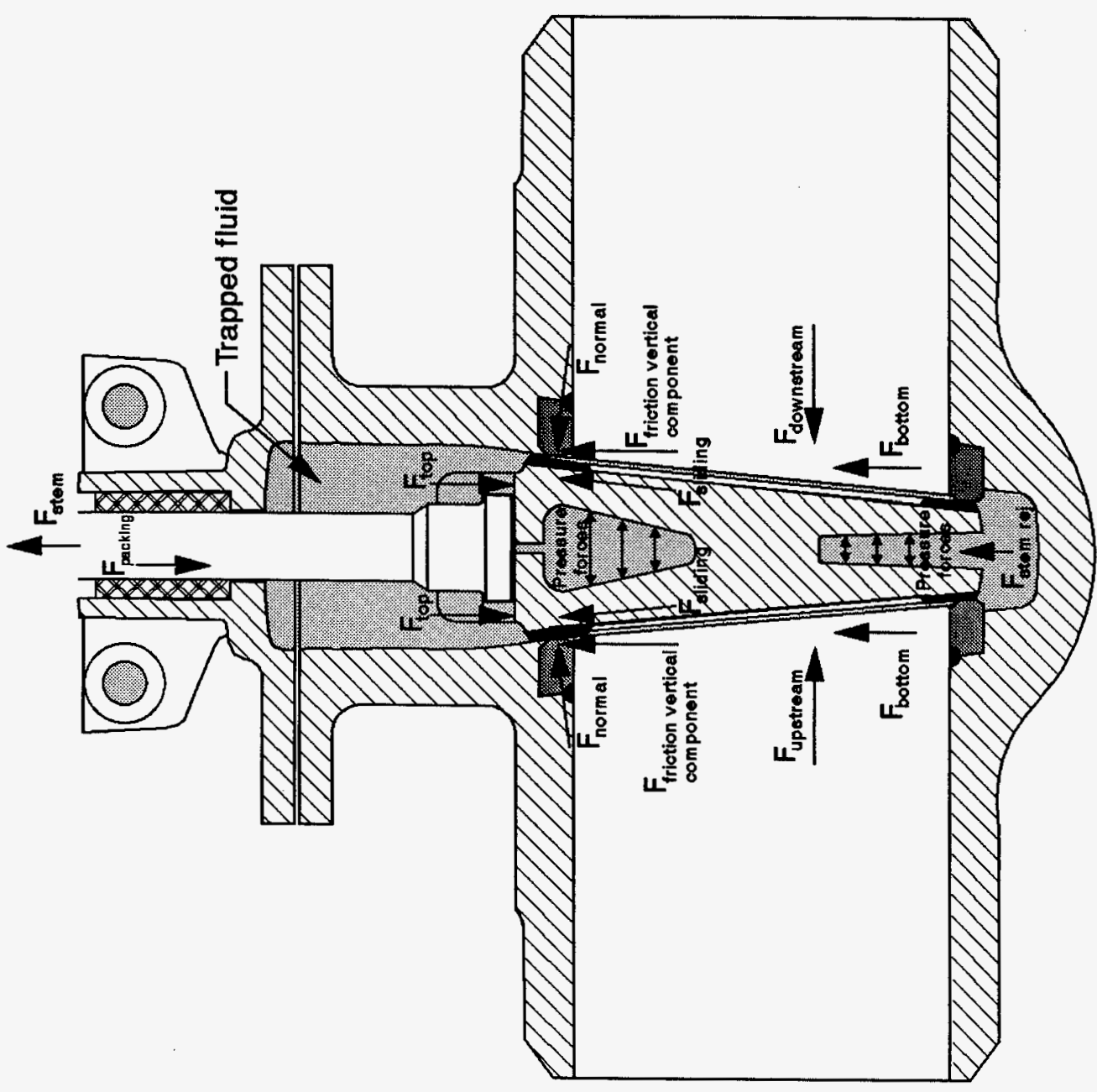

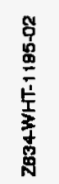




\section{Introduction}

equally and independently to the pressure of the fluid between the discs. However, the disc assembly in a flex-wedge valve is made from a single piece of metal, with the upstream and downstream halves of the disc connected in the center by a hub. As with the double-disc design, the two discs respond to the pressure of the fluid between them, but the area exposed to the pressure is smaller, because of the presence of the hub.

In addition, not all of the area exposed to the bonnet pressure (in the flex-wedge design) responds in a way that results in additional force at the disc/seat interface. When the disc assembly is exposed to pressure locking loads, part of the pressure load deforms the disc and presses it against the valve body seat, and part of the pressure load is reacted in the hub. The effect, theoretically, is that for valves of a given size, the more flexible disc design is more likely to be affected by pressure locking loads, with a greater stem force necessary to unwedge a pressure-locked disc assembly.

One other feature of the flex-wedge gate design contributes to the effects of pressure locking. The angle of the disc, usually about 5 degrees from vertical (in an upright valve), creates a projected horizontal area on the disc that is acted on vertically by the bonnet pressure and the downstream pressure, and another acted on by the bonnet pressure and the upstream pressure, as shown in Figure 3. These areas are typically modeled as elliptical areas defined by the downstream and upstream seat orifices in the valve when viewed from the axis parallel to the stem. The corresponding forces, indicated as $F_{\text {top }}-F_{\text {botom }}$ in Figures 2 and 3, resist opening in much the same way that the stem rejection load assists opening.

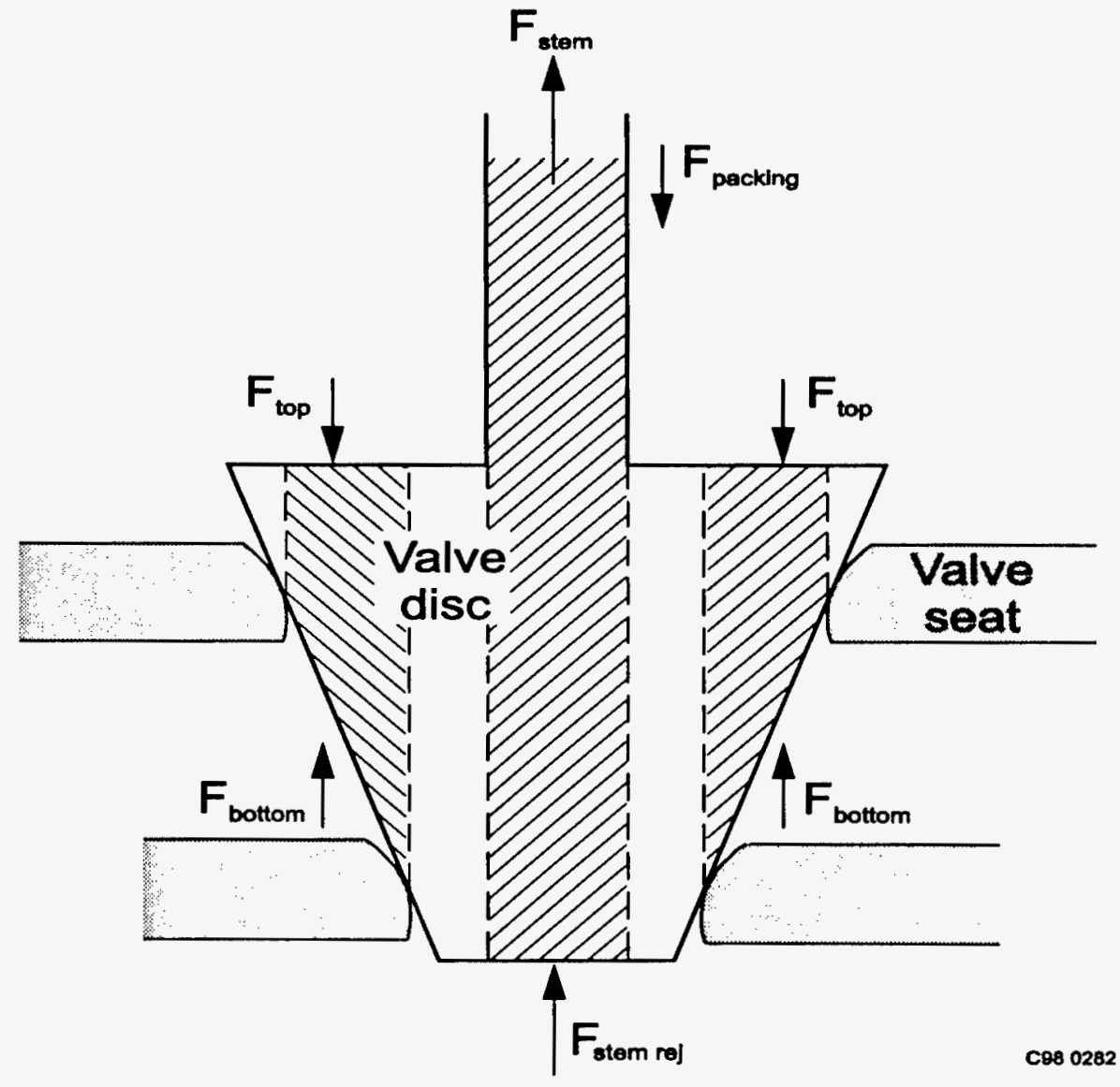

Figure 3. Sketch showing some of the forces affecting a pressure locking load. 
When a valve opens against normal differential pressure, only the downstream $F_{\text {top }}-F_{\text {botom }}$ force is active; the upstream $F_{\text {top }}-F_{\text {bottom }}$ force is zero, because the bonnet pressure $\left(F_{\text {top }}\right)$ is equal to the upstream pressure $\left(\mathrm{F}_{\text {bottom }}\right)$. However, in the pressure locked case, both the upstream and downstream $F_{\text {top }}-F_{\text {bottom }}$ loads act to resist opening, resulting in yet another increase in the opening load, as compared to the typical differential pressure opening situation. The magnitude of the load increase depends on the bonnet, upstream, and downstream pressures.

Taken together, the load increases described in the preceding paragraphs can cause the thrust needed to open a pressure locked valve to be higher than the value typically calculated by industry formulas for the design basis differential pressure conditions. Since most valve actuators are sized and set according to design basis conditions, the higher thrust demands due to pressure locking can exceed the capability of the actuator, causing the valve to fail to open.

The bonnet pressure that causes pressure locking can be either hydraulically or thermally induced. Hydraulically induced pressure locking can result from various operational sequences involving lowpressure system interface with high-pressure systems, or from system depressurization during an accident. In a typical scenario, a valve closed at high pressure might experience pressure locking if an attempt is made to reopen the valve after both the upstream and downstream sides have been depressurized, and with the high pressure remaining in the bonnet. Such a scenario occurred, for example, in 1991 at the Fitzpatrick Nuclear Power Plant (discussed in the next paragraph). Thermally induced pressure locking can occur by thermal expansion of water trapped in the bonnet. A valve closed under cold conditions might experience pressure locking if the valve were later heated by a slug of hot fluid coming into contact with the closed disc, by convection or conduction from adjacent hot piping, or by steam from a line break inside the containment. An instance of thermally induced pressure locking occurred, for example, in 1995 at the Susquehanna Steam Electric Station (discussed in a subsequent paragraph).

The instance of pressure locking that occurred at the Fitzpatrick station was hydraulically induced (NRC Information Notice 92-26). The utility hydro-tested the piping between the inboard and outboard low-pressure coolant injection (LPCI) valves. The inboard LPCI valve is a 24-in. flexible-wedge motoroperated gate valve. After the hydro-test, the utility depressurized the piping between the valves and filled and vented the system to return it to service, unaware that high-pressure fluid remained trapped in the valve bonnet. About 10 hours later the utility commanded the inboard valve to open. The valve actuator was energized for about 30 seconds, and then the circuit breaker tripped. (The normal stroke time for this valve is 120 seconds.) The valve had failed to open. The root cause of the failure was pressure locking.

An instance of thermally induced pressure locking was reported at the Susquehanna Steam Electric Station in 1995 (NRC Information Notice 96-08). When performing a valve modification to eliminate the potential for pressure locking, the utility discovered internal damage to a high-pressure coolant injection (HPCI) valve in Unit 1 . The utility determined that the damage had been caused by high pressure produced by heatup of fluid trapped in the valve bonnet. The heat source was the hot water in the feedwater system, which has a connection about three pipe diameters from the HPCI valve. No known attempt to open the valve was made while the valve was in a pressure locked condition, but the utility's analysis revealed that the actuator for the HPCI valve did not have sufficient thrust capability to open the valve against the pressure locking load that caused the valve damage.

Other examples of pressure locking are discussed in NUREG-1275, Vol. 9, Pressure Locking and Thermal Binding of Gate Valves, and in other NRC information notices.

The magnitudes of possible loads due to pressure locking depend on the valve design and on the pressures prevalent in the specific system where the valve is installed. Leaking valves tend to be less susceptible to pressure locking, because the leakage may prevent the bonnet from becoming or remaining 


\section{Introduction}

pressurized. However, variations due to valve seating conditions, pressure conditions, and pressure changes cause valve leakage to be inconsistent, so that a valve that leaks under some conditions might not leak under other conditions. Typical modifications to gate valves to prevent pressure locking include venting the bonnet to the high-pressure side by drilling a hole through the disc, or by installing a vent line between the bonnet and the upstream side.

Thermal binding is a term describing the effects of heatup and cooldown on differential expansion and contraction of the valve internals. Valves closed in the hot condition might experience thermal binding loads when the seat rings contract against the disc after cooldown, as shown in Figure 4 . These binding loads may be minor, or they may be so large that the valve must be reheated in order to free the disc. In theory, a more flexible disc design is less likely to be affected by thermal binding loads. (As mentioned earlier, the opposite is true of pressure locking loads.)

\section{Scope}

The work described in this report consisted of laboratory testing of two gate valves: a 6 -in. Walworth flexible-wedge gate valve, and a 6-in. Anchor/Darling double-disc gate valve. The test valves are described in detail later in this report. The objectives of the INEEL gate valve pressure locking and thermal binding program include the following:

1. Determine the relationship between bonnet pressurization and opening thrust requirement for a flex-wedge gate valve and a double-disc gate valve

2. Evaluate the impact of temperature changes in the bonnet region on the rate of bonnet pressurization and on the associated thrust requirement to overcome thermally induced pressure locking, including the effects of entrapped air in the bonnet

3. Evaluate the effect of leakage rates for bonnet depressurization in mitigating or eliminating pressure locking in hydraulically induced and thermally induced pressure locking

4. Evaluate the effects of air pockets in the bonnet on reducing a valve's susceptibility to pressure locking, and determine the extent to which air will remain entrapped during operation (that is, whether the air pocket will remain intact, bleed off, or dissolve into the coolant)

5. Study the occurrence of thermal binding in the sample valves, including the magnitude of temperature difference across the valve and the thrust needed to unseat a thermally bound valve. 


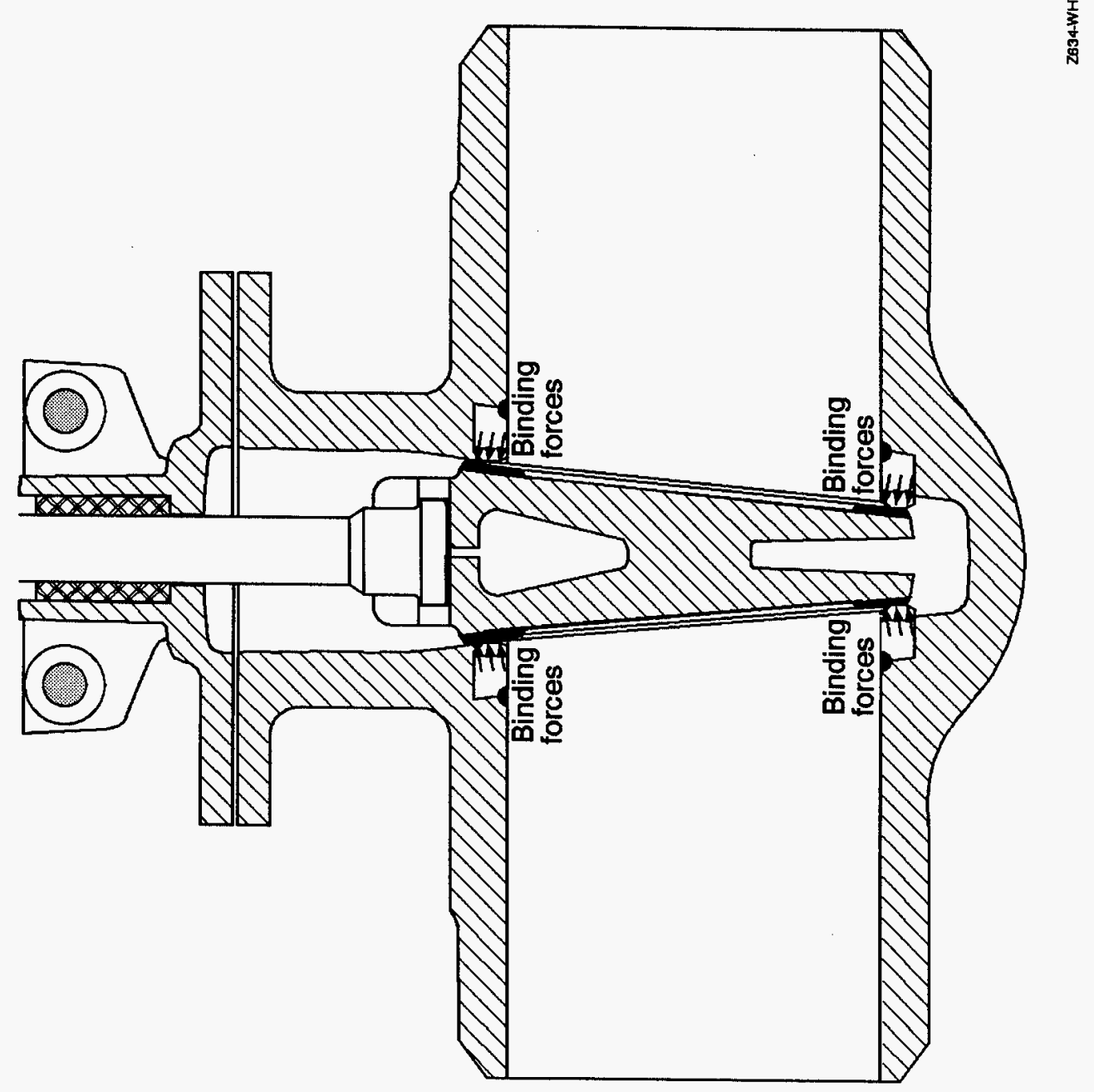




\section{TEST EQUIPMENT}

\section{Walworth Gate Valve}

The flexible-wedge valve tested in this project was a Walworth 6-in., 600-lb-class flexible-wedge gate valve. The disc in this particular design is relatively flexible for its pressure class. We deliberately selected this valve for testing, because we expected that a valve with a more flexible disc assembly (thinner discs, smaller diameter hub) would be more likely to respond to pressure locking loads than a valve with a stiffer disc assembly. Applicable specifications for the valve are listed below.

$\begin{array}{lll}\text { Disc thickness (one disc) } & 13.21 \mathrm{~mm} & (0.520 \mathrm{in.}) \\ \text { Mean seat diameter } & 140.08 \mathrm{~mm} & (5.515 \mathrm{in} .) \\ \text { Stem diameter } & 31.75 \mathrm{~mm} & (1.250 \mathrm{in} .) \\ \text { Hub diameter } & 65.53 \mathrm{~mm} & (2.580 \mathrm{in} .) \\ \text { Hub length } & 23.57 \mathrm{~mm} & (0.928 \mathrm{in} .) \\ \text { Wedge angle } & 5^{\circ} 0^{\prime} \text { to } 4^{\circ} 56^{\prime} & \\ \text { Poisson's ratio (disc material) } & 0.3 & \\ \text { Modulus of elasticity (disc material) } & 205,000 \mathrm{MPa} & (29,700 \mathrm{ksi}) \text { (A217WC6) }\end{array}$

Because the valve had been used in previous testing, the valve sealing surfaces were reconditioned. Following this reconditioning, the valve seat leakage was well below accepted limits.

Previous testing by the INEEL and the industry has shown that new and reconditioned valves tend to operate with extremely low disc-to-seat friction factors, and a wear-in period of operation, often referred to as preconditioning, is necessary to bring the friction factors up to a representative, stable level. Before any testing, the sealing surfaces of the Walworth valve were preconditioned (the valve was subjected to multiple wear-in strokes without flow) to achieve a reasonable disc friction factor.

To ensure success of these tests, we equipped the valve with an SMB-0 actuator with a 25-ft-lb motor, which is about twice as powerful as would be used in a typical safety-related application for a valve this size in a commercial plant.

\section{Anchor/Darling Gate Valve}

The double-disc valve tested in this project was an Anchor/Darling 6-in., 900-lb-class double-disc gate valve. We selected this design to observe valve response to pressure locking loads without the need to consider the disc hub and stiffness in the calculations (in the double-disc design, the two discs are free to respond independently to the pressure between them). However, as with the Walworth valve, the configuration of the disc assembly is such that the response of the valve to thermal binding loads is likely to be minimal. The important valve-specific information is listed below.

$\begin{array}{lll}\text { Upstream mean seat diameter } & 142.09 \mathrm{~mm} & (5.594 \mathrm{in} .) \\ \text { Downstream mean seat diameter } & 138.13 \mathrm{~mm} & (5.438 \mathrm{in} .) \\ \text { Stem diameter } & 38.10 \mathrm{~mm} & (1.500 \mathrm{in} .) \\ \text { Internal wedge angle } & 25^{\circ} & \\ \text { Disc and disc guide material } & \text { A515-70 w/COCR } \\ \text { Disc and body seat hardfacing } & \text { Stellite 6 } & \\ \text { Internal wedge hardfacing } & \text { Stellite } 6\end{array}$


For this valve, as received from the manufacturer, the seat leakage was well below accepted limits. No seat reconditioning was required. As with the Walworth valve, the valve sealing surfaces of the Anchor/Darling valve were preconditioned (the valve was subjected to multiple wear-in strokes without flow) to provide a stable disc friction factor.

For these tests, we used an SMB-1 actuator, equipped with a 60 -ft-lb motor; the actuator was more than twice as powerful as would be used with a valve this size in a typical plant application.

\section{Instrumentation}

Table 1 lists the instrumentation used with the test valves. Generally, the instruments shown in Table 1 were used any time a pressure locking test or thermal binding test was conducted; however, a subset of this list was used in many tests to minimize data processing time and storage space (for example, temperature measurements were excluded from some cold tests). Instruments were calibrated as indicated in Table 1.

Tests were conducted at the INEEL on the motor-operated valve load simulator (MOVLS), a test stand designed for testing of MOV actuators. For these tests, the MOVLS was modified to allow testing of the entire valve assembly (as opposed to testing only the actuator).

Data were recorded by a MEGADAC 2200C data acquisition system (DAS). The DAS was used in the real-time mode to monitor test parameters during setup, switch setting, and all non-data-collection strokes. The DAS was used in the collect-to-tape mode to collect, store, and process all data in accordance with the DAS operating procedures. For all opening stroke tests, data were collected at 600 samples per second per channel. Data were collected at one sample per second during heatups. Equipment calibration and data collection were performed in accordance with the MOVLS operating procedures.

Figure 5 shows the test setup for pressure lock testing. Pressure and temperature were measured on the upstream and downstream sides of the disc, in the bonnet, and under the disc. Stem force, valve position, and other parameters were also measured. 
Test Equipment

Table 1. Test instrumentation.

\begin{tabular}{|c|c|c|}
\hline TCS Channel & Description & Calibration \\
\hline Channel 01 & Bonnet fluid temperature & Yes \\
\hline Channel 02 & Upstream fluid temperature & Yes \\
\hline Channel 03 & Downstream fluid temperature & Yes \\
\hline Channel 16 & Motor current, I1, RMS & Yes \\
\hline Channel 19 & Motor voltage, V1-2, RMS & Yes \\
\hline Channel 21 & Motor rotor temperature & Not required \\
\hline Channel 32 & Stem force (load cell) & Yes \\
\hline Channel 33 & Torque spring force & Yes \\
\hline Channel 34 & Bonnet pressure & Yes \\
\hline Channel 35 & Upstream pressure & Yes \\
\hline Channel 36 & Downstream pressure & Yes \\
\hline Channel 40 & Motor torque & Yes \\
\hline Channel 50 & Stem force (Smart Stem) & Yes \\
\hline Channel 51 & Stem torque (Smart Stem) & Yes \\
\hline Channel 66 & Torque switch & Not required \\
\hline Channel 67 & Motor power & Yes \\
\hline Channel 68 & Motor power factor & Yes \\
\hline Channel 69 & Torque spring position & Yes \\
\hline Channel 72 & Motor speed & Yes \\
\hline Channel 74 & Transformer voltage & Not required \\
\hline Channel 75 & Stem position & Not required \\
\hline Channel 77 & Motor current, Il, Peak & Yes \\
\hline Channel 78 & Motor current, 12, Peak & Yes \\
\hline Channel 79 & Motor current, I3, Peak & Yes \\
\hline
\end{tabular}




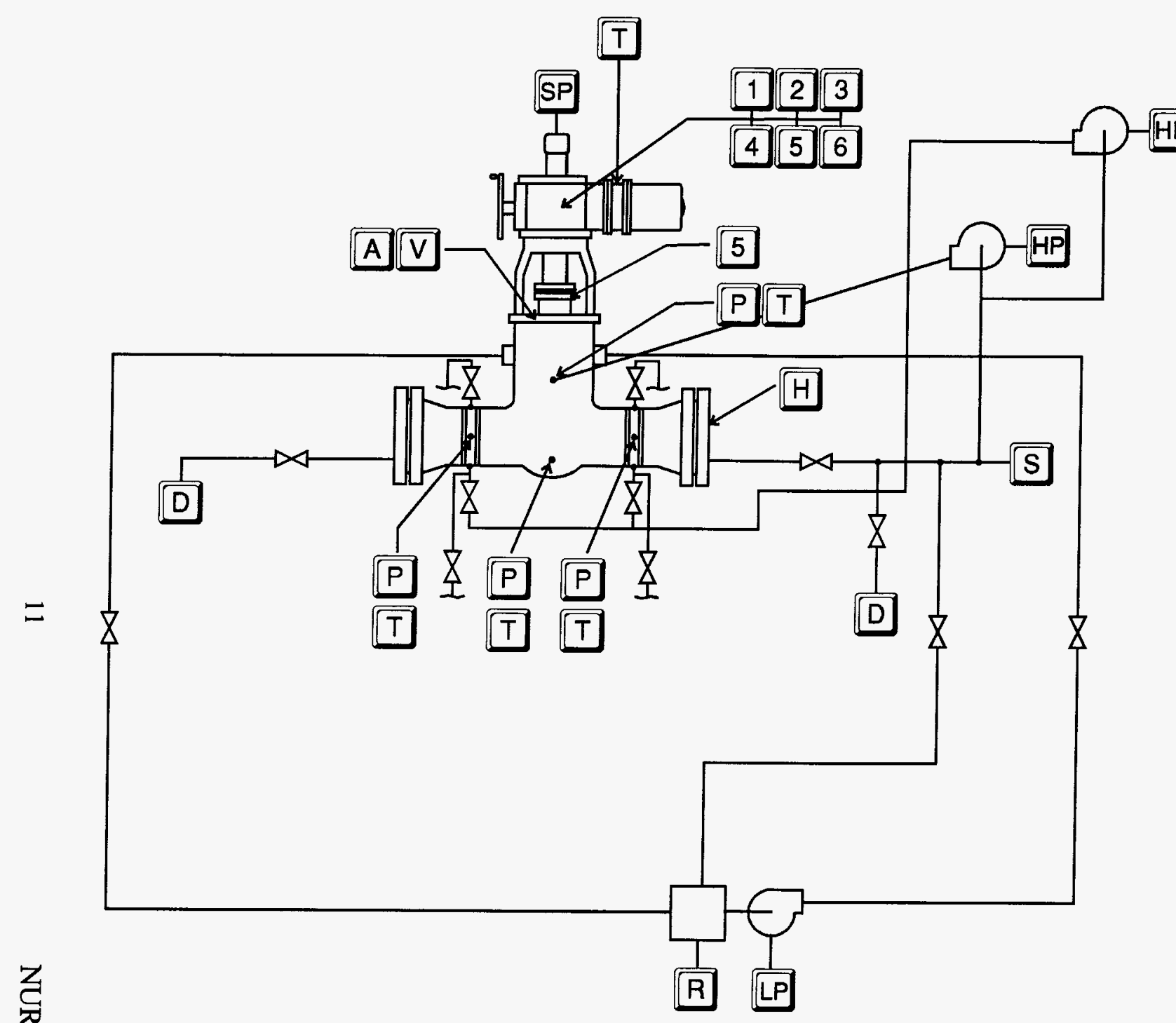

\section{Legend}

回 Low pressure pump

四 Pressure

High pressure pump

[T Temperature

田 Heater

11 Valve position

2. Valve current and power

(3) Valve voltage

44 Torque spring deflection and force

5 Stem force and stem torque

6 Motor speed

D Drain

圆 Reservoir

(1) D.I. water

(1) Motor torque

S Stem position

(A) Air injection

(v) High point vent

Figure 5. Test setup and instrumentation for the pressure locking tests. 


\section{TEST SEQUENCE}

Table 2 lists the tests that were performed on each valve. The assembly and checkout tests for both valves included unloaded (static) closing and opening tests, and upstream and downstream differential pressure tests to quantify the initial conditions of the sealing surfaces and to determine if the valve was ready for testing. The valve sealing surfaces were preconditioned (the valve was subjected to multiple wear-in strokes) until a reasonable and stable disc friction factor was achieved. This preconditioning consisted of numerous cold and hot cycles. Data were collected periodically during preconditioning to evaluate valve performance.

Cold hydrostatic opening tests were conducted to provide measurements for determining the disc-toseat friction factors for both the upstream seat and the downstream seat. Both valves were subjected to two pressure locking test sequences: cold pressure locking tests and hot pressure locking tests. The cold pressure locking tests focused on the relationship between bonnet pressure and the unwedging load. The hot pressure locking tests also examined this relationship, but in addition, the hot testing examined the relationship between bonnet temperature and bonnet pressure (for thermally induced pressure locking) and the effects of air entrapped in the bonnet. We selected arbitrary temperature and pressure limits of $143^{\circ} \mathrm{C}$ $\left(290^{\circ} \mathrm{F}\right)$ and $8.27 \mathrm{MPa}(1200 \mathrm{psig})$ for the pressure locking tests. Thermal binding tests consisted of opening the valve cold after it had been closed hot.

\section{Cold Pressure Locking Tests}

The cold pressure locking tests evaluated the relationship between the fluid pressures occurring at various locations in the valve and the valve opening thrust. The test matrix consisted of various upstream, downstream, and bonnet pressures distributed across the full range of possible conditions. We also performed periodic baseline valve strokes throughout the testing that allowed us to evaluate the wedging versus unwedging relationship, obtain upstream and downstream seat friction values, and determine the load due to packing friction. The baseline strokes included an unloaded (static) valve closing and opening cycle and two hydrostatic opening stokes, one with the downstream side and the bonnet pressurized, and one with the upstream side and the bonnet pressurized.

Two different methods were used to simulate pressure locking conditions. The first method began with the valve open and pressurized to $8.27 \mathrm{MPa}(1,200 \mathrm{psig})$. The valve was then closed, and the

Table 2. Tests performed.

\begin{tabular}{lcc}
\hline \multicolumn{1}{c}{ Test } & Flexible-Wedge Gate Valve & Double-Disc Gate Valve \\
\hline Assembly and checkout & $\mathrm{X}$ & $\mathrm{X}$ \\
Cold hydrostatic & $\mathrm{X}$ & $\mathrm{X}$ \\
Cold pressure lock & $\mathrm{X}$ & $\mathrm{X}$ \\
Hot pressure lock & $\mathrm{X}$ & $\mathrm{X}$ \\
Leakage effect & $\mathrm{X}$ & $\mathrm{X}$ \\
Entrapped air & $\mathrm{X}$ & $\mathrm{X}$ \\
Thermal binding & $\mathrm{X}$ & $\mathrm{X}$ \\
\hline
\end{tabular}


pressures in the upstream leg, downstream leg, and bonnet were reduced to the desired test values. Then the valve was opened, with measurements taken of the stem force required to extract the valve disc.

Table 3 lists the combinations of downstream, bonnet, and upstream pressures used with first method.

The second method began with the valve open and depressurized. The valve was then closed, and the pressure in the bonnet was increased to the desired test values. Then the valve was opened, with measurements taken of the stem force required to extract the valve disc. Testing with the bonnet pressurized by this method included the combinations of downstream, bonnet, and upstream pressures listed in Table 4.

Table 3. Matrix of test pressures for first pressurization method.

\begin{tabular}{|c|c|c|c|c|c|}
\hline \multicolumn{2}{|c|}{ Downstream Pressure } & \multicolumn{2}{|c|}{ Bonnet Pressure } & \multicolumn{2}{|c|}{ Upstream Pressure } \\
\hline$(\mathrm{MPa})$ & (psi) & $(\mathrm{MPa})$ & (psi) & (MPa) & (psi) \\
\hline 0 & 0 & 0 & 0 & 0 & 0 \\
\hline 0 & $\mathbf{0}$ & 2.07 & 300 & 0 & 0 \\
\hline 0 & 0 & 4.14 & 600 & $\mathbf{0}$ & 0 \\
\hline $\mathbf{0}$ & 0 & 6.21 & 900 & 0 & 0 \\
\hline 0 & 0 & 8.27 & 1,200 & 0 & 0 \\
\hline 2.07 & 300 & 8.27 & 1,200 & $\mathbf{0}$ & 0 \\
\hline 4.14 & 600 & 8.27 & 1,200 & 0 & 0 \\
\hline 6.21 & 900 & 8.27 & 1,200 & 0 & 0 \\
\hline 8.27 & 1,200 & 8.27 & 1,200 & 0 & 0 \\
\hline $\mathbf{0}$ & 0 & 8.27 & 1,200 & 2.07 & 300 \\
\hline 0 & 0 & 8.27 & 1,200 & 4.14 & 600 \\
\hline 0 & 0 & 8.27 & 1,200 & 6.21 & 900 \\
\hline 0 & 0 & 8.27 & 1,200 & 8.27 & 1,200 \\
\hline 2.07 & 300 & 8.27 & 1,200 & 4.14 & 600 \\
\hline 2.07 & 300 & 8.27 & 1,200 & 2.07 & 300 \\
\hline
\end{tabular}

Table 4. Matrix of test pressures for second pressurization method.

\begin{tabular}{cccccccc}
\hline \multirow{2}{*}{ Downstream Pressure } & & \multicolumn{2}{c}{ Bonnet Pressure } & & \multicolumn{2}{c}{ Upstream Pressure } \\
$(\mathrm{MPa})$ & $(\mathrm{psi})$ & & $(\mathrm{MPa})$ & $(\mathrm{psi})$ & & $(\mathrm{MPa})$ & $(\mathrm{psi})$ \\
\hline 0 & 0 & 2.07 & 300 & & 0 & 0 \\
0 & 0 & 4.14 & 600 & & 0 & 0 \\
0 & 0 & 6.21 & 900 & & 0 & 0 \\
0 & 0 & 8.27 & 1,200 & & 0 & 0 \\
\hline
\end{tabular}




\section{Hot Pressure Locking Tests}

Tests similar to those described above were performed on the valve at elevated temperatures. In addition, tests were performed to evaluate the impact of temperature changes on the rate of bonnet pressurization and on the associated thrust required to unseat the valve during opening. The effects of valve seat leakage on bonnet pressurization were also investigated, as were the effects of air entrapped in the bonnet.

Testing was performed with the valve heated both internally and externally. For the tests with internal heating, the heater in the upstream leg of the valve heated the fluid at $44^{\circ} \mathrm{C}\left(80^{\circ} \mathrm{F}\right)$ per hour until the upstream fluid temperature reached $143^{\circ} \mathrm{C}\left(290^{\circ} \mathrm{F}\right)$; the upstream pressure was controlled at $0.34 \mathrm{MPa}$ (50 psig). Discharge from the downstream side of the valve was measured as an indication of leakage from the bonnet to the downstream side. For external heating, heat tape wrapped around the valve body was used to heat the fluid in the valve. Once again, the fluid temperatures were limited to $143^{\circ} \mathrm{C}\left(290^{\circ} \mathrm{F}\right)$ and the upstream pressure was controlled at $0.34 \mathrm{MPa}(50 \mathrm{psig})$.

The bonnet pressure was monitored during the heatup and compared to the measured leakage to establish the relationship between leakage and thermally induced bonnet pressurization. If and when the bonnet pressure reached $8.27 \mathrm{MPa}(1,200 \mathrm{psig})$, we opened the valve, measuring the stem load required to extract the disc.

\section{Entrapped Air Tests}

Following the hot pressure locking tests, typical air pockets of various volumes were introduced into the bonnet, and the valve was heated. The air pockets were established by draining a known volume from the lower drain line while allowing air to enter through the high bonnet vent. After the appropriate air volume was established, the valve was heated to $143^{\circ} \mathrm{C}\left(290^{\circ} \mathrm{F}\right)$ using the external heaters (heat tape). The pressure was monitored during heatup.

The Walworth gate valve test began with the valve in the open position (because seat leakage, though very minor, was enough to prevent bonnet-only pressurization), and air pockets representing $0.5,1.0$, and $2.0 \%$ of the valve volume were introduced into the bonnet. Testing included a baseline test with no air pocket. In each instance, the valve was heated at $44^{\circ} \mathrm{C}\left(80^{\circ} \mathrm{F}\right)$ per hour until the bonnet pressure reached a maximum of $8.27 \mathrm{MPa}(1,200 \mathrm{psig})$. Each time the valve pressure reached $8.27 \mathrm{MPa}$, the valve was depressurized to $0.34 \mathrm{MPa}(50 \mathrm{psig})$. Heatup continued to approximately $143^{\circ} \mathrm{C}\left(290^{\circ} \mathrm{F}\right)$.

Additional tests were conducted with the Walworth valve to determine if the air pockets remain in the valve. For these tests, a $2.0 \%$ air pocket was introduced into the valve, and typical flow over the valve disc and through the bonnet was simulated. The flow through the bonnet was representative of the small percentage of flow that goes over the disc under normal valve flow conditions.

The Anchor/Darling double-disc gate valve produced a tight seal, so the entrapped air tests were performed with bonnet-only pressurization. Two tests were performed with an air pocket representing $2.0 \%$ of the bonnet volume introduced into the bonnet. Baseline tests with no air pocket were also performed. The valve was heated to $143^{\circ} \mathrm{C}\left(290^{\circ} \mathrm{F}\right)$ or $8.27 \mathrm{MPa}(1,200 \mathrm{psi})$, whichever occurred first. The pressure was monitored during heatup, and pressure locking tests (opening the valve) were performed when the bonnet pressure reached $8.27 \mathrm{MPa}$. 


\section{Thermal Binding Tests}

The tests for thermal binding consisted of target of opportunity tests run in conjunction with the tests described above. During the heated tests, the final step was to close the valve hot and then allow the system to cool (usually overnight). After the valve cooled to steady-state conditions, an opening stroke was performed to determine the effect of any thermal binding on the thrust needed to unwedge the valve. Thermal binding tests were not performed with temperature gradients across the valve body and disc. 


\section{PRESSURE LOCKING TEST RESULTS}

\section{Walworth Gate Valve}

The cold and hot pressure locking tests discussed below provide stem thrust values measured during valve opening at pressure locking conditions, for comparison with values measured during standard hydrostatic opening tests. The results also provide an opportunity to compare stem thrust values measured during pressure locking tests at various pressures. In addition, the tests provide information on the effects of valve leakage and entrapped air.

\section{Cold Pressure Locking Tests}

The results of the cold pressure locking tests are summarized in Table 5. (Test data are presented in this report in SI units of measurement; Appendix A presents the data in U.S. Customary units of measurement.) The table shows the peak unwedging thrust measured during the opening stroke, along with the upstream, bonnet, and downstream pressures that correspond in time with the peak unwedging thrust measurement, for three kinds of tests: pressure locking tests (designated PL in the table), the accompanying hydrostatic tests (designated $\mathrm{HU}$ for hydrostatic testing of the upstream seat and $\mathrm{HD}$ for hydrostatic testing of the downstream seat), and static (no pressure) tests (designated S). Where the stem packing load was measured in a static test, that value is also shown. Disc factor and disc/seat friction factor values are shown for the hydrostatic upstream and hydrostatic downstream tests. As an example of the effect of pressure locking, the stem thrust measurement for Test 227, a hydrostatic opening test, was $64,900 \mathrm{~N}\left(14,590 \mathrm{lb}_{\mathrm{f}}\right)$, compared with $94,000 \mathrm{~N}\left(21,132 \mathrm{lb}_{\mathrm{f}}\right)$ for Tests 230 , a pressure locking test conducted at approximately the same pressure. Overall, the stem thrust needed to overcome pressure locking loads was higher by a factor of about 1.3 to 1.45 , compared with hydrostatic opening tests at similar pressures.

Figure 6 shows stem force traces for five pressure locking tests in which the bonnet was pressurized at $0,2.07,4.14,6.21$, and $8.27 \mathrm{MPa}(0,300,600,900$, and $1,200 \mathrm{psig})$. The traces have been truncated to focus on the unwedging/unseating portion of the opening stroke. The plot shows a nearly linear relationship between the bonnet pressure and the unwedging/unseating load.

Additional results from cold pressure locking tests of the Walworth valve are listed in Table 6. These results are similar to those shown in Table 5, except that they were obtained from tests performed during preconditioning, when the disc-to-seat friction factors were low. These results are included here for completeness.

\section{Hot Pressure Locking Tests}

Two of the heatup tests produced bonnet pressures capable of causing pressure locking loads. In two other heatup tests, valve leakage precluded bonnet pressurization, so we terminated the heatup [at about $143^{\circ} \mathrm{C}\left(290^{\circ} \mathrm{F}\right)$ ] and used a high-pressure pump to pressurize the bonnet for the pressure locked opening stroke. The results of the thermally induced pressure locking tests are summarized in Table 7. The table includes data from static (no pressure) and hydrostatic opening strokes, along with data from the four pressure locked opening strokes. Similar to the results from the cold tests, the results from the hot tests show that the stem thrust needed to overcome pressure locking loads was higher by a factor of 1.1 to 1.5 , compared with hydrostatic opening tests at similar pressures. In the four pressure locking tests, we observe that higher pressures correspond with higher thrust requirements, in a relationship that is approximately linear. This observation is consistent with the results from the cold tests. 
Table 5. Walworth gate valve, cold pressure locking test results. ${ }^{\mathrm{a}}$

\begin{tabular}{|c|c|c|c|c|c|c|c|c|c|}
\hline \multicolumn{2}{|c|}{ Test } & \multicolumn{3}{|c|}{ Pressure (MPa) } & \multirow{2}{*}{$\begin{array}{c}\text { Bonnet } \\
\text { Temperature } \\
\left({ }^{\circ} \mathrm{C}\right)\end{array}$} & \multirow{2}{*}{$\begin{array}{l}\text { Peak } \\
\text { Unwedging } \\
\text { Thrust } \\
\text { (N) }\end{array}$} & \multirow{2}{*}{$\begin{array}{c}\text { Packing } \\
\text { Drag } \\
\text { (N) }\end{array}$} & \multicolumn{2}{|c|}{ Valve } \\
\hline Number & Type $^{b}$ & Up & Bonnet & Down & & & & $\begin{array}{c}\text { Disc } \\
\text { Factor }^{\mathrm{c}}\end{array}$ & $\begin{array}{l}\text { Friction } \\
\text { Factor }^{\mathrm{d}}\end{array}$ \\
\hline 226 & $S$ & 0.01 & 0.02 & 0.01 & 23 & 19,363 & 5,671 & - & - \\
\hline 227 & $\mathrm{HD}$ & 7.39 & 7.41 & -0.03 & 22 & 64,900 & - & 0.569 & 0.594 \\
\hline 228 & HU & -0.02 & 7.16 & 7.11 & 25 & 64,997 & - & 0.591 & 0.618 \\
\hline 229 & PL & -0.02 & 3.41 & -0.01 & 23 & 60,727 & - & - & - \\
\hline 230 & PL & -0.02 & 7.34 & -0.02 & 21 & 94,000 & - & - & - \\
\hline 231 & PL & -0.02 & 7.77 & 2.50 & 22 & 83,618 & - & - & - \\
\hline 232 & PL & 2.19 & 7.28 & -0.02 & 23 & 82,888 & - & - & - \\
\hline 233 & $\mathbf{S}$ & -0.01 & 0.01 & -0.01 & 21 & 26,978 & 5,649 & - & - \\
\hline 234 & $\mathrm{HD}$ & 6.96 & 6.98 & -0.01 & 22 & 63,062 & - & 0.586 & 0.612 \\
\hline 235 & HU & -0.02 & 7.18 & 7.13 & 22 & 65,736 & - & 0.596 & 0.624 \\
\hline $237^{e}$ & $\mathbf{S}$ & -0.02 & -0.01 & -0.03 & 21 & 47,205 & 5,280 & - & - \\
\hline
\end{tabular}

a. Appendix A presents these data in U.S. Customary units of measurement.

b. Test type: $\mathrm{S}=$ static (no-load) opening test, $\mathrm{HU}=$ hydro opening test across upstream seat, $\mathrm{HD}=$ hydro opening test across downstream seat, $\mathbf{P L}=$ pressure lock opening test.

c. Disc factors were calculated from the peak unwedging thrust, using the equation described in Appendix B.

d. Friction factors were calculated from the peak unwedging thrust, using the equation described in Appendix C.

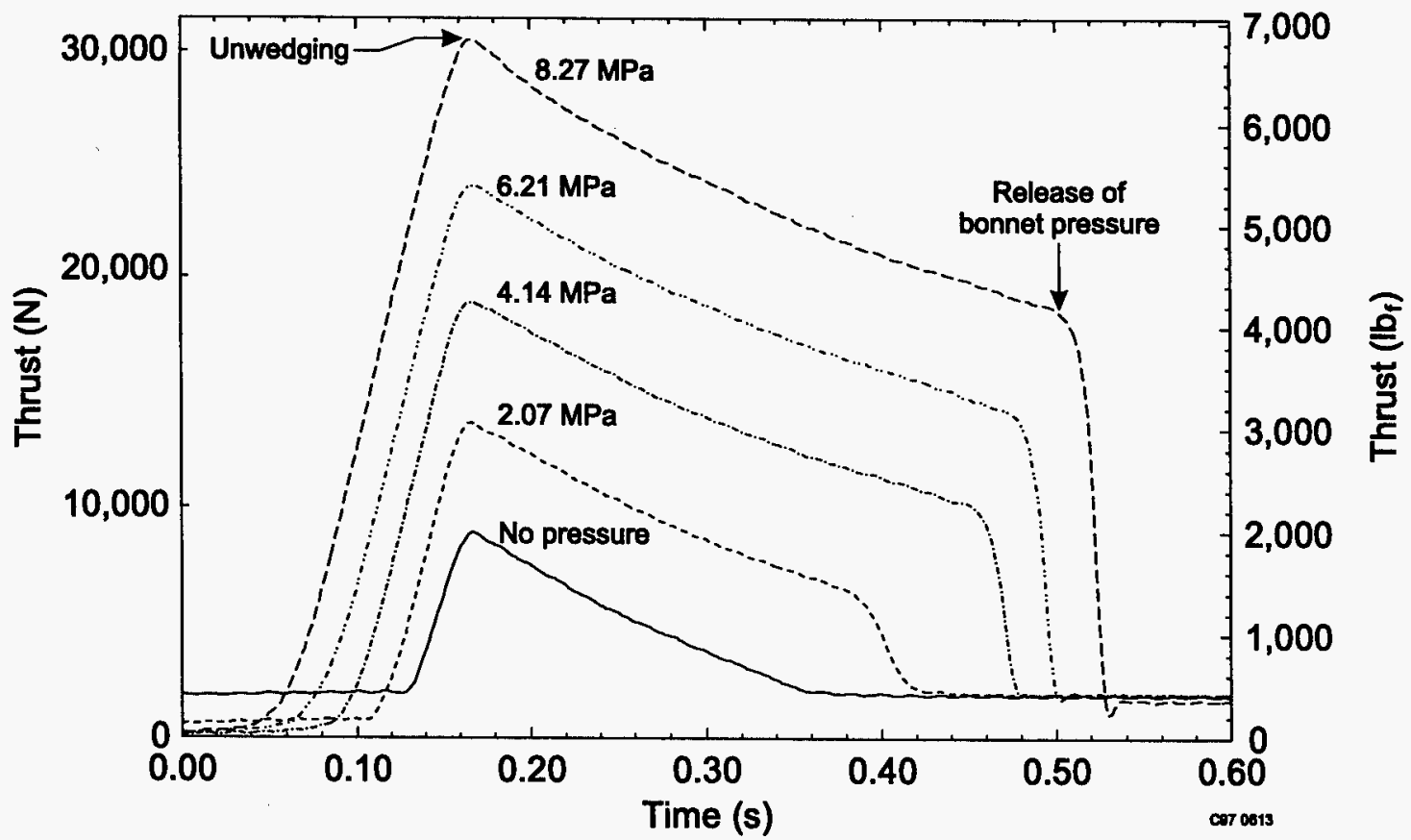

Figure 6. Opening thrust measurements from pressure locking tests at five different pressures. 
Pressure Locking Test Results

Table 6. Walworth gate valve, cold pressure locking test results ${ }^{\mathrm{a}}$ (low friction tests).

\begin{tabular}{|c|c|c|c|c|c|c|c|c|c|}
\hline Tes & & & $\begin{array}{c}\text { Pressure } \\
(\mathrm{MPa})\end{array}$ & & & & 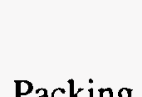 & & lve \\
\hline Number & Type $^{\text {b }}$ & Up & Bonnet & Down & $\begin{array}{c}\text { Temperature } \\
\left({ }^{\circ} \mathrm{C}\right) \\
\end{array}$ & $\begin{array}{l}\text { Thrust } \\
(\mathrm{N})\end{array}$ & $\begin{array}{c}\text { Drag } \\
(\mathrm{N})\end{array}$ & $\begin{array}{c}\text { Disc } \\
\text { Factor }^{c}\end{array}$ & $\begin{array}{l}\text { Friction } \\
\text { Factor }^{\mathrm{d}} \\
\end{array}$ \\
\hline 201 & $\mathrm{HD}$ & 7.53 & 7.54 & -0.01 & 22 & 7,531 & - & 0.101 & 0.100 \\
\hline 203 & $\mathrm{HU}$ & 0.00 & 7.63 & 7.60 & 22 & 7,544 & & 0.100 & 0.100 \\
\hline 204 & $S$ & 0.00 & 0.00 & 0.00 & 22 & 8,843 & 1,815 & - & - \\
\hline 205 & PL & -0.01 & 1.53 & -0.01 & 22 & 13,545 & - & - & - \\
\hline 206 & PL & -0.01 & 3.43 & -0.01 & 22 & 18,758 & - & - & - \\
\hline 207 & PL & -0.01 & 5.36 & -0.01 & 23 & 23,842 & - & - & - \\
\hline 208 & PL & -0.01 & 7.56 & 0.00 & 23 & 30,252 & - & - & 一 \\
\hline 209 & PL & -0.01 & 7.45 & 2.08 & 22 & 27,993 & - & - & - \\
\hline 210 & PL & -0.01 & 7.43 & 4.05 & 22 & 22,472 & - & 一 & - \\
\hline 211 & PL & -0.01 & 8.00 & 6.29 & 22 & 21,191 & - & - & 一 \\
\hline 212 & HU & -0.01 & 7.79 & 7.76 & 22 & 10,778 & - & 0.127 & 0.123 \\
\hline 213 & PL & 2.16 & 7.69 & -0.01 & 22 & 32,330 & - & - & - \\
\hline 214 & PL & 4.28 & 7.80 & -0.01 & 23 & 28,820 & - & - & - \\
\hline 215 & PL & 6.20 & 7.74 & -0.01 & 22 & 24,621 & - & - & - \\
\hline 216 & HD & 7.83 & 7.84 & -0.01 & 22 & 8,665 & - & 0.108 & 0.108 \\
\hline 217 & PL & 4.23 & 7.76 & 2.05 & 22 & 26,013 & - & - & - \\
\hline 218 & PL & 2.20 & 7.46 & 2.18 & 23 & 29,621 & - & - & - \\
\hline 219 & HD & 7.53 & 7.53 & -0.01 & 23 & 9,301 & - & 0.116 & 0.116 \\
\hline 221 & $\mathrm{HU}$ & -0.01 & 7.53 & 7.49 & 22 & 14,016 & - & 0.158 & 0.157 \\
\hline 222 & PL & -0.01 & 1.76 & -0.01 & 22 & 18,162 & - & - & - \\
\hline 223 & PL & -0.01 & 3.77 & -0.01 & 23 & 25,871 & - & - & - \\
\hline 224 & PL & -0.01 & 5.72 & -0.01 & 23 & 32,285 & - & - & - \\
\hline 225 & PL & -0.01 & 7.76 & -0.01 & 22 & 39,536 & - & - & - \\
\hline
\end{tabular}

a. Appendix A presents these data in U.S. Customary units of measurement.

b. Test type: $\mathrm{S}=$ static (no-load) opening test, $\mathrm{HU}=$ hydro opening test across upstream seat, $\mathrm{HD}=$ hydro opening test across downstream seat, $\mathrm{PL}=$ pressure lock opening test.

c. Disc factors were calculated from the peak unwedging thrust, using the equation described in Appendix B.

d. Friction factors were calculated from the peak unwedging thrust, using the equation described in Appendix C. 
Table 7. Walworth gate valve thermally induced pressure locking test results. ${ }^{\mathrm{a}}$

\begin{tabular}{|c|c|c|c|c|c|c|c|c|c|}
\hline \multicolumn{2}{|c|}{ Test } & \multicolumn{3}{|c|}{$\begin{array}{c}\text { Pressure } \\
(\mathrm{MPa})\end{array}$} & \multirow{2}{*}{$\begin{array}{c}\text { Bonnet } \\
\text { Temperature } \\
\left({ }^{\circ} \mathrm{C}\right)\end{array}$} & \multirow{2}{*}{$\begin{array}{c}\text { Peak } \\
\text { Unwedging } \\
\text { Thrust } \\
(\mathrm{N})\end{array}$} & \multirow{2}{*}{$\begin{array}{l}\text { Packing } \\
\text { Drag } \\
(\mathrm{N})\end{array}$} & \multicolumn{2}{|c|}{ Valve } \\
\hline Number & Type $^{b}$ & Up & Bonnet & Down & & & & $\begin{array}{c}\text { Disc } \\
\text { Factor }^{\mathrm{c}}\end{array}$ & $\begin{array}{l}\text { Friction } \\
\text { Factor }^{d}\end{array}$ \\
\hline 307 & PL & 0.23 & 7.40 & -0.01 & 95 & 81,184 & - & - & - \\
\hline 308 & $S$ & 0.10 & 0.11 & 0.08 & 103 & 28,264 & 5,249 & - & - \\
\hline 309 & $\mathrm{HD}$ & 7.05 & 7.06 & -0.01 & 88 & 52,912 & - & 0.489 & 0.507 \\
\hline 310 & $\mathrm{HU}$ & 0.00 & 6.36 & 6.32 & 86 & 46,391 & - & 0.474 & 0.491 \\
\hline 312 & $S$ & 1.38 & 1.43 & 1.35 & 22 & 26,093 & 6,152 & - & - \\
\hline 313 & $\mathrm{HD}$ & 7.26 & 7.28 & 0.03 & 21 & 49,936 & - & 0.445 & 0.459 \\
\hline 314 & $\mathrm{HU}$ & 0.04 & 7.32 & 7.27 & 19 & 54,010 & - & 0.481 & 0.498 \\
\hline 316 & PL & -0.01 & 7.87 & -0.02 & 96 & 80,495 & - & - & - \\
\hline 317 & S & 0.06 & 0.06 & 0.06 & 82 & 28,486 & 5,373 & - & - \\
\hline 318 & HD & 7.30 & 7.32 & -0.03 & 83 & 53,859 & - & 0.480 & 0.498 \\
\hline 319 & $\mathrm{HU}$ & -0.02 & 6.96 & 6.92 & 83 & 56,506 & - & 0.530 & 0.551 \\
\hline 322 & $S$ & 0.28 & 0.30 & 0.39 & 21 & 22,695 & 6,156 & - & - \\
\hline 323 & $\mathrm{HD}$ & 6.92 & 6.94 & 0.30 & 19 & 53,094 & - & 0.514 & 0.534 \\
\hline 324 & $\mathrm{HU}$ & 0.27 & 7.00 & 6.96 & 24 & 56,208 & - & 0.539 & 0.561 \\
\hline 325 & $S$ & 0.32 & 0.34 & 0.30 & 22 & 17,544 & 6,147 & - & - \\
\hline 326 & $\mathrm{HD}$ & 7.56 & 7.58 & -0.03 & 19 & 65,838 & - & 0.561 & 0.586 \\
\hline 327 & HU & -0.02 & 7.40 & 7.35 & 21 & 67,862 & - & 0.595 & 0.622 \\
\hline 329 & PL & 0.24 & 7.62 & -0.02 & 52 & 75,664 & - & - & - \\
\hline 330 & $S$ & 0.46 & 0.29 & 0.38 & 64 & 22,339 & 5,800 & - & - \\
\hline 331 & $\mathrm{HD}$ & 7.45 & 7.47 & -0.03 & 58 & 66,247 & - & 0.574 & 0.599 \\
\hline 332 & $\mathrm{HU}$ & -0.01 & 7.22 & 7.17 & 56 & 67,800 & - & 0.611 & 0.641 \\
\hline 341 & HU & -0.01 & 7.72 & 7.68 & 19 & 70,024 & - & 0.593 & 0.621 \\
\hline 342 & $S$ & 0.01 & 0.01 & 0.01 & 21 & 26,351 & 5,809 & - & - \\
\hline 343 & PL & 0.01 & 7.24 & 0.02 & 18 & 86,745 & - & - & - \\
\hline
\end{tabular}

a. Appendix A presents these data in U.S. Customary units of measurement.

b. Test type: $\mathrm{S}=$ static (no-load) opening test, $\mathrm{HU}=$ hydro opening test across upstream seat, $\mathrm{HD}=$ hydro opening test across downstream seat, $\mathrm{PL}=$ pressure lock opening test.

c. Disc factors were calculated from the peak unwedging thrust, using the equation described in Appendix B.

d. Friction factors were calculated from the peak unwedging thrust, using the equation described in Appendix C. 


\section{Effects of Valve Leakage}

Leakage from the bonnet during heatup was measured during tests with both internal and external heating, as summarized in Table 8 . Table 9 summarizes the leakage rates recorded during cold differential pressure tests. All the measured leakage rates were very small, well within code requirements (ANSI B16.104) for this valve.

When we heated the unpressurized bonnet water, the leakage was sufficient to prevent pressurization as the fluid expanded. In contrast, when we began the heating test with the bonnet already pressurized to $4.83 \mathrm{MPa}(700 \mathrm{psig})$, pressurization due to thermal expansion occurred. We suspect that the initial pressure (before heating) caused the disc surfaces to seal to the seat surfaces more effectively than in the tests without initial pressure.

Note that evidence of valve leakage during a cold differential pressure test does not necessarily mean that leakage will prevent pressure locking. The disc elastic response during a pressure locked condition and its match-up to the seat is different during pressure locking as compared to the differential pressure

Table 8. Leak rate data from heatup tests. ${ }^{a}$

\begin{tabular}{|c|c|c|c|c|c|}
\hline $\begin{array}{c}\text { Initial } \\
\text { Bonnet } \\
\text { Pressure } \\
(\mathrm{MPa}) \\
\end{array}$ & $\begin{array}{c}\text { Average } \\
\text { Heat } \\
\text { Rate } \\
\left({ }^{\circ} \mathrm{C} / \mathrm{hr}\right) \\
\end{array}$ & $\begin{array}{l}\text { Average Leak } \\
\text { Rate From } \\
\text { Bonnet to } \\
\text { Downstream } \\
\text { (mL/min) }\end{array}$ & $\begin{array}{c}\text { Range of Bonnet } \\
\text { to Downstream } \\
\text { Leak Rates } \\
(\mathrm{mL} / \mathrm{min}) \\
\end{array}$ & $\begin{array}{c}\text { Average Leak Rate } \\
\text { from Upstream to } \\
\text { Maintain } 0.34 \mathrm{MPa} \\
(\mathrm{mL} / \mathrm{min})\end{array}$ & $\begin{array}{l}\text { Range of Upstream } \\
\text { Leak Rates to } \\
\text { Maintain } 0.34 \mathrm{MPa} \\
(\mathrm{mL} / \mathrm{min})\end{array}$ \\
\hline 0.34 & 25 & 16.2 & 12.5 to 22.2 & - & - \\
\hline 4.14 & NA & 41.1 & NA & - & 一 \\
\hline 8.27 & NA & 1.5 & NA & - & - \\
\hline 0.34 & 37 & 1.6 & 1.45 to 1.83 & - & - \\
\hline 0.34 & 30 & 1.2 & 0.91 to 3.12 & 2.33 & 1.38 to 3.12 \\
\hline 0.34 & 47 & 24.2 & 4.97 to 130 & 2.15 & 1.82 to 2.49 \\
\hline 4.83 & 8 & 2.3 & - & 9.7 & - \\
\hline
\end{tabular}

Table 9. Leak rate data from cold differential pressure tests. ${ }^{\mathrm{a}}$

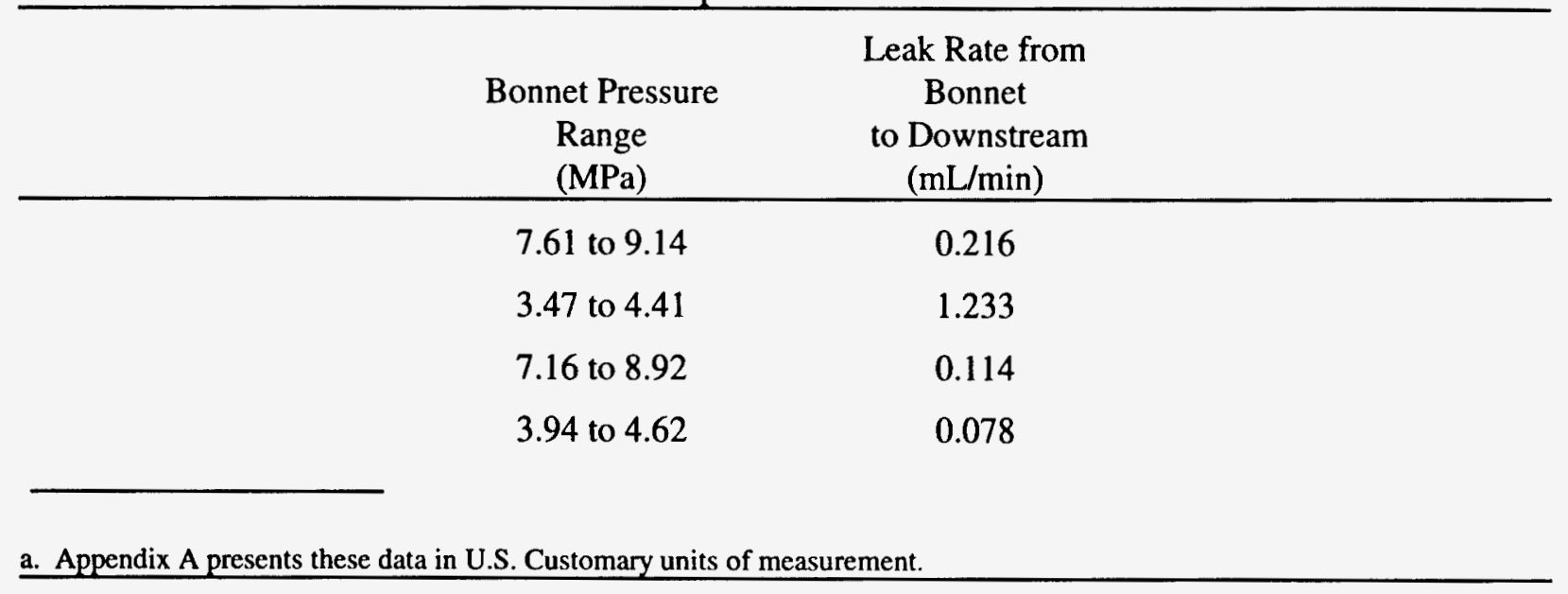


case. This difference was evident in the results we saw, in that the leakage rates during the cold differential pressure tests showed no relationship to the leakage rates during the bonnet heatup/pressurization tests. This demonstrates that the disc can match up to the seat surface differently during different kinds of operating conditions.

\section{Effects of Entrapped Air}

In addition to the tests already described, we performed tests to determine the effect of entrapped air on the bonnet pressurization rate during heatup and on the associated opening stem load during opening. These tests were performed with heat applied to the external surfaces of the valve. We also investigated the extent to which the air will remain entrapped during operation, that is, whether an air pocket will remain intact, bleed off, or dissolve into the water.

The investigation included parametric tests with air pockets representing $0.5,1.0$, and $2.0 \%$ of the total valve volume, along with a baseline test with no entrapped air. After the appropriate air volume was established, the valve was heated to $143^{\circ} \mathrm{C}\left(290^{\circ} \mathrm{F}\right)$. The pressure was monitored during the test, and the valve was depressurized to $0.34 \mathrm{MPa}(50 \mathrm{psig})$ any time the pressure reached $8.27 \mathrm{MPa}(1,200 \mathrm{psig})$.

Figure 7 shows results from the baseline heatup test with no entrapped air. The pressure increases rapidly after the bonnet pressure reaches $1.38 \mathrm{MPa}(200 \mathrm{psig}$ ). Subsequent pressurization (following scheduled depressurizations) are very repeatable. Figures 8 through 10 show the same kind of data, but from tests with entrapped air volumes representing $0.5,1.0$, and $2.0 \%$ of the valve volume. Here the behavior is similar, except that the initial pressurization begins at a higher temperature. As in the no-air test, subsequent repressurizations following depressurizations occur immediately.

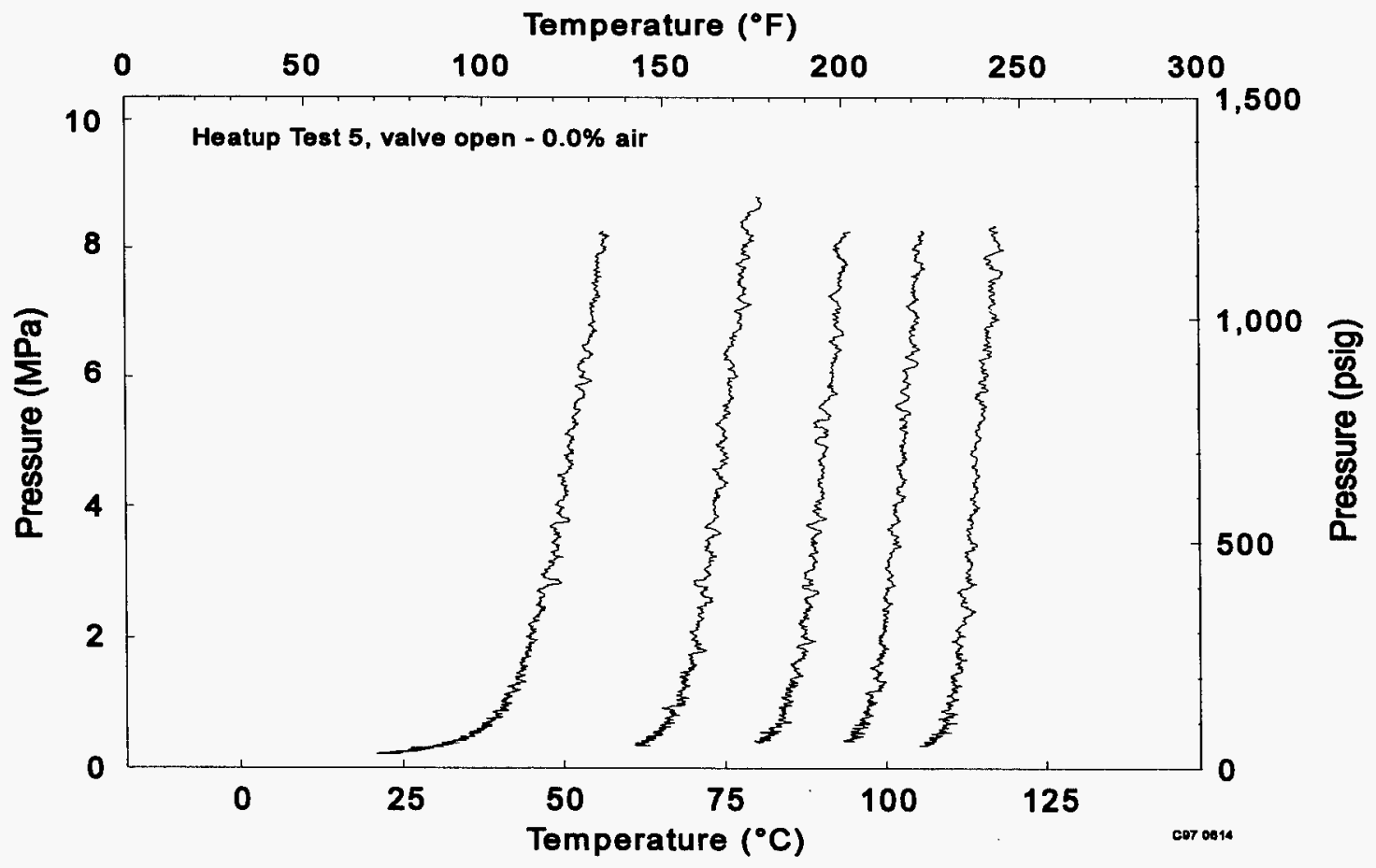

Figure 7. Pressure versus temperature with no entrapped air. 
Pressure Locking Test Results

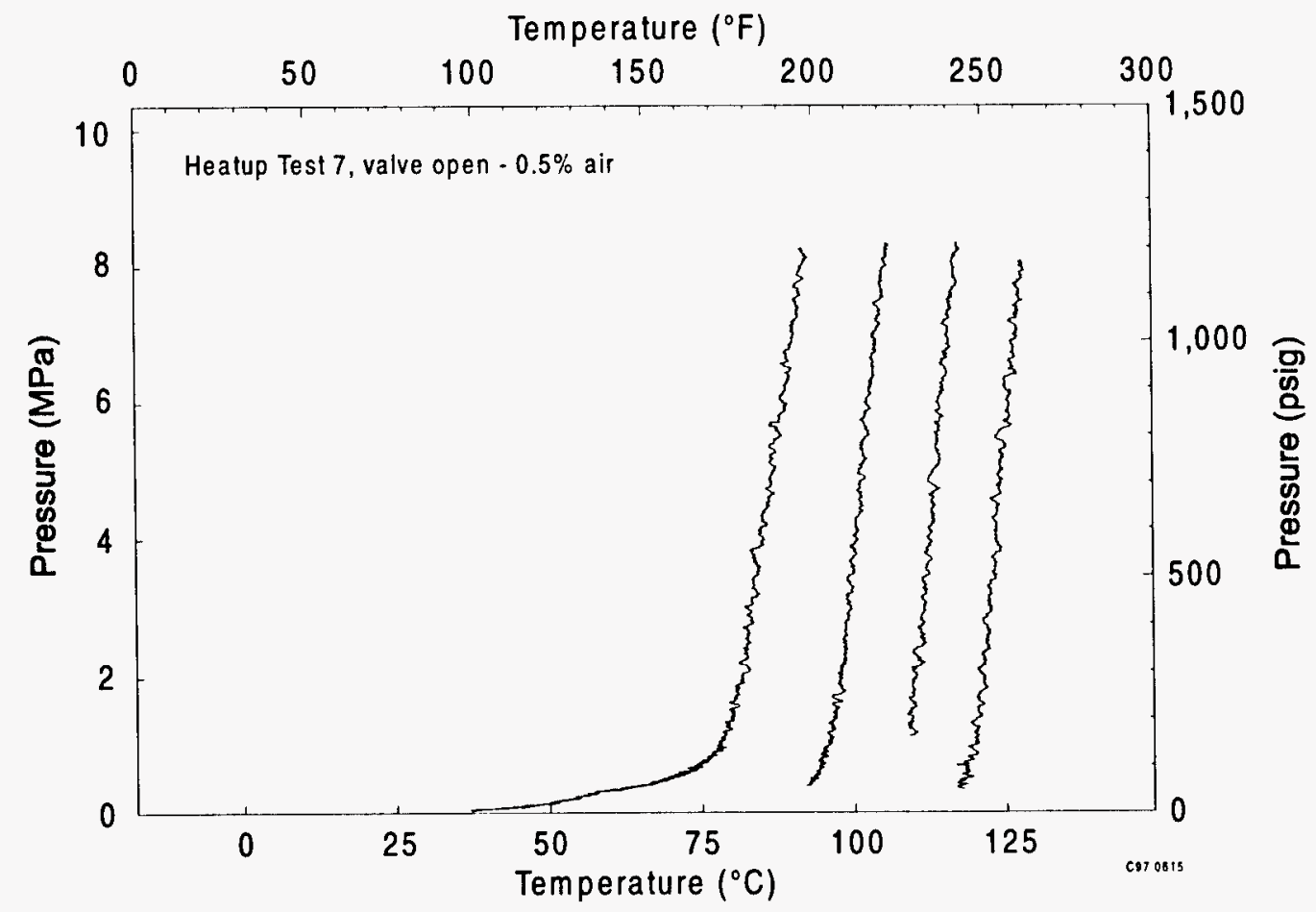

Figure 8. Pressure versus temperature with $0.5 \%$ entrapped air.

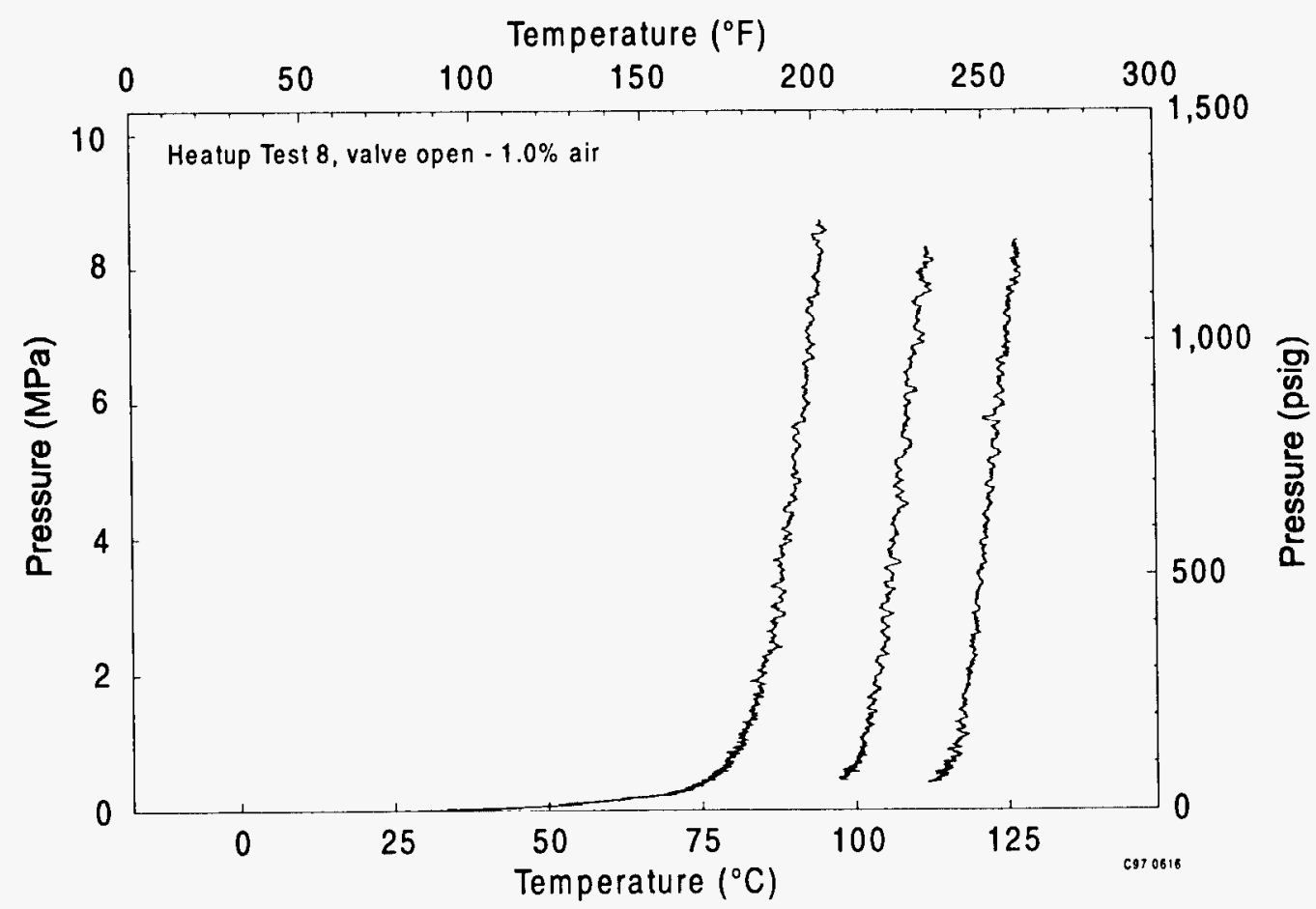

Figure 9. Pressure versus temperature with $1.0 \%$ entrapped air. 


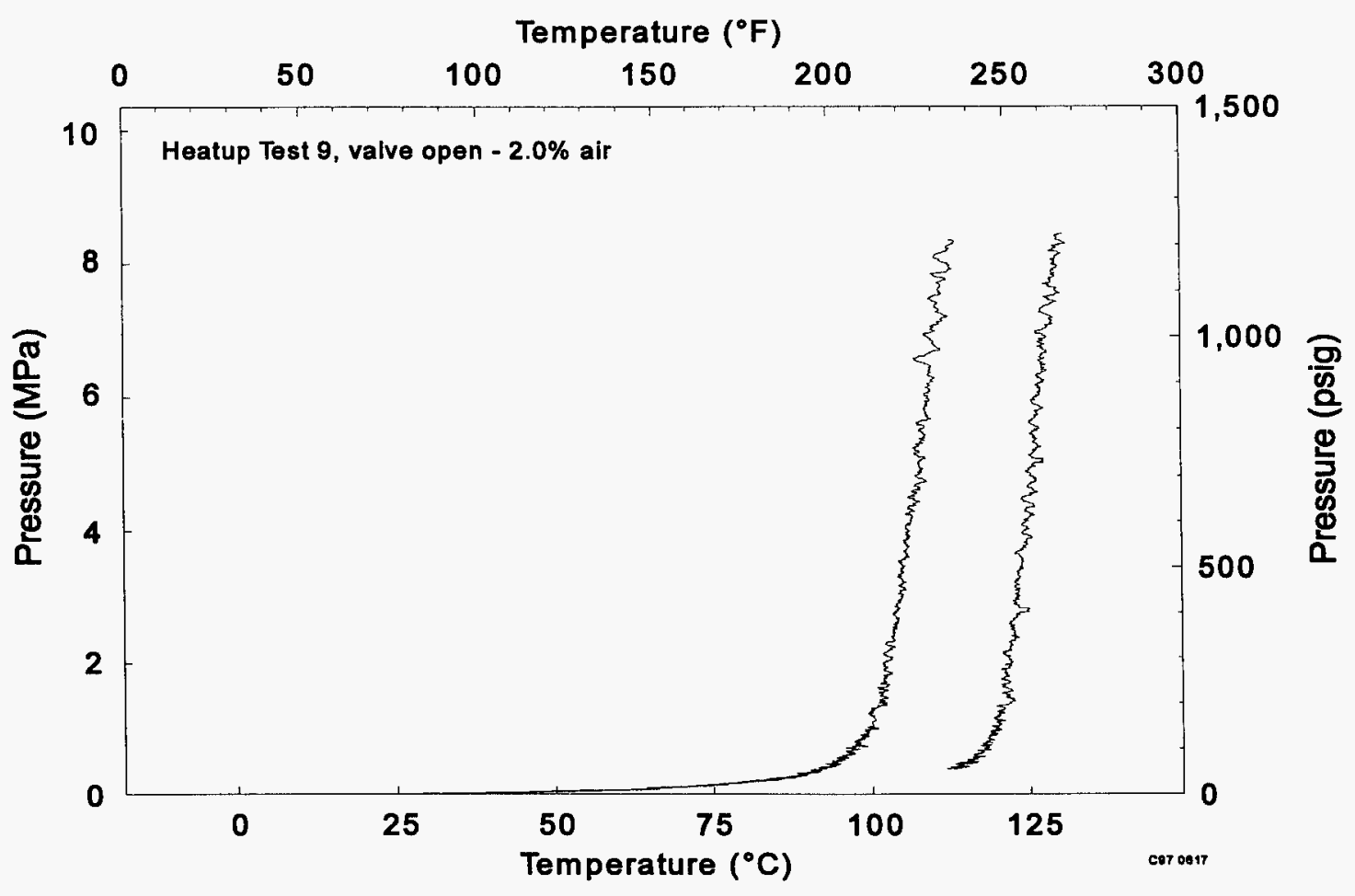

Figure 10. Pressure versus temperature with $2.0 \%$ entrapped air.

The entrapped air tests were limited to air pockets of $2 \%$ of the valve volume. To investigate the effects of larger volumes of air, we performed an analysis to calculate the outcome that would be expected from such heatups with air pockets ranging in initial volume from 1.0 to $20.0 \%$ of the valve volume. We included initial air volumes of 1.0 and $2.0 \%$ in the analysis, with the intention of comparing the actual results derived from tests with the outcomes predicted by the calculation. The analysis assumed a closed gate valve with water trapped in the bonnet. The analysis also assumed that no water or air leakage occurs and that the valve body does not expand as the pressure and temperature increase. The results of the analysis represent a prediction of the pressure increase in the bonnet region as the temperature of the valve increases.

Figure 11 shows the results of the analysis, with predicted bonnet pressure plotted versus valve temperature, for air pockets of several initial volumes. For any of the traces, the calculation predicts a gradual increase in pressure as the temperature increases, until the pressure is sufficient to collapse the air pocket, after which the pressure increase is much steeper. For air pockets greater in volume than $10 \%$ of the valve volume, the gradual increase follows the saturation pressure line after about $110^{\circ} \mathrm{C}\left(230^{\circ} \mathrm{F}\right)$. As long as the pressure response is following the saturation pressure line, there is at least a small void in the liquid, consisting of water vapor and possibly some air (depending on whether or not the air has dissolved). Once the temperature and the resultant liquid expansion are sufficient to collapse the void (the point where "the system goes solid"), the pressure increases significantly with small increases in temperature.

The general shape of the predicted curve shown in Figure 11 for the $2 \%$ air pocket is similar to the test results shown in Figure 10; however, a much higher temperature is required to collapse the void in the tests than is indicated by the prediction. We attribute this difference to the assumptions used in the prediction, namely, that there was no leakage or valve body expansion. 


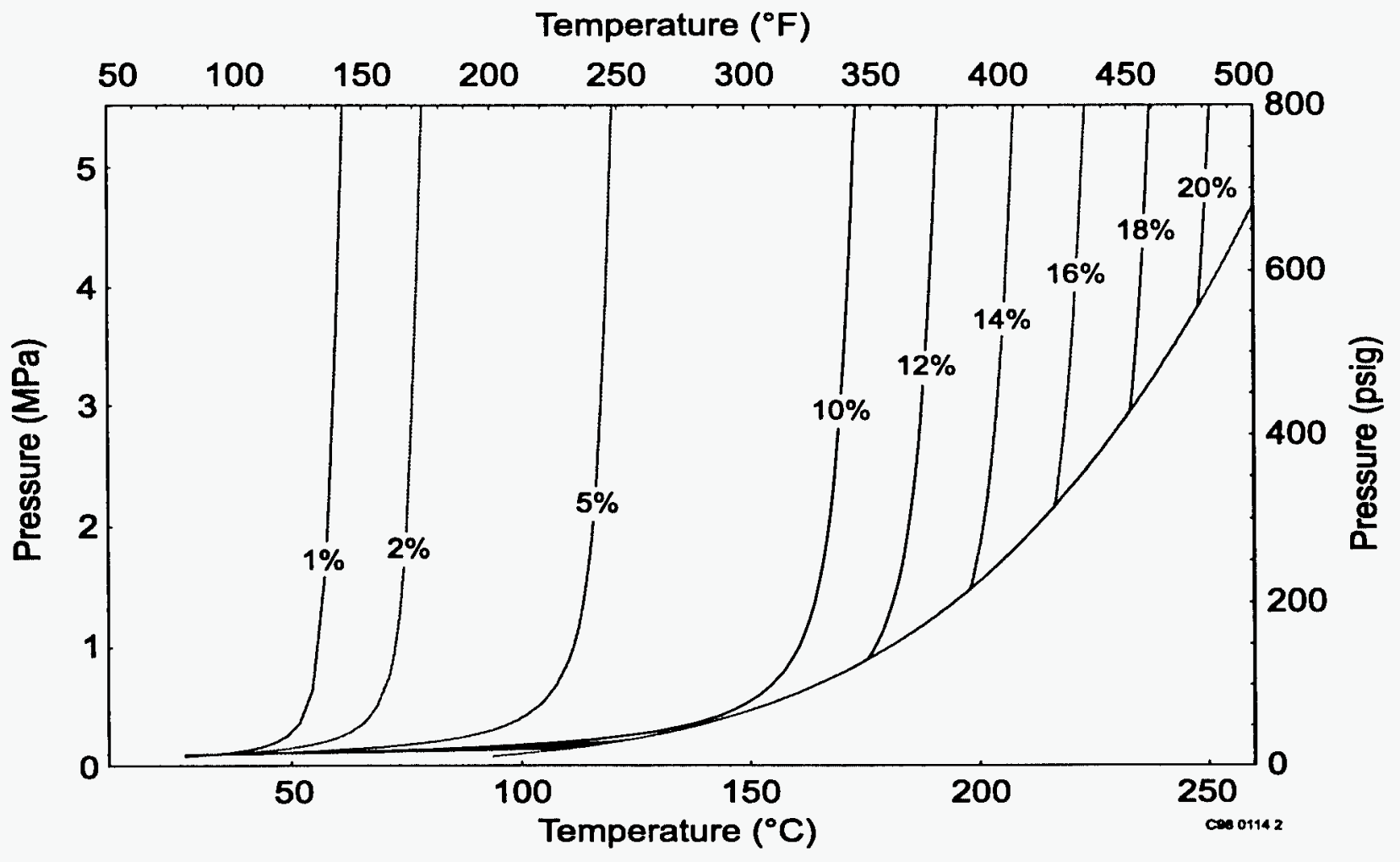

Figure 11. Predicted pressure/temperature relationship for a valve with air pockets of various initial volumes, assuming no valve leakage and no valve expansion due to temperature and pressure increases.

By adjusting the analysis to account for a very small amount of water leakage and for slight valve body expansion due to the temperature and pressure increases, we can produce a new estimate that more closely matches the test measurements. Figure 12 shows the results of this analysis for various initial air pocket volumes up to $10 \%$. The $2 \%$ prediction in this analysis matches the test results for the $2 \%$ air pocket (shown in Figure 10) quite closely. For air pocket initial volumes of 5 to $10 \%$, the predictions shown in Figure 12 indicate collapse of the void at much higher pressures (and temperatures) than indicated by the predictions shown in Figure 11. The comparison between Figure 12 and Figure 11 shows how minor changes in leakage or valve body expansion can affect the pressure increases that occur as the temperature increases.

We performed additional tests to evaluate the likelihood that an air pocket would remain trapped in the valve bonnet. In these tests, a $2.0 \%$ air pocket was established in the valve bonnet with the valve cold, and the valve was pressurized to $8.27 \mathrm{MPa}(1,200 \mathrm{psig})$ to collapse the air pocket. The valve was then depressurized to determine whether the air pocket persisted. This procedure was then repeated with the valve hot. In both cases, the air pocket remained in the bonnet after depressurization. The final test series was performed with water flow through the bonnet, simulating typical flow over the disc for a valve in service. Flow through the valve bonnet reduced the size of the air pocket over time, as shown in Figure 13.

\section{Anchor/Darling Gate Valve}

The cold and hot pressure locking tests discussed below provide stem thrust values measured during valve opening at pressure locking conditions, for comparison with values measured during standard hydrostatic opening tests. The results also provide an opportunity to compare stem thrust values measured during pressure locking tests at various pressures. In addition, the tests provided information on the effects of valve leakage and entrapped air. 


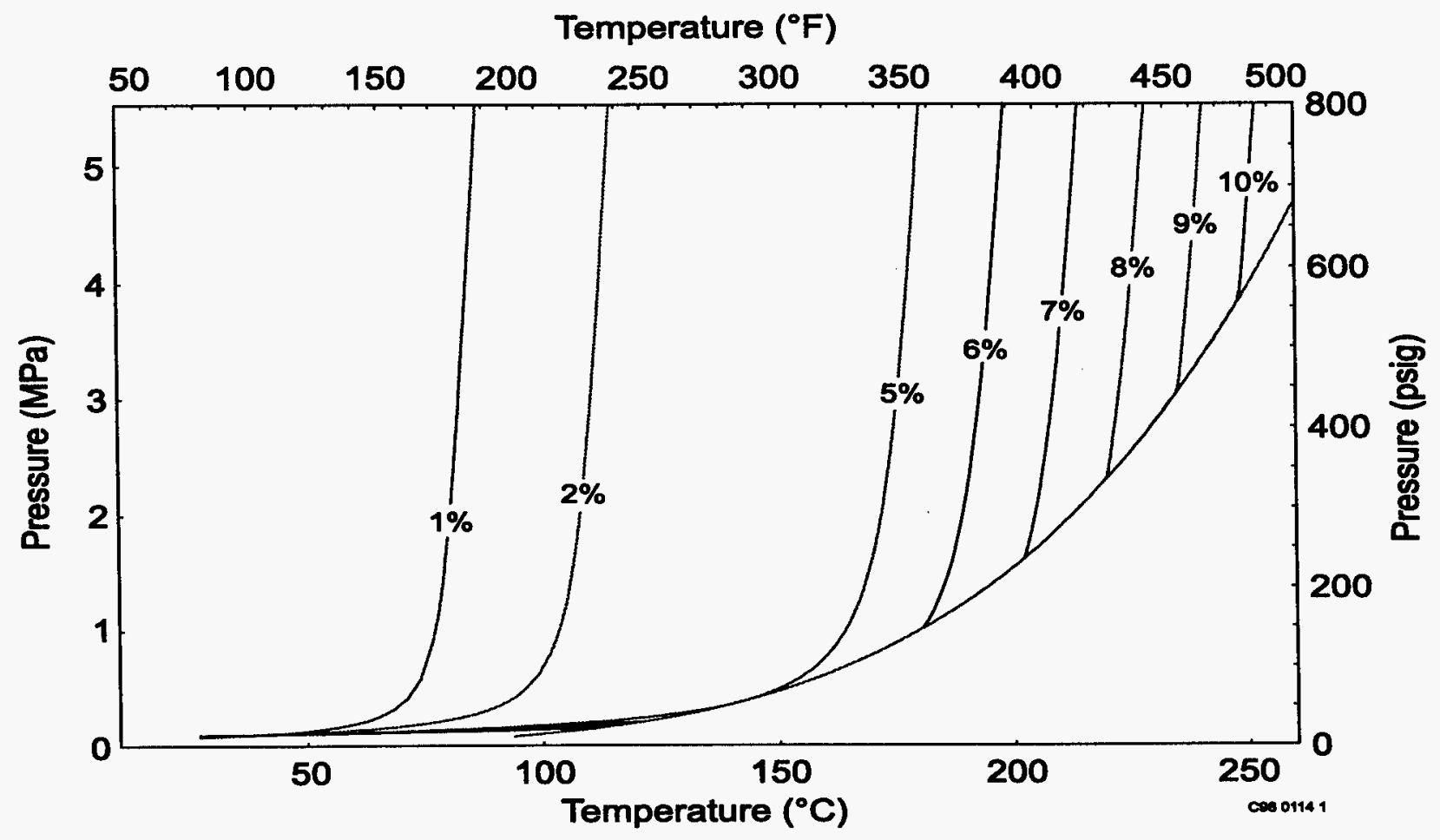

Figure 12. Predicted pressure/temperature relationship assuming very small valve leakage and very small expansion of valve body with the increase in temperature and pressure.

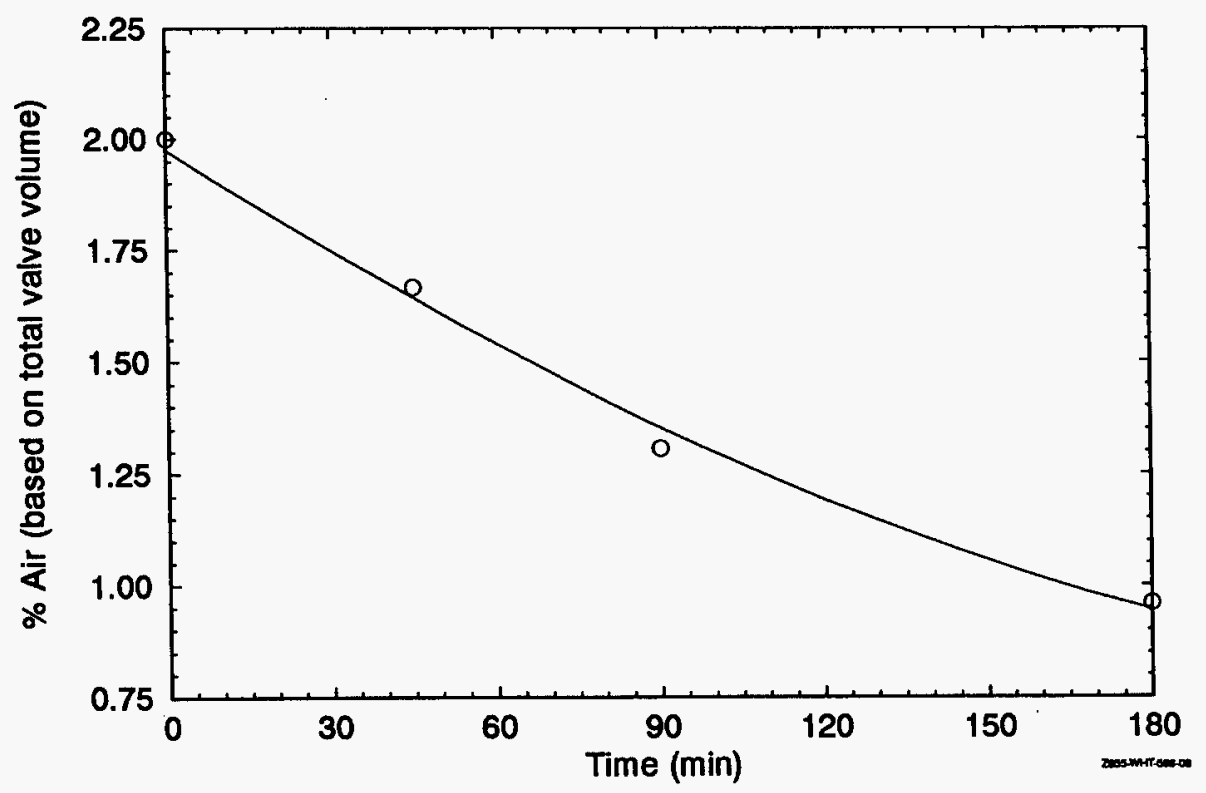

Figure 13. Entrapped air remaining in the valve bonnet with flow over time. 


\section{Cold Pressure Locking Tests}

The results of the cold pressure locking tests for the Anchor/Darling valve are summarized in Table 10. The table shows the peak unwedging thrust measured during the opening stroke, along with the upstream, bonnet, and downstream pressures that correspond in time with the peak thrust measurement. Where the stem packing load was measured in a static (no pressure) opening stroke, that value is also shown. Disc factor values are shown for the pressure locked strokes as well as for the hydrostatic opening strokes. (Because the two halves of the double disc assembly in this valve respond to pressure independently, it is possible to calculate a disc factor, using the equation described in Appendix B, even in tests that had pressure only in the bonnet. This was not the case with the Walworth flex-wedge valve, where the two halves of the disc are connected by a hub.) Unlike the data for the Walworth valve, the Anchor/Darling data do not include a calculation of a friction factor; the lack of a disc angle in the doubledisc valve makes such a calculation unnecessary, since the result would be identical to the disc factor.

The valve disc factor data shown in Table 10 indicate some interesting trends. The disc factors for the hydrostatic opening tests (designated HU for hydrostatic testing of the upstream seat and HD for hydrostatic testing of the downstream seat) show a gradual increase during the course of each of the two tests series (the 200 series tests and the 400 series tests). Within each test series, we observed that the stem thrust required to overcome pressure locking was greater than we expected for the parallel disc valve. We expected the stem thrust measurements in the pressure locking tests (designated PL in the table) to be higher by a factor of two, compared with the corresponding hydrostatic opening tests (see the equation in Appendix B). Instead, they were higher by a factor of 2.05 to 2.3 in the 200 series tests (excluding test 221 , which we consider an anomaly), and by a factor of 2.1 to 2.15 in the 400 series tests.

Table 10. Anchor/Darling gate valve, cold pressure locking test results. ${ }^{a}$

\begin{tabular}{|c|c|c|c|c|c|c|c|}
\hline $\mathrm{Te}$ & & & $\begin{array}{c}\text { Pressure } \\
(\mathrm{MPa})\end{array}$ & & Inwedoing & & \\
\hline Number & Type $^{b}$ & $\mathrm{Up}_{\mathrm{p}}$ & Bonnet & Down & $(\mathrm{N})$ & $(\mathrm{N})$ & Factor $^{c}$ \\
\hline 201 & $S$ & 0.03 & 0.06 & 0.03 & 16,574 & 6,036 & - \\
\hline 202 & HD & 7.29 & 7.31 & -0.03 & 41,902 & - & 0.403 \\
\hline 203 & HU & -0.02 & 6.96 & 6.92 & 47,147 & - & 0.446 \\
\hline 204 & $S$ & 0.00 & 0.02 & -0.01 & 16,934 & 6,005 & - \\
\hline 205 & PL & -0.03 & 1.59 & -0.03 & 29,474 & - & 0.504 \\
\hline 206 & PL & -0.03 & 3.42 & -0.03 & 55,994 & - & 0.506 \\
\hline 207 & PL & -0.03 & 5.34 & -0.03 & 80,637 & - & 0.487 \\
\hline 208 & PL & -0.03 & 7.43 & -0.03 & 103,043 & - & 0.459 \\
\hline 209 & PL & -0.03 & 7.48 & 2.05 & 91,144 & - & 0.467 \\
\hline 210 & PL & -0.03 & 7.72 & 4.08 & 88,751 & 一 & 0.516 \\
\hline 211 & PL & -0.02 & 7.58 & 6.05 & 68,632 & - & 0.497 \\
\hline 212 & $\mathrm{HU}$ & -0.02 & 7.07 & 7.02 & 50,692 & - & 0.473 \\
\hline 213 & $S$ & 0.02 & 0.03 & 0.01 & 13,100 & 5,863 & - \\
\hline 214 & HD & 7.68 & 7.70 & -0.02 & 49,184 & 一 & 0.451 \\
\hline
\end{tabular}


Table 10. (continued).

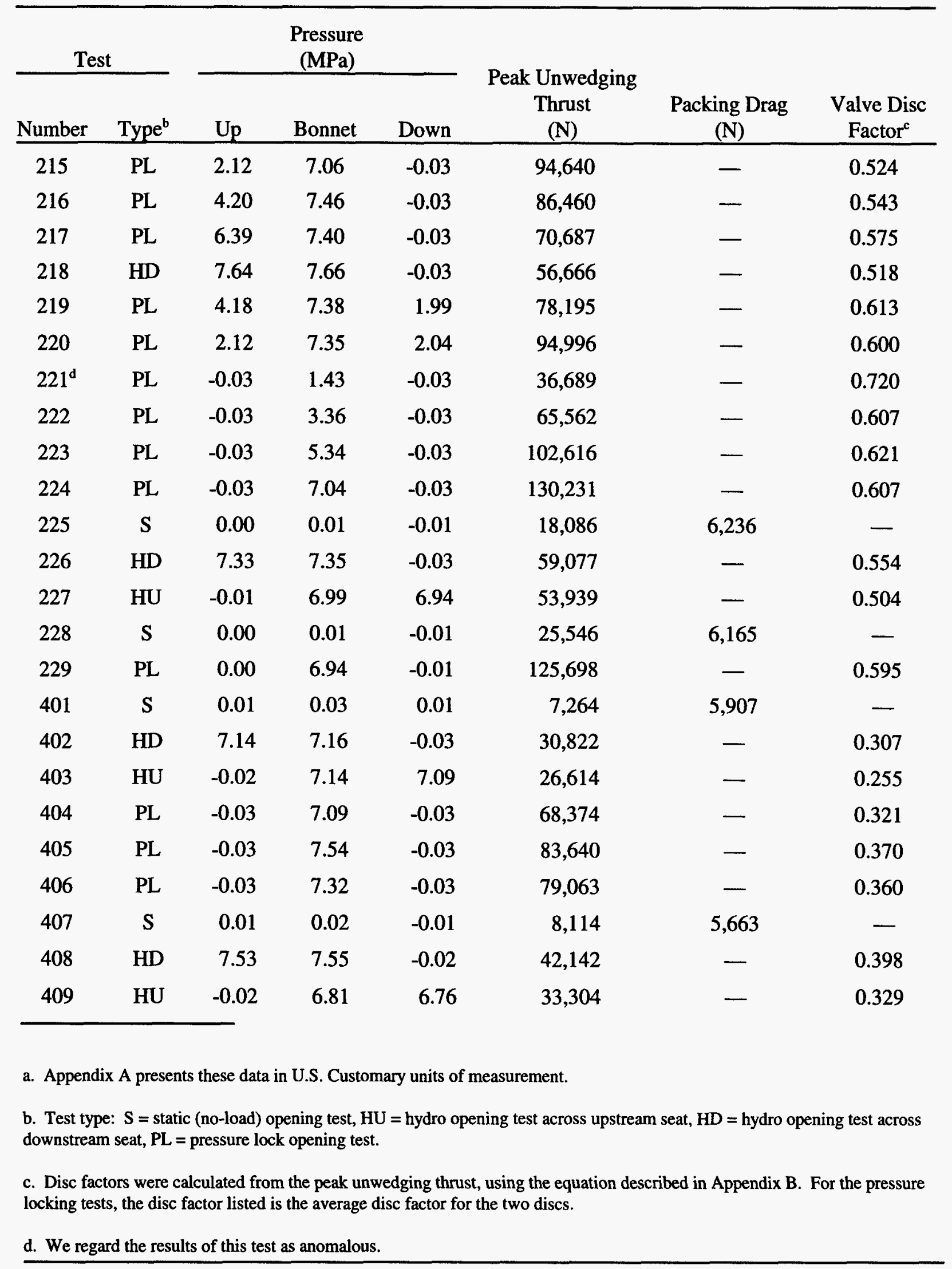




\section{Hot Pressure Locking Tests}

The thermally induced pressure locking tests for the Anchor/Darling valve consisted of six heatup tests using the internal heater, similar to the tests of the Walworth valve. Four of the heatup tests produced bonnet pressures capable of causing pressure locking loads. For each of those heatups, a valve opening stroke was performed when the bonnet pressure reached approximately $8.27 \mathrm{MPa}(1,200 \mathrm{psig})$. In the other two tests, seat leakage prevented the valve from pressurizing sufficiently during heatup, so for those tests we used a high-pressure pump to pressurize the bonnet. This strategy allowed measurement of the opening stem thrust at hot pressure locking conditions for all six heatups. The results of the six pressure locked opening strokes in the hot test series, along with the accompanying static (no pressure) and hydrostatic opening strokes, are summarized in Table 11. As with the cold test series, the stem thrust required to overcome pressure locking is more than twice as high as the opening thrust in the corresponding hydrostatic tests, higher by a factor of 2.1 to 2.4 .

Table 11. Anchor/Darling gate valve, thermally induced pressure locking test results. ${ }^{\mathrm{a}}$

\begin{tabular}{|c|c|c|c|c|c|c|c|c|}
\hline \multicolumn{2}{|c|}{ Test } & \multicolumn{3}{|c|}{$\begin{array}{c}\text { Pressure } \\
(\mathrm{MPa})\end{array}$} & \multirow{2}{*}{$\begin{array}{l}\text { Temp } \\
\left({ }^{\circ} \mathrm{C}\right) \\
\text { Bonnet }\end{array}$} & \multirow{2}{*}{$\begin{array}{c}\text { Peak } \\
\text { Unwedging } \\
\text { Thrust } \\
(N) \\
\end{array}$} & \multirow{2}{*}{$\begin{array}{c}\text { Packing } \\
\text { Drag } \\
(\mathrm{N}) \\
\end{array}$} & \multirow{2}{*}{$\begin{array}{c}\text { Valve Disc } \\
\text { Factor }^{\mathbf{c}} \\
\end{array}$} \\
\hline Number & Type $^{\text {b }}$ & Up & Bonnet & Down & & & & \\
\hline 301 & $S$ & 1.30 & 1.32 & 1.28 & 22 & 10,787 & 6,152 & - \\
\hline 302 & HD & 6.91 & 6.92 & 0.31 & 22 & 37,841 & - & 0.400 \\
\hline 303 & $\mathrm{HU}$ & 0.38 & 7.02 & 6.97 & 22 & 44,923 & - & 0.447 \\
\hline 306 & PL & 0.34 & 7.21 & -0.04 & - & 118,443 & - & 0.554 \\
\hline 307 & $\mathbf{S}$ & 0.62 & 0.64 & 0.61 & 68 & 13,687 & 6,152 & - \\
\hline 308 & HD & 7.52 & 7.53 & 0.36 & 56 & 46,746 & 一 & 0.458 \\
\hline 309 & $\mathrm{HU}$ & 0.37 & 6.84 & 6.80 & 52 & 48,281 & - & 0.489 \\
\hline 311 & $\mathbf{S}$ & 1.68 & 1.70 & 1.67 & 23 & 12,113 & 5,987 & - \\
\hline 312 & HD & 7.51 & 7.53 & 0.34 & 22 & 45,661 & - & 0.449 \\
\hline 313 & $\mathrm{HU}$ & 0.35 & 7.22 & 7.17 & 22 & 52,209 & 一 & 0.503 \\
\hline 318 & PL & 0.33 & 7.07 & -0.03 & - & 127,201 & - & 0.580 \\
\hline 319 & $\mathbf{S}$ & 0.39 & 0.41 & 0.38 & 94 & 14,377 & 6,321 & - \\
\hline 320 & HD & 7.74 & 7.76 & 0.31 & 84 & 54,406 & - & 0.511 \\
\hline 321 & $\mathrm{HU}$ & 0.41 & 7.02 & 6.96 & 82 & 55,683 & - & 0.551 \\
\hline 323 & $S$ & 0.01 & 0.03 & 0.00 & 22 & 14,813 & 6,517 & - \\
\hline 324 & HD & 7.24 & 7.26 & 0.00 & 23 & 50,225 & 一 & 0.479 \\
\hline 326 & $S$ & 1.13 & 1.16 & 1.12 & 23 & 10,173 & 6,041 & - \\
\hline 327 & $\mathrm{HD}$ & 7.44 & 7.45 & 0.37 & 22 & 46,595 & - & 0.463 \\
\hline 328 & $\mathrm{HU}$ & 0.36 & 7.55 & 7.50 & 22 & 47,680 & - & 0.443 \\
\hline 331 & PL & 0.36 & 7.34 & -0.03 & - & 119,555 & - & 0.550 \\
\hline 332 & $S$ & 0.97 & 0.98 & 0.94 & 67 & 13,598 & 6,330 & 一 \\
\hline 333 & $\mathrm{HD}$ & 7.69 & 7.71 & 0.33 & 59 & 48,650 & - & 0.463 \\
\hline 334 & $\mathrm{HU}$ & 0.36 & 7.05 & 7.00 & 46 & 49,927 & - & 0.490 \\
\hline 336 & $S$ & 0.01 & 0.03 & 0.00 & 24 & 14,292 & 6,308 & - \\
\hline 337 & HD & 7.60 & 7.62 & 0.00 & 23 & 53,583 & - & 0.491 \\
\hline
\end{tabular}


Table 11. (continued).

\begin{tabular}{|c|c|c|c|c|c|c|c|c|}
\hline \multicolumn{2}{|c|}{ Test } & \multicolumn{3}{|c|}{$\begin{array}{c}\text { Pressure } \\
(\mathrm{MPa})\end{array}$} & \multirow{2}{*}{$\begin{array}{c}\text { Temp } \\
\left({ }^{\circ} \mathrm{C}\right) \\
\text { Bonnet }\end{array}$} & \multirow{2}{*}{$\begin{array}{c}\text { Peak } \\
\text { Unwedging } \\
\text { Thrust } \\
(\mathrm{N}) \\
\end{array}$} & \multirow{2}{*}{$\begin{array}{c}\text { Packing } \\
\text { Drag } \\
\text { (N) }\end{array}$} & \multirow{2}{*}{$\begin{array}{c}\text { Valve Disc } \\
\text { Factor }^{\mathrm{c}} \\
\end{array}$} \\
\hline Number & Type $^{b}$ & Up & Bonnet & Down & & & & \\
\hline 338 & $\mathrm{HU}$ & -0.02 & 7.84 & 7.79 & 23 & 56,119 & - & 0.474 \\
\hline 339 & $\mathbf{S}$ & 2.39 & 2.41 & 2.37 & 24 & 17,117 & 6,179 & - \\
\hline 340 & HD & 7.49 & 7.52 & 0.34 & 24 & 50,283 & - & 0.492 \\
\hline 341 & HU & 0.37 & 7.64 & 7.59 & 23 & 52,222 & - & 0.478 \\
\hline 344 & PL & 0.32 & 7.62 & -0.03 & - & 125,889 & - & 0.559 \\
\hline 345 & $\mathbf{S}$ & 1.94 & 1.96 & 1.92 & 57 & 18,967 & 6,010 & - \\
\hline 346 & $\mathrm{HD}$ & 7.57 & 7.59 & 0.32 & 54 & 57,916 & 一 & 0.557 \\
\hline 347 & $\mathrm{HU}$ & 0.37 & 7.51 & 7.46 & 45 & 54,967 & - & 0.511 \\
\hline 349 & $S$ & 0.00 & 0.01 & -0.01 & 24 & 15,813 & 6,303 & - \\
\hline 350 & HD & 7.52 & 7.54 & 0.00 & 24 & 63,094 & - & 0.580 \\
\hline 351 & $\mathrm{HU}$ & -0.02 & 7.79 & 7.74 & 24 & 57,271 & - & 0.486 \\
\hline 352 & $\mathrm{~S}$ & 1.98 & 2.01 & 1.96 & 24 & 7,388 & 6,156 & - \\
\hline 353 & $\mathrm{HD}$ & 7.64 & 7.66 & 0.35 & 24 & 63,316 & - & 0.603 \\
\hline 354 & $\mathrm{HU}$ & 0.35 & 7.54 & 7.49 & 23 & 56,377 & - & 0.519 \\
\hline 361 & PL & 0.42 & 7.56 & -0.02 & - & 144,745 & - & 0.647 \\
\hline 362 & $\mathbf{S}$ & 5.45 & 5.47 & 5.43 & 105 & 4,537 & 5,196 & - \\
\hline 363 & HD & 7.75 & 7.77 & 0.32 & 98 & 47,885 & - & 0.463 \\
\hline 364 & HU & 0.96 & 7.47 & 7.41 & 98 & 32,686 & - & 0.351 \\
\hline 366 & $\mathbf{S}$ & 0.03 & 0.04 & 0.01 & 27 & 11,552 & 6,107 & - \\
\hline 367 & $\mathrm{HD}$ & 7.53 & 7.55 & -0.03 & 25 & 45,029 & - & 0.420 \\
\hline 368 & $\mathrm{HU}$ & -0.02 & 6.64 & 6.59 & 25 & 35,056 & - & 0.348 \\
\hline 369 & $\mathbf{S}$ & 4.36 & 4.39 & 4.34 & 27 & 5,111 & 5,667 & - \\
\hline 370 & $\mathrm{HD}$ & 7.77 & 7.78 & 0.35 & 25 & 46,755 & - & 0.449 \\
\hline 371 & $\mathrm{HU}$ & 0.36 & 6.87 & 6.83 & 25 & 34,821 & - & 0.360 \\
\hline 375 & PL & 0.37 & 7.62 & 0.01 & - & 113,336 & - & 0.501 \\
\hline 377 & $\mathrm{~S}$ & 8.40 & 8.42 & 8.37 & 96 & $-1,917$ & 5,249 & - \\
\hline 378 & $\mathrm{HD}$ & 7.52 & 7.54 & 0.44 & 88 & 35,933 & - & 0.370 \\
\hline 379 & HU & 0.46 & 6.68 & 6.63 & 91 & 33,179 & - & 0.362 \\
\hline 381 & $\mathbf{S}$ & 0.08 & 0.09 & 0.06 & 24 & 7,233 & 6,010 & - \\
\hline 382 & $\mathrm{HD}$ & 7.43 & 7.45 & 0.03 & 23 & 34,207 & - & 0.330 \\
\hline 383 & HU & -0.01 & 6.94 & 6.89 & 23 & 29,287 & - & 0.287 \\
\hline
\end{tabular}

a. Appendix A presents these data in U.S. Customary units of measurement.

b. Test type: $\mathrm{S}=$ static (no-load) opening test, $\mathrm{HU}=$ hydro opening test across upstream seat, $\mathrm{HD}=$ hydro opening test across downstream seat, $\mathrm{PL}=$ pressure lock opening test.

c. Disc factors were calculated from the peak unwedging thrust, using the equation described in Appendix B. For the pressure locking tests, the disc factor listed is the average disc factor for the two discs. 


\section{Effects of Valve Leakage}

Of the six heatup tests, the first three provide data that indicate the effects of valve leakage during heatup. The initial bonnet pressures in these tests were $2.07,0$, and $4.14 \mathrm{MPa}(300,0$, and $600 \mathrm{psig})$. The pressures were monitored during heatup, and the heatup was terminated when the bonnet pressure reached 8.27 MPa (1,200 psig), or if the bonnet failed to pressurize, heatup was terminated when the upstream fluid temperature reached about $143^{\circ} \mathrm{C}\left(290^{\circ} \mathrm{F}\right)$.

Figure 14 shows valve bonnet pressure versus bonnet fluid temperature for these three heatup tests. Test 1 began with a bonnet pressure of $2.07 \mathrm{MPa}(300 \mathrm{psig})$, and the bonnet pressure increased rapidly after the valve reached $38^{\circ} \mathrm{C}\left(100^{\circ} \mathrm{F}\right)$. The duration of the heatup was 1.9 hours. Test 2 began with no pressure in the bonnet, and the bonnet did not pressurize (2.9-hour heatup), because of slight seat leakage. Test 3 began with a bonnet pressure of $4.14 \mathrm{MPa}(600 \mathrm{psig})$, and the bonnet pressurized rapidly, as in Test 1. The duration of the heatup was 1.6 hours. The results from Test 2 show that only slight seat leakage is sufficient to prevent bonnet pressurization during heatup. As with the Walworth valve, the leakage rate varied considerably.

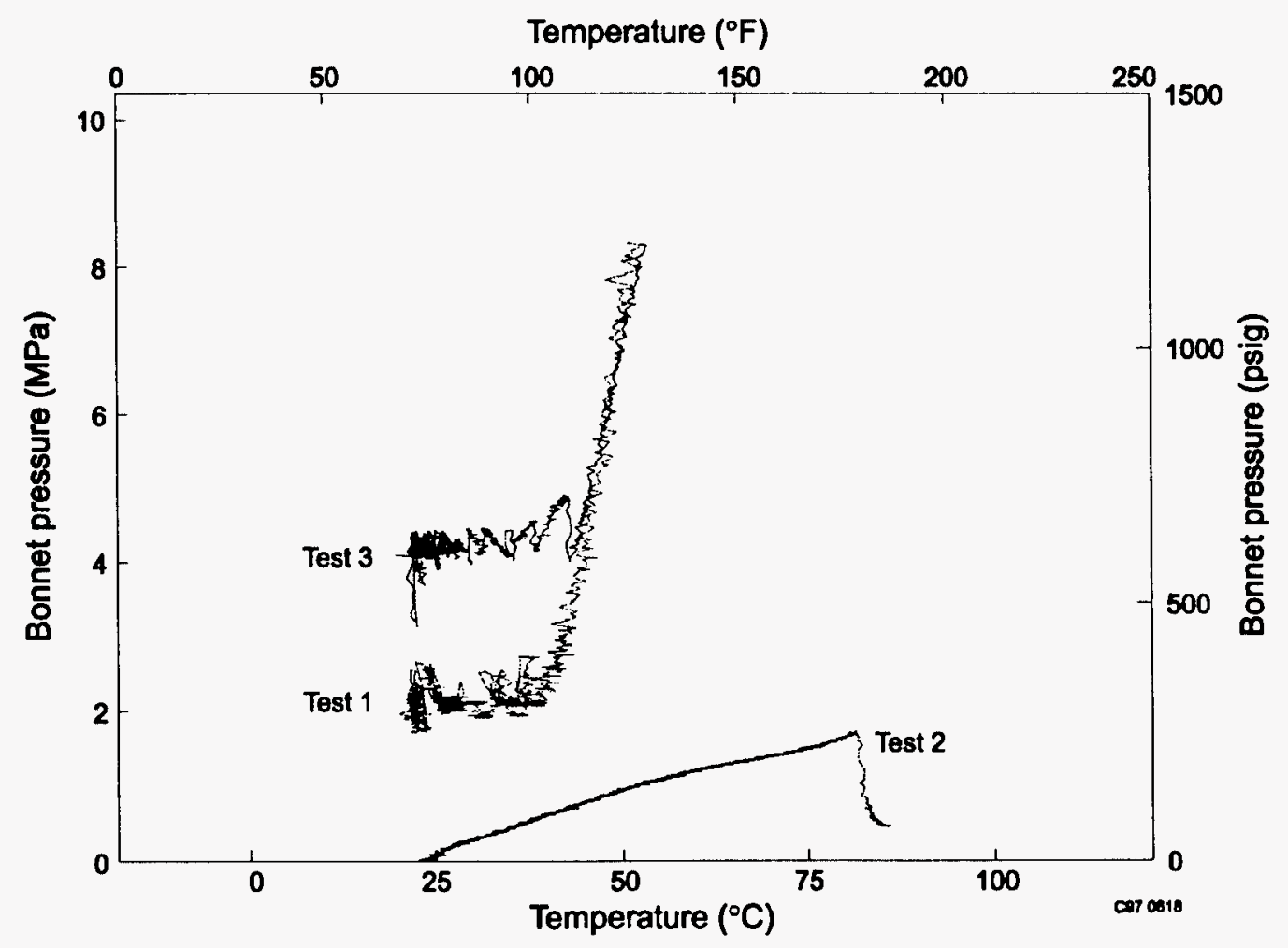

Figure 14. Pressure versus temperature for heatup tests performed at three different initial pressures. 


\section{Effects of Entrapped Air}

The other three heatup tests were performed to provide data on the effects of entrapped air. Two of these tests were performed with air pockets in the bonnet representing $2.0 \%$ of the bonnet volume; the other was a baseline test with no entrapped air. After the appropriate air volume was established, the valve was heated. The pressure was monitored during heatup, and heatup was terminated when the bonnet pressure reached $8.27 \mathrm{MPa}(1,200 \mathrm{psig})$, or at $143^{\circ} \mathrm{C}\left(290^{\circ} \mathrm{F}\right)$ if the bonnet did not pressurize.

Figure 15 shows valve bonnet pressure versus bonnet fluid temperature for these three heatup tests. Test 4 was conducted with no entrapped air and with internal fluid heating applied for 1.3 hours. Test 5 was conducted with 2.0\% entrapped air and with internal fluid heating for 4.1 hours. Test 6 was conducted with $2.0 \%$ entrapped air and with both internal and external heating, for 2.3 hours. With Test 5 , the heatup was not rapid enough to cause the bonnet to pressurize; slight valve leakage, possibly combined with the effects of the air bubble, contributed to the failure to pressurize. A comparison of the results from Tests 4 and 6 illustrates the effect of entrapped air. With air trapped in the valve bonnet, rapid pressurization due to heating is delayed until a higher temperature is reached.

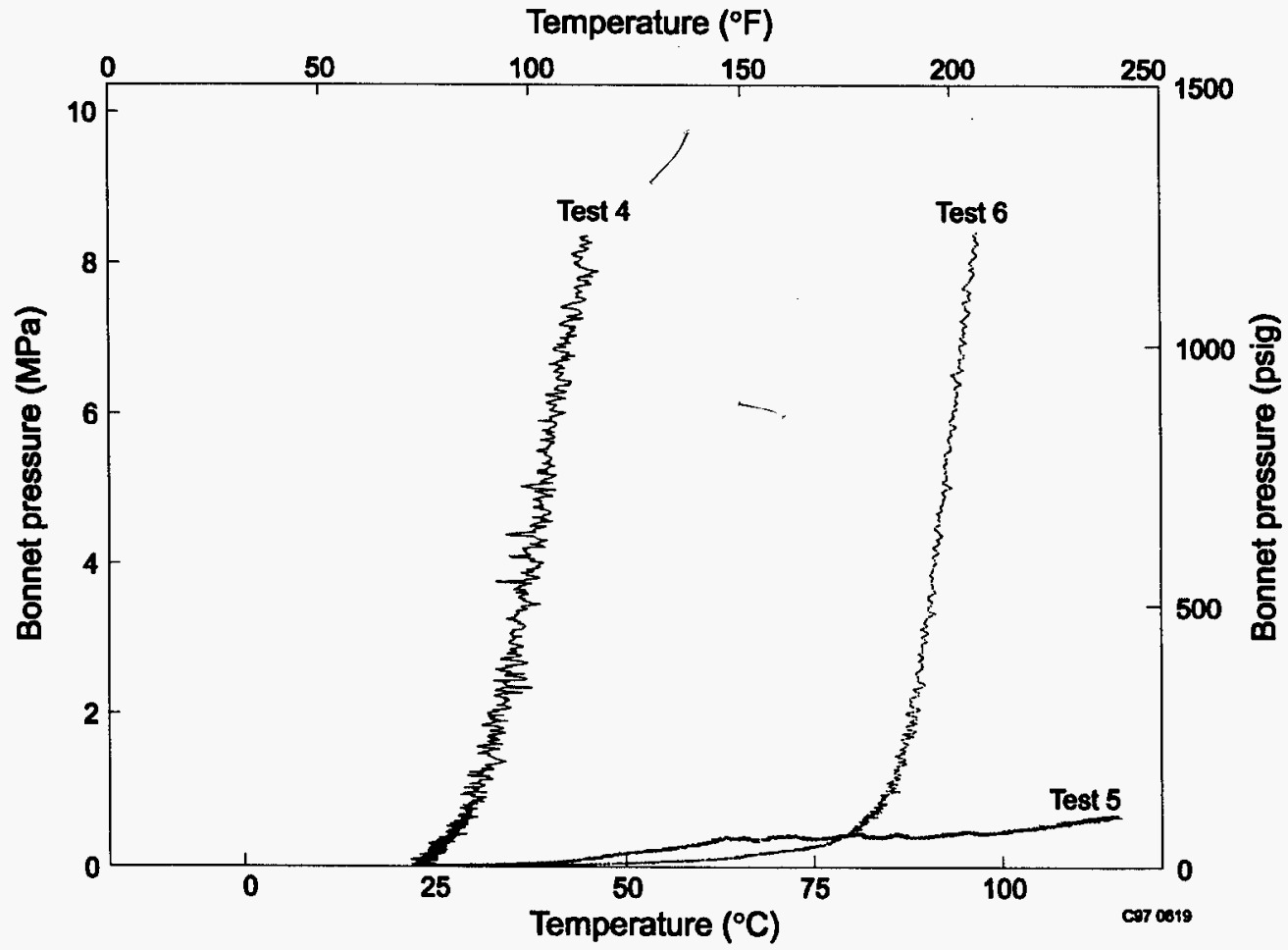

Figure 15. Pressure versus temperature in three heatup tests, comparing the effects of entrapped air (Test 6) and no entrapped air (Test 4). 


\section{THERMAL BINDING TEST RESULTS}

The following discussion presents results from thermal binding tests for the two valves we tested. A discussion of pertinent thermal binding data from an earlier test program is included.

\section{Walworth Gate Valve}

Figure 16 shows the effect of thermal binding on unwedging thrusts for the Walworth valve. The figure shows stem thrust versus time for two unloaded (static) unwedging tests (tests 342 and 348) and for a thermal binding test (351). For this particular thermal binding test, we filled the valve with cold fluid, heated the valve body with the external heaters, and closed the valve when the valve body was hot but before the disc had time to heat up. The intent of this strategy was to maximize the possible thermal binding effect (seating an unexpanded disc in an expanded valve body seat). We then allowed the entire valve assembly to cool before opening the valve for the thermal binding test. The data (presented in Figure 16) show very little effect of thermal binding on the valve opening thrust. The thermal binding opening stroke produced a peak thrust of $28,415 \mathrm{~N}\left(6388 \mathrm{lb}_{\mathfrak{t}}\right)$, compared with values of 26,351 and $25,858 \mathrm{~N}$ (5924 and $5813 \mathrm{lb}_{\mathrm{f}}$ ) for the two unloaded opening strokes. Thus, the results show an average increase of about $9 \%$ due to thermal binding effects.

\section{Anchor/Darling Gate Valve}

Figure 17 shows the effect of thermal binding on unwedging thrusts for the Anchor/Darling valve. The figure shows stem thrust versus time for three unloaded (static) unwedging tests (Tests 301, 307, and 311 ) and the thermal binding test (310). The peak opening thrust measured during the thermal binding

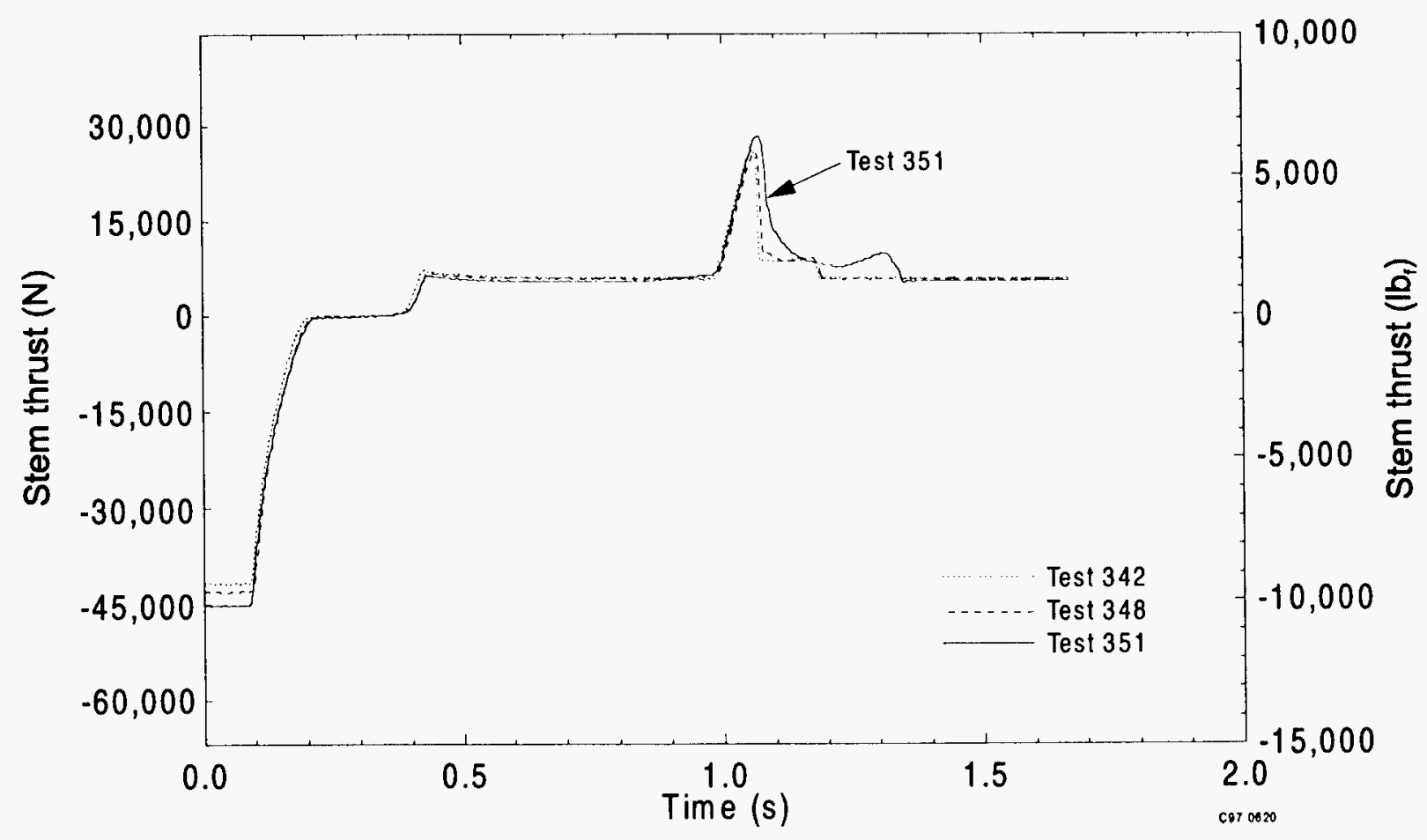

Figure 16. Stem thrust measured in a thermal binding test (Test 351) of the Walworth valve, compared with results from unloaded (static) opening strokes. 


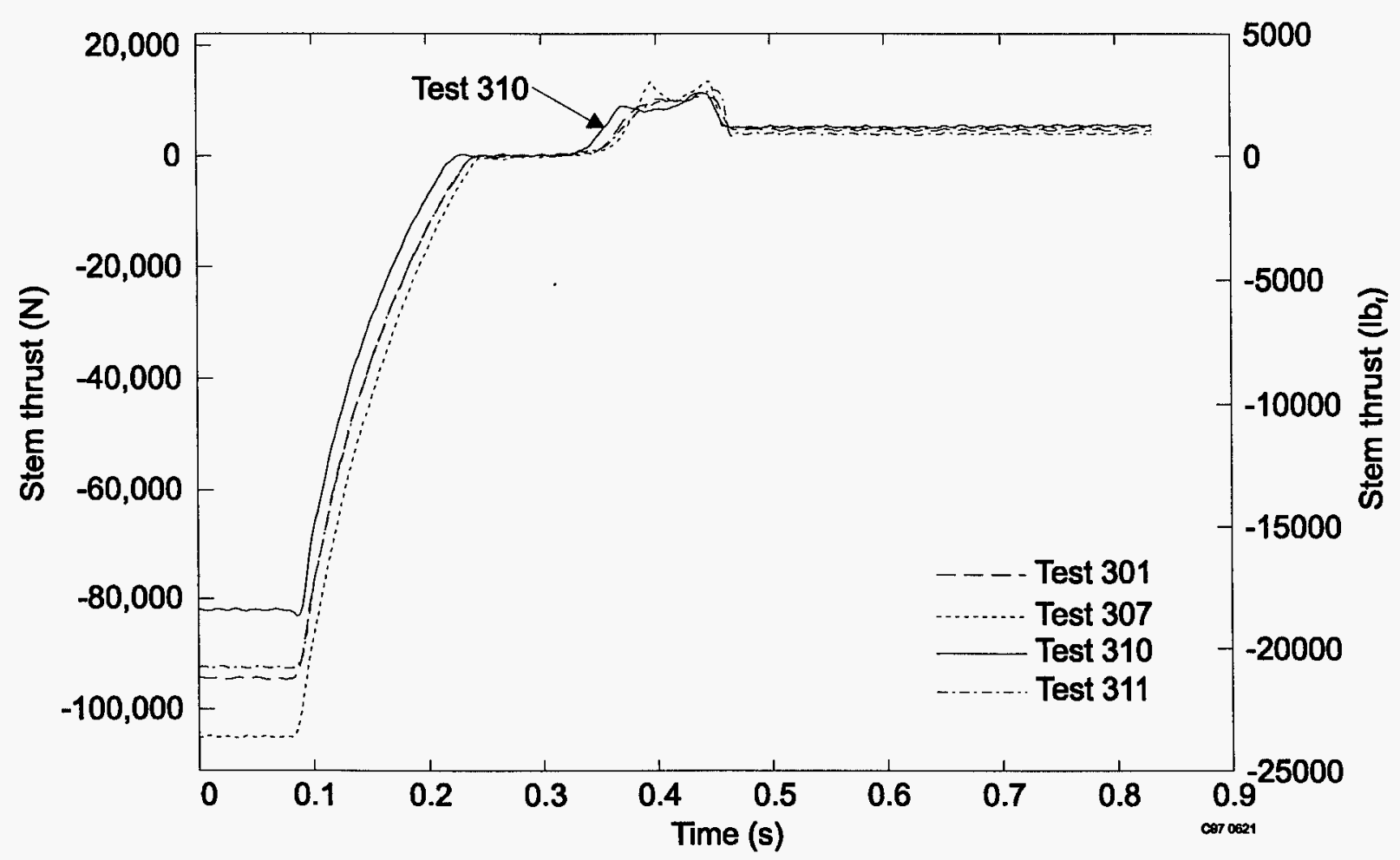

Figure 17. Stem thrust measured in a thermal binding test (Test 310) of the Anchor/Darling valve, compared to the results of unloaded (static) tests.

test was $11,565 \mathrm{~N}\left(2600 \mathrm{lb}_{\mathrm{f}}\right)$, a value similar to the peak values measured in the static tests. Thus, the data show no effect of thermal binding on valve opening thrust.

\section{Results from Earlier Tests}

To further evaluate how thermal binding might affect the stem thrust required to open a valve, we reviewed the applicable data from the Generic Issue 87 (GI-87) Phase 2 test program, sponsored by the NRC and conducted by INEEL in 1989. The program featured testing of six gate valves at full-scale blowdown loads. The GI-87 Phase 2 testing and results are described in detail in NUREG/CR-5558.

The focus of the GI-87 testing was to evaluate the ability of typical gate valves to perform containment isolation functions. In Phase 2, seventeen flow interruption tests were performed, seven of which involved high-energy design-basis line-break loads. Of interest to the present study is the fact that the test plan in that program called for the valve to be closed hot at the end of a test sequence, followed typically by an unwedging stroke later on, after the valve had cooled. This sequence provides the opportunity for us to evaluate these data for thermal binding effects.

Table 12 identifies the six valves tested in the GI-87 Phase 2 program. All six valves were flexible-wedge gate valves. The valves were instrumented to measure stem force, upstream, bonnet, and downstream pressures and temperatures, and other important parameters.

The results presented in the following discussion include the data derived from instances where an opening stroke was preceded by a closing stroke at higher temperature or pressure. These instances represent possible thermal binding conditions. Data from cold opening strokes preceded by cold closing 
Table 12. GI-87 Phase 2 test valves.

\begin{tabular}{clll}
\hline $\begin{array}{c}\text { Valve } \\
\text { Identification }\end{array}$ & Size & Class & Manufacturer \\
\hline Valve 1 & 6 -inch & $900-\mathrm{lb}$ & Anchor/Darling \\
Valve 2 & 6 -inch & $900-\mathrm{lb}$ & Velan \\
Valve 3 & 6 -inch & $600-\mathrm{lb}$ & Walworth \\
Valve 4 & 10 -inch & $900-\mathrm{lb}$ & Anchor/Darling \\
Valve 5 & 10 -inch & $900-\mathrm{lb}$ & Powell \\
Valve 6 & 10 -inch & $900-\mathrm{lb}$ & Velan \\
\hline
\end{tabular}

strokes are also included to provide a baseline for comparison For Valves 1 and 2, measurements of stem thrust were taken by a calibrated load cell installed in the valve stem. For the other four valves, stem thrust was measured by load cells installed in the flange between the valve and the actuator. Pressure and temperature measurements reported here were taken in the valve bonnet. Pressure measurements are included in this discussion because in many instances the valve was closed (hot) with significant system pressure and then later opened (cold) with little or no system pressure. By including the pressure data, we can evaluate the possibility that depressurization contributed to the observed results. (High system pressure "stretches" the valve, allowing the disc to seat more deeply during valve closure; subsequent depressurization allows the valve to "shrink" enough for the valve body seats to "squeeze" the disc more tightly than would otherwise be the case.)

Table 13 contains the GI-87 data that pertain to thermal binding. In each instance, data from an opening stroke is accompanied by data from the preceding closing stroke. The test identifier (CL2, CC1, etc.) listed in the table is the identifier for the opening stroke. Thrust data listed in the table are the peak thrust measurements taken either during wedging or unwedging.

The test data for Valve 1 are shown in Figures 18 and 19. Figure 18 displays the ratio of the unwedging stem thrust to the wedging stem thrust, plotted against the temperature change that occurred during the interval between the wedging stroke and the unwedging stroke. The six static wedging and unwedging tests (no significant change in temperature or pressure) form a cluster at a ratio of 0.2 , while test T1S9 shows a ratio of 0.66 with a temperature drop of $138^{\circ} \mathrm{C}\left(249^{\circ} \mathrm{F}\right)$. All seven tests were depressurized, so pressure is not a factor in these ratios (see Figure 19).

Figures 20 and 21 show the unwedging to wedging stem force ratios versus the changes in temperature and pressure for Valve 2. The two static tests have ratios of about 0.17 , while the other tests range from 0.44 to 1.07 . Test T3COS 1 , with a ratio of 0.44 for a $6.31 \mathrm{MPa}(915 \mathrm{psi}$ ) pressure drop, did not experience a change in temperature, and thus provides an indication of how a change in pressure alone affects the unwedging to wedging ratio. By way of comparison, Test T1S7 shows how a significant drop in pressure combined with a drop in temperature affects the unwedging to wedging ratio.

Valve 3 is the same Walworth valve used in the pressure locking and thermal binding tests discussed earlier in this report. The data in Figures 22 and 23 show what appears to be a linear relationship, but the combined effects of both a temperature drop and a pressure drop cannot be separated. The ratio for the static tests (no temperature or pressure changes) is around 0.20 ; the ratio reaches 0.63 with a temperature drop of $128^{\circ} \mathrm{C}\left(231^{\circ} \mathrm{F}\right)$ and a pressure drop of $8.77 \mathrm{MPa}(1,272 \mathrm{psi})$ combined. 
Table 13. GI-87 Phase 2 thermal binding test data."

\begin{tabular}{|c|c|c|c|c|c|c|c|}
\hline $\begin{array}{c}\text { Valve } \\
\text { Number } \\
\end{array}$ & $\begin{array}{c}\text { Test } \\
\text { Number }\end{array}$ & $\begin{array}{c}\text { Pressure } \\
\text { Wedging } \\
(\mathrm{MPa}) \\
\end{array}$ & $\begin{array}{l}\text { Temperature } \\
\text { Wedging } \\
\left({ }^{\circ} \mathrm{C}\right)\end{array}$ & $\begin{array}{c}\text { Thrust } \\
\text { Wedging } \\
(\mathrm{N})\end{array}$ & $\begin{array}{c}\text { Pressure } \\
\text { Unwedging } \\
(\mathrm{MPa})\end{array}$ & $\begin{array}{c}\text { Temperature } \\
\text { Unwedging } \\
\left({ }^{\circ} \mathrm{C}\right)\end{array}$ & $\begin{array}{c}\text { Thrust } \\
\text { Unwedging } \\
\text { (N) } \\
\end{array}$ \\
\hline \multirow[t]{7}{*}{ Valve 1} & CL2 & 0.08 & 6 & $-109,853$ & 0.08 & 6 & 24,256 \\
\hline & $\mathrm{CC} 1$ & 0.00 & 14 & $-111,797$ & 0.06 & 14 & 25,110 \\
\hline & $\mathrm{CC} 3$ & 0.06 & 14 & $-114,124$ & 0.07 & 14 & 24,817 \\
\hline & $\mathrm{CC} 7$ & 0.08 & 21 & $-117,905$ & 0.07 & 21 & 23,104 \\
\hline & $\mathrm{CC} 8$ & 0.07 & 21 & $-116,050$ & 0.07 & 24 & 24,652 \\
\hline & $\mathrm{HC} 2$ & 0.00 & 19 & $-116,508$ & 0.00 & 19 & 26,818 \\
\hline & T1S9 & 0.00 & 210 & $-113,318$ & 0.00 & 72 & 74,503 \\
\hline \multirow[t]{6}{*}{ Valve 2} & SU1 & 0.38 & 22 & $-114,764$ & 0.38 & 22 & 19,497 \\
\hline & $\mathrm{CCS} 1$ & 0.09 & 22 & $-105,716$ & 0.09 & 23 & 17,348 \\
\hline & T1S7 & 6.21 & 276 & $-101,282$ & 0.00 & 214 & 107,878 \\
\hline & T6A1S7 & 2.92 & 230 & $-108,448$ & 0.00 & 181 & 69,592 \\
\hline & T6CS7 & 6.78 & 277 & $-109,093$ & 0.00 & 218 & 67,880 \\
\hline & T3COS1 & 6.43 & 48 & $-113,723$ & 0.12 & 48 & 49,553 \\
\hline \multirow[t]{5}{*}{ Valve 3} & CL4 & 0.08 & 25 & $-73,614$ & 0.08 & 25 & 15,400 \\
\hline & $\mathrm{HCl}$ & 0.03 & 26 & $-74,041$ & 0.03 & 26 & 13,082 \\
\hline & T1AS78 & 5.96 & 274 & $-66,995$ & 0.00 & 231 & 29,096 \\
\hline & T5S78 & 7.31 & 288 & $-70,798$ & 0.00 & 250 & 29,412 \\
\hline & T7S78 & 8.77 & 299 & $-71,363$ & 0.00 & 171 & 45,238 \\
\hline \multirow[t]{2}{*}{ Valve 4} & $\operatorname{CCS} 1$ & 0.01 & 9 & $-158,886$ & 0.01 & 9 & 62,199 \\
\hline & T1S7 & 2.52 & 343 & $-160,541$ & 0.00 & 106 & 157,000 \\
\hline \multirow[t]{3}{*}{ Valve 5} & $\mathrm{CCS} 1$ & 0.08 & 20 & $-167,271$ & 0.08 & 20 & 24,981 \\
\hline & HCS1 & 0.02 & 19 & $-167,765$ & 0.02 & 19 & 23,754 \\
\hline & T1AS7 & 6.37 & 276 & $-249,932$ & 0.05 & 259 & 99,467 \\
\hline \multirow[t]{6}{*}{ Valve 6} & SU2 & 0.00 & 18 & $-163,268$ & 0.00 & 18 & 24,412 \\
\hline & $\mathrm{CCl}$ & 0.42 & 19 & $-166,933$ & 0.42 & 19 & 21,601 \\
\hline & $\mathrm{HC} 1$ & 0.00 & 19 & $-169,406$ & 0.00 & 19 & 16,085 \\
\hline & T1S78 & 6.01 & 278 & $-237,468$ & 0.00 & 220 & 136,663 \\
\hline & T1AS7 & 8.30 & 302 & $-239,621$ & 0.00 & 215 & 131,752 \\
\hline & T1BS7 & 7.61 & 295 & $-215,120$ & 0.01 & 207 & 142,179 \\
\hline
\end{tabular}




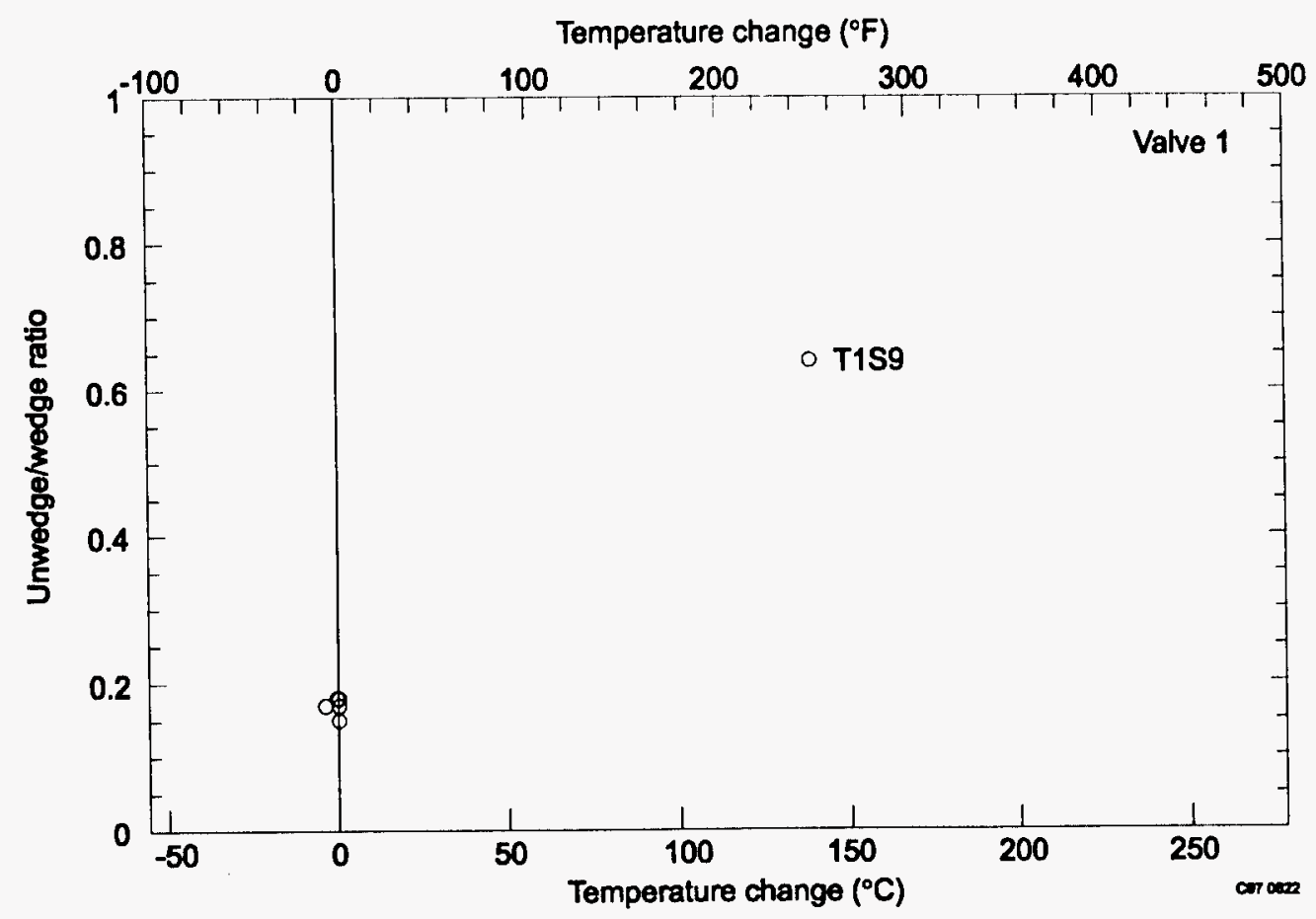

Figure 18. Thermal binding data from GI-87 tests; unwedging/wedging ratio versus temperature change for Valve 1.

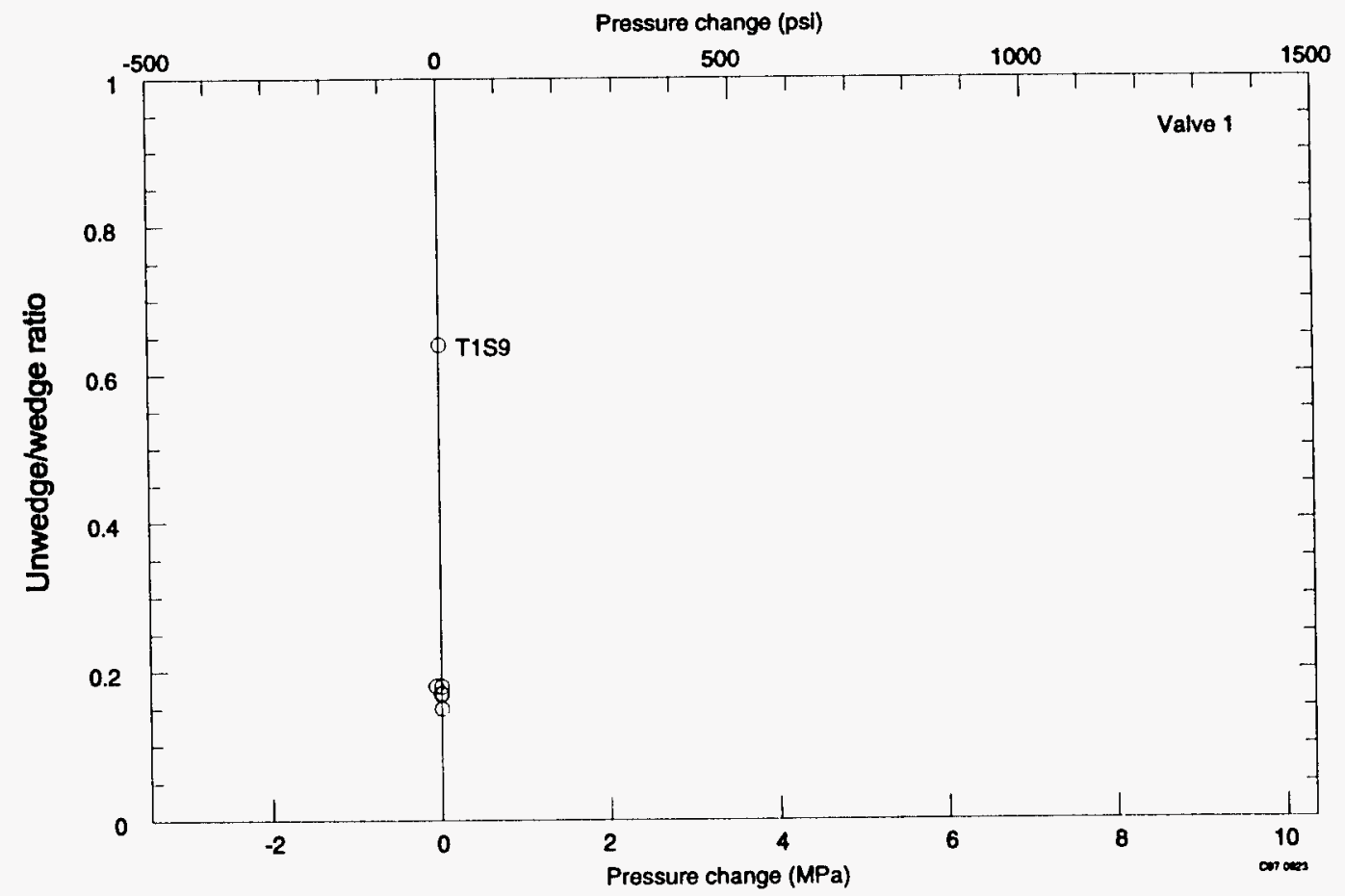

Figure 19. Thermal binding data from GI-87 tests; unwedging/wedging ratio versus pressure change for Valve 1. 


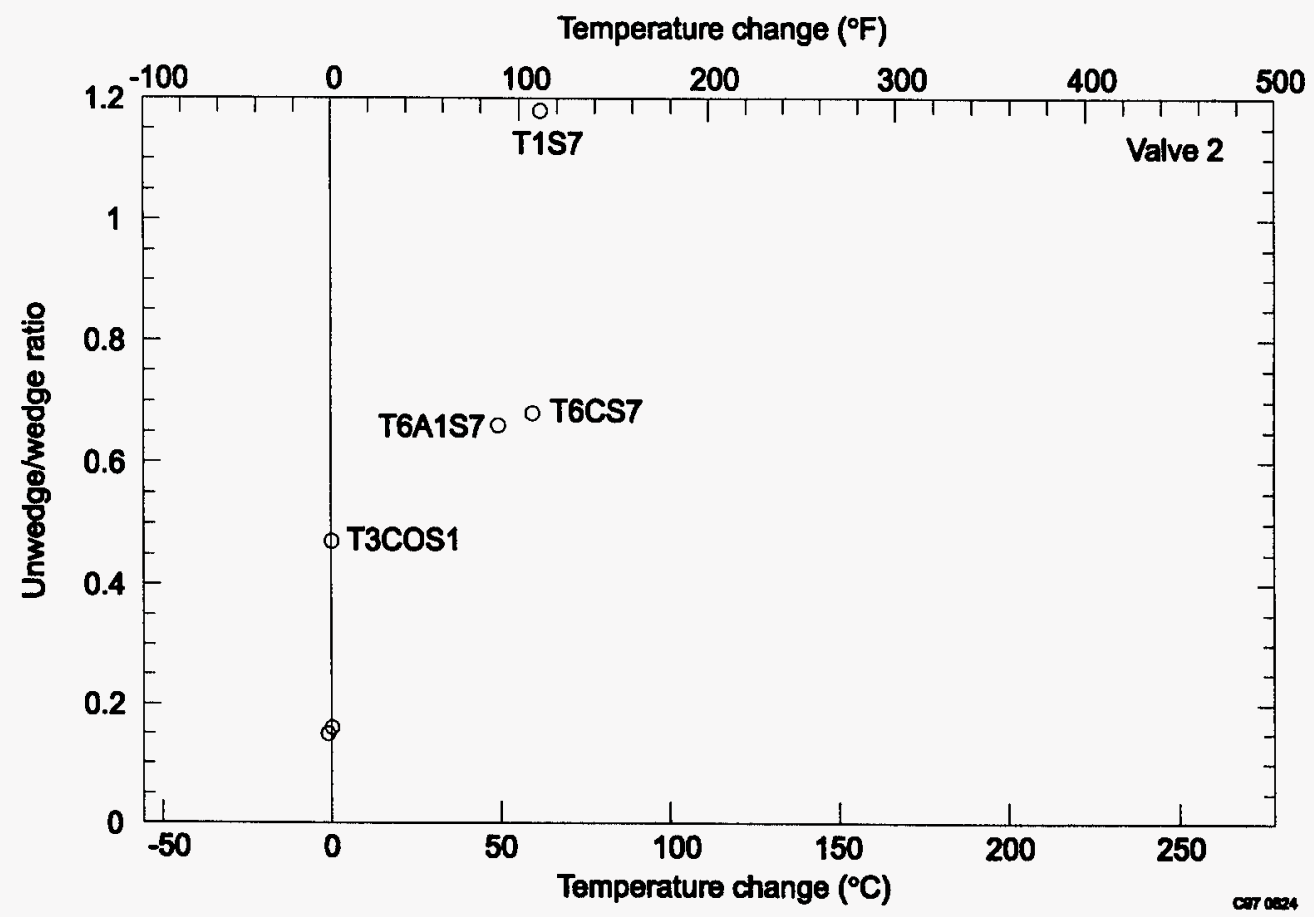

Figure 20. Thermal binding data from GI-87 tests; unwedging/wedging ratio versus temperature change for Valve 2.

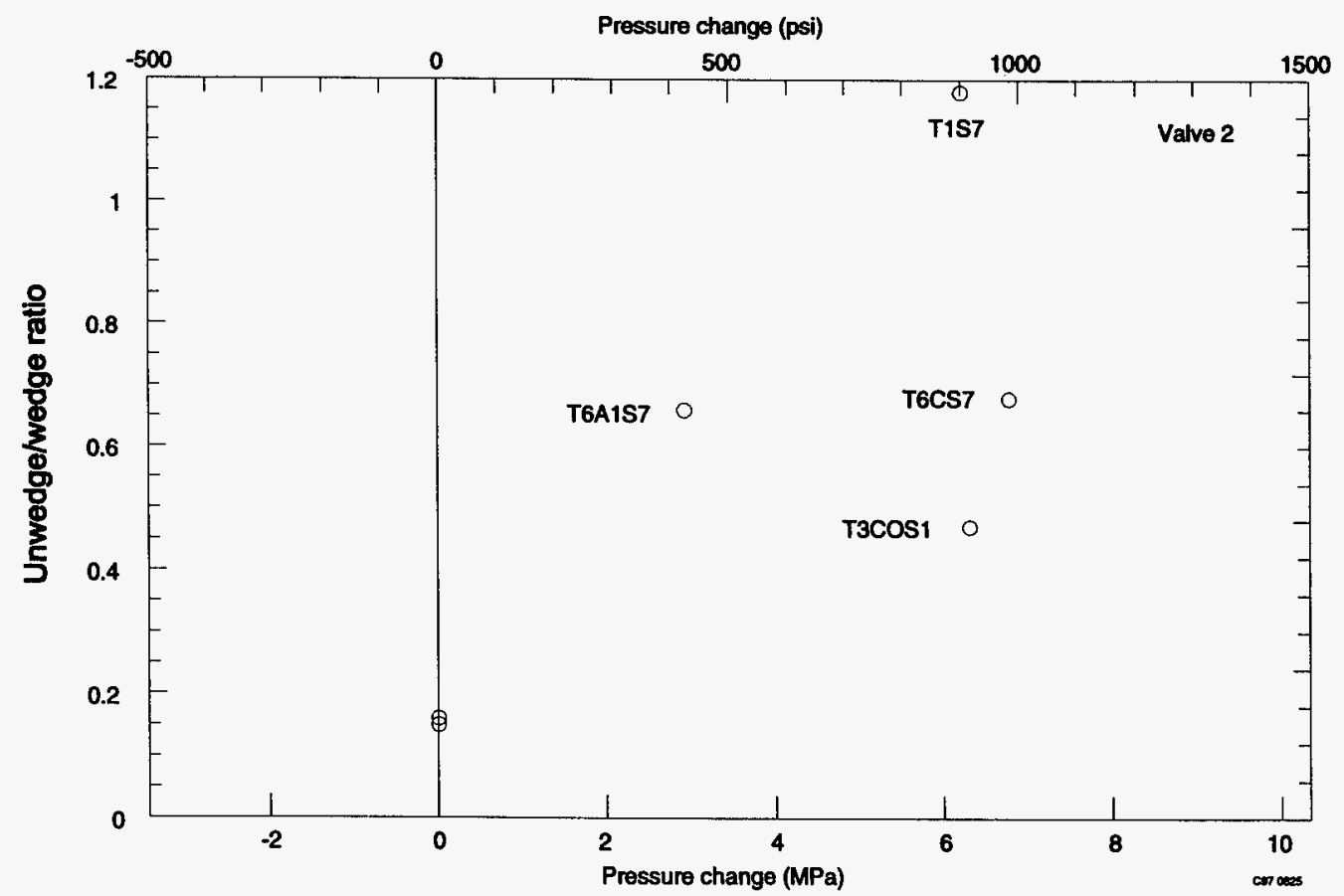

Figure 21. Thermal binding data from GI-87 tests; unwedging/wedging ratio versus pressure change for Valve 2. 
Thermal Binding Test Results

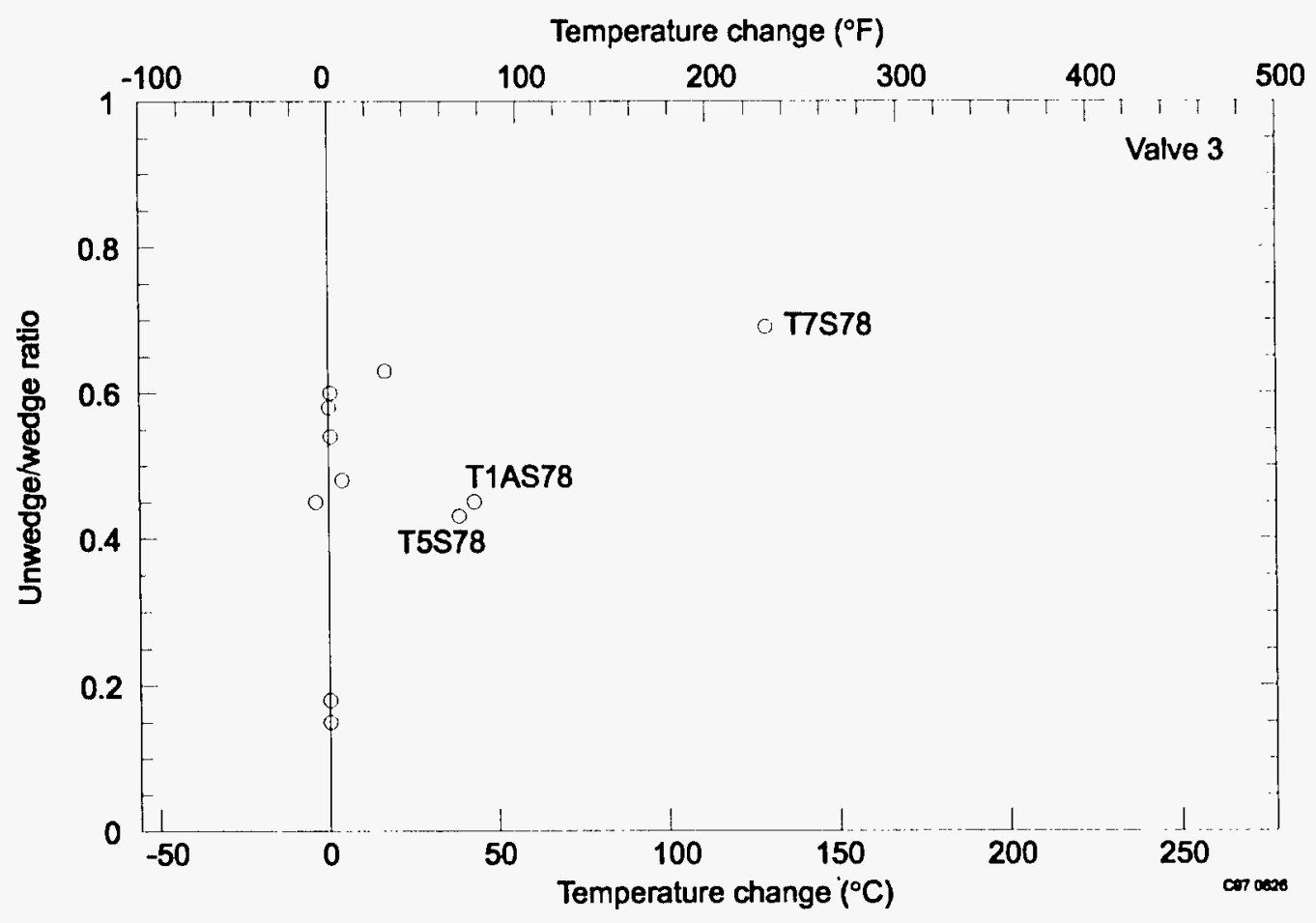

Figure 22. Thermal binding data from GI-87 tests; unwedging/wedging ratio versus temperature change for Valve 3.

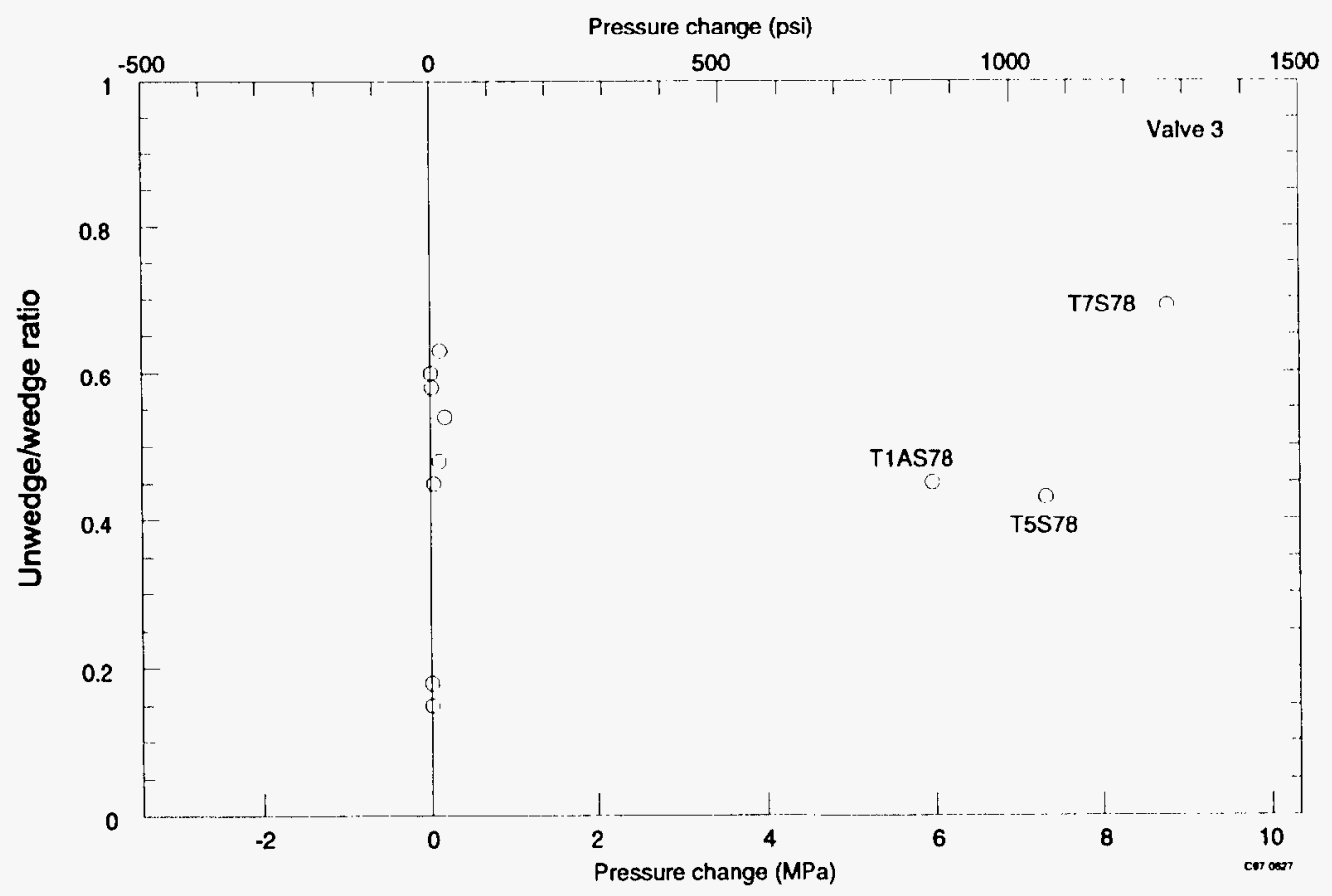

Figure 23. Thermal binding data from GI-87 tests; unwedging/wedging ratio versus pressure change for Valve 3. 
Valves 4 and 5 had fewer test strokes that could be used for this evaluation. Valve 4 had one true static test (ratio equals 0.39 ) and one test that provided thermal binding results (ratio equals 0.98 ) with the combined effects of temperature and pressure (see Figures 24 and 25). Valve 5 had two static tests (ratios equal 0.14 and 0.15 ) and one test that provided thermal binding results (ratio equals 0.40 ), again with the combined effects of temperature and pressure (see Figures 26 and 27).

Valve 6 data are shown in Figures 28 and 29. The figure shows results for three static tests and three tests that provided thermal binding results. The unwedging to wedging ratio for the static tests averaged 0.12 . The combined effects of temperature and pressure result in ratios reaching as high as 0.66 at thermal binding conditions.

Overall, the results show that disc binding due to thermal and pressure effects can occur. Whereas the ordinary unseating loads for these six valves are typically about $20 \%$ of the previous seating load, the thermal-binding/depressurization unseating loads ranged from about 40 to $120 \%$ of the previous seating load.

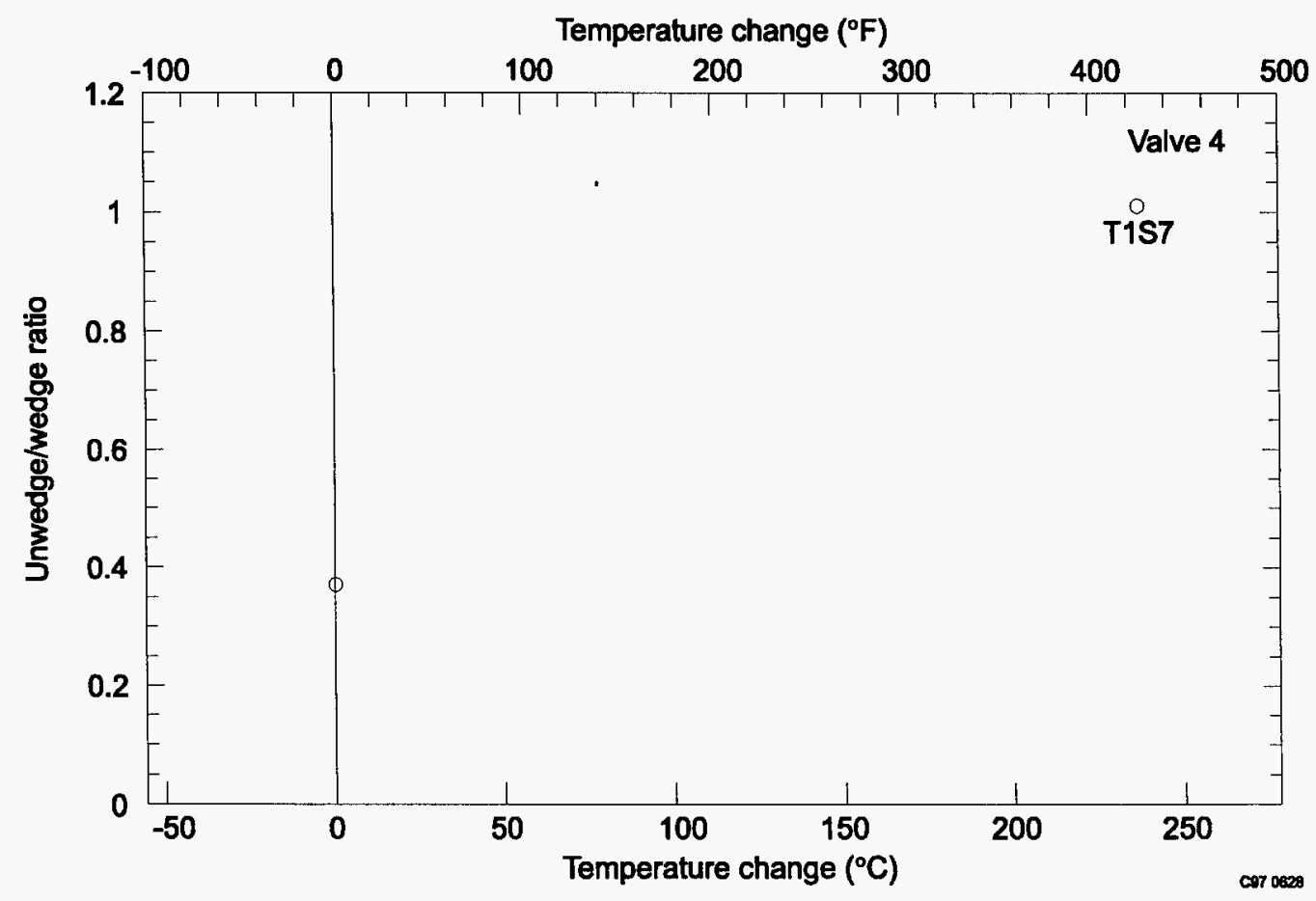

Figure 24. Thermal binding data from GI-87 tests; unwedging/wedging ratio versus temperature change for Valve 4. 
Thermal Binding Test Results

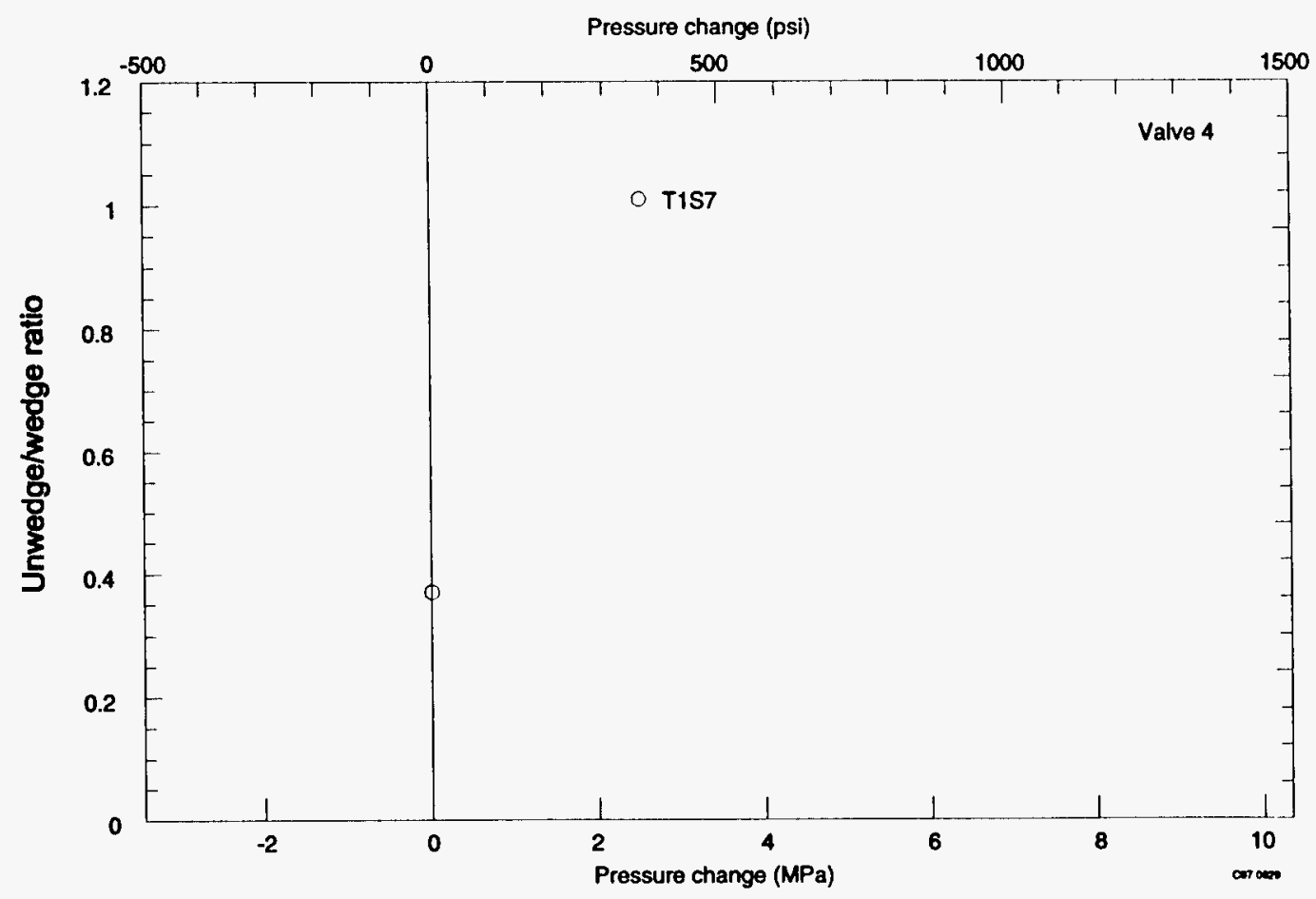

Figure 25. Thermal binding data from GI-87 tests; unwedging/wedging ratio versus pressure change for Valve 4.

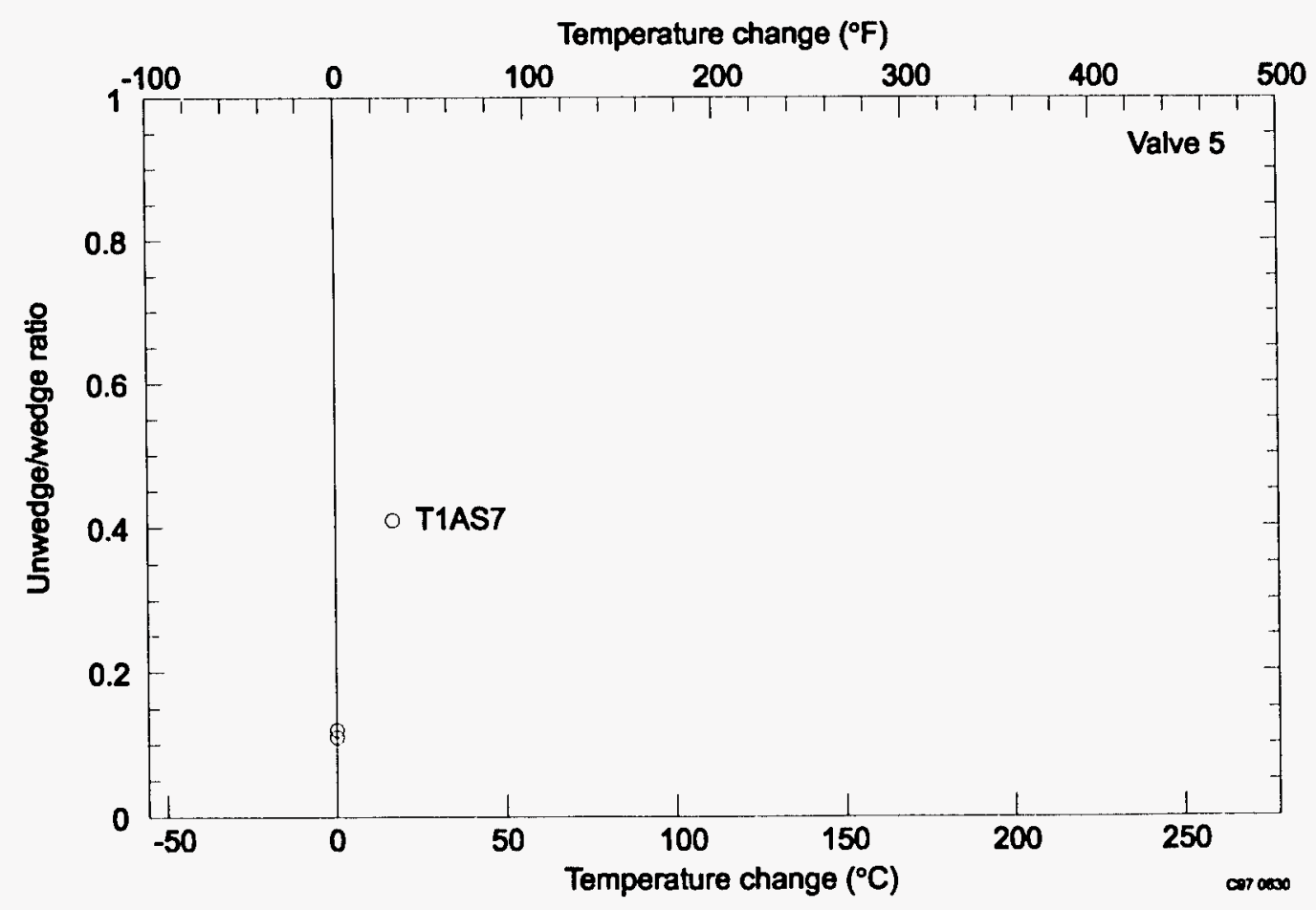

Figure 26. Thermal binding data from GI-87 tests; unwedging/wedging ratio versus temperature change for Valve 5. 


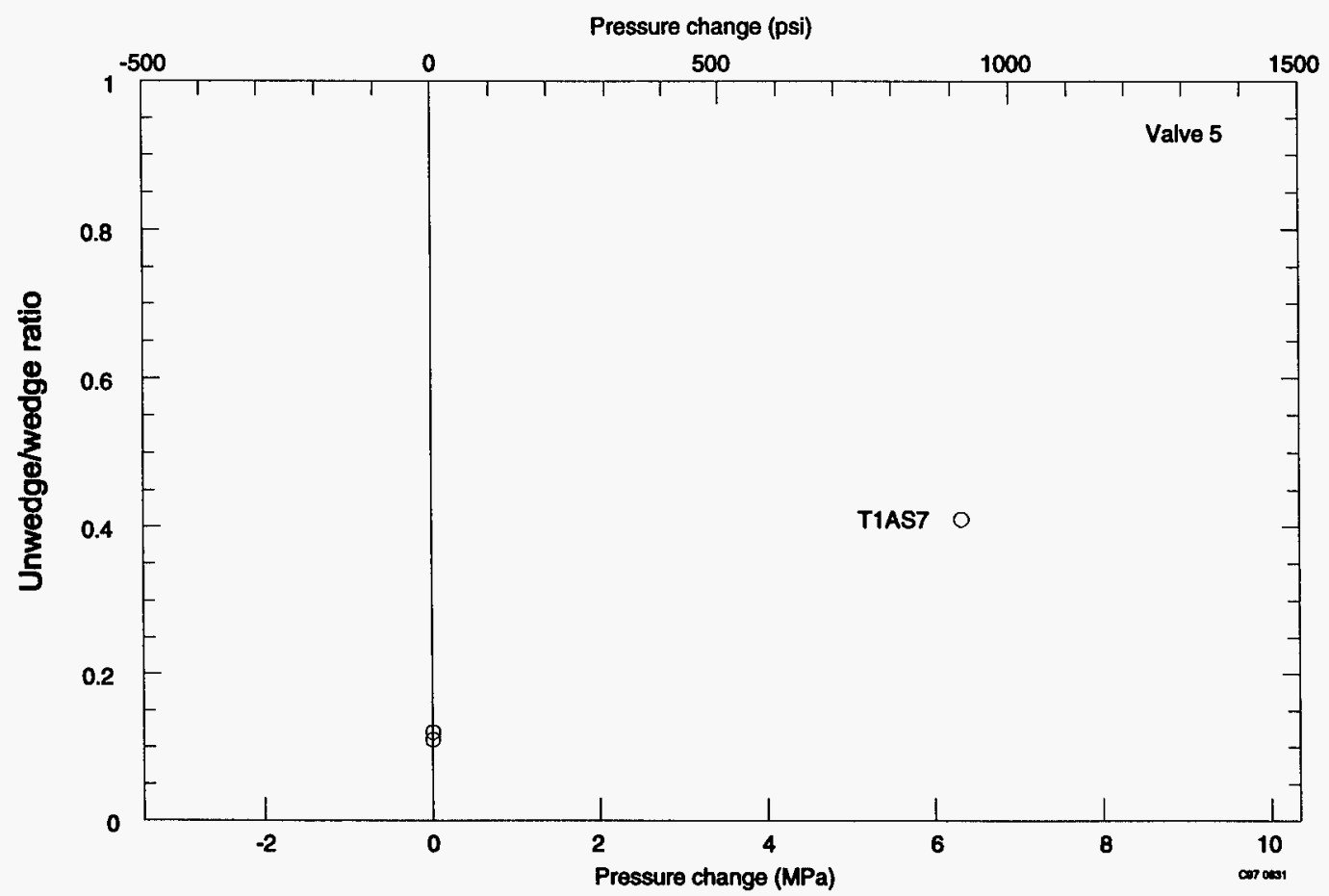

Figure 27. Thermal binding data from GI-87 tests; unwedging/wedging ratio versus pressure change for Valve 5.

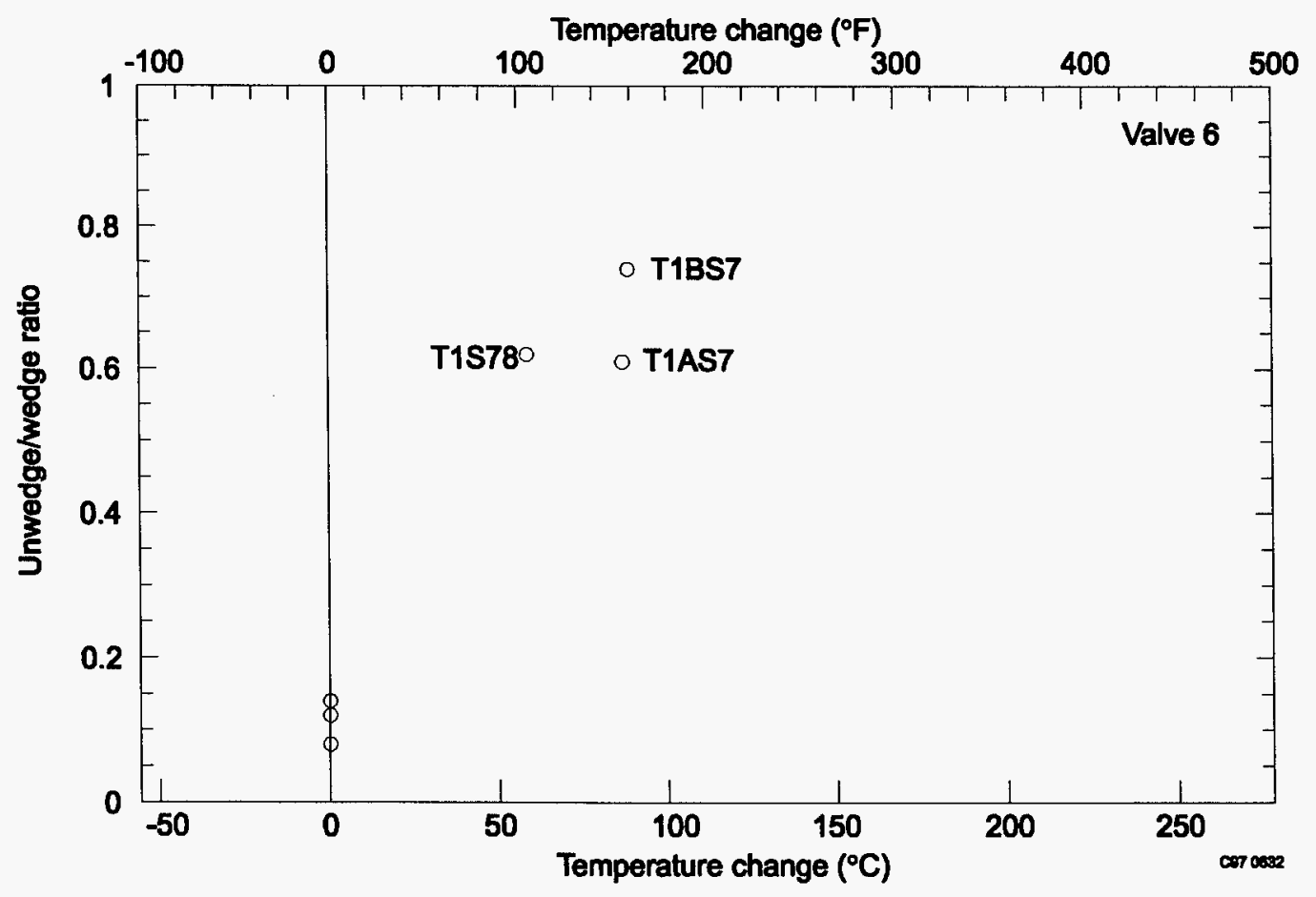

Figure 28. Thermal binding data from GI-87 tests; unwedging/wedging ratio versus temperature change for Valve 6. 
Thermal Binding Test Results

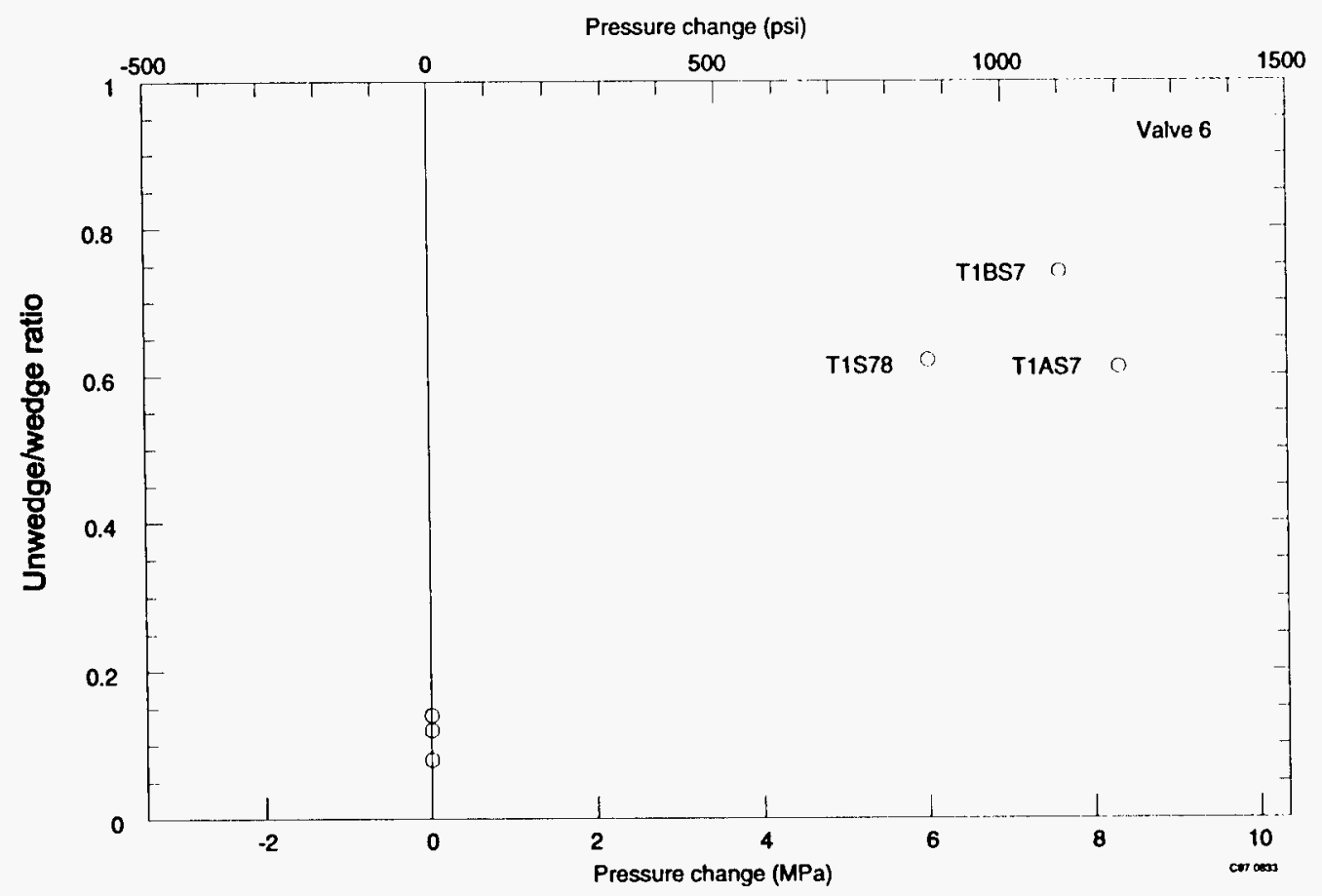

Figure 29. Thermal binding data from GI-87 tests; unwedging/wedging ratio versus pressure change for Valve 6. 


\section{SUMMARY}

Pressure locking can occur when the bonnet pressure in a gate valve is higher than the upstream and downstream pressures. Pressure locking may be thermally induced (when heatup of the valve causes the water trapped in the bonnet to pressurize), or it may be induced by operating sequences that leave highpressure water trapped in the bonnet after the upstream and downstream sides are depressurized. Thermal binding can occur when cooling of a hot valve causes the valve body to contract such that the seats compress the disc more tightly than usual. The effect of pressure locking and thermal binding conditions is that the valve might be more difficult to open than anticipated by typical calculations used to size the motor actuator installed on the valve.

We tested a typical flexible-wedge gate valve and a typical double-disc gate valve at various pressure locking loads. Test temperatures ranged from room temperature to about $93^{\circ} \mathrm{C}\left(200^{\circ} \mathrm{F}\right)$. The cold (room temperature) pressure locking tests consisted of opening the valve with the valve bonnet pressurized with cold water. The hot pressure locking tests consisted of inducing pressure in the bonnet by heating the valve with fluid trapped in the bonnet, then opening the valve against the bonnet pressure. Thermal binding effects were also investigated as tests of opportunity. The stem thrust needed to open the valves against pressure locking loads and thermal binding loads was measured and tabulated, along with the results from unloaded tests and typical hydrostatic opening tests. Some of the tests were designed to investigate the relationship between valve heatup and bonnet pressure. The effects of valve leakage on pressure locking conditions were also investigated, along with the effects of the presence of air pockets entrapped in the valve bonnet. Tests were also conducted to determine whether an air pocket would remain in the bonnet after pressurization and after typical flow through the bonnet.

The test results show that these two valves are susceptible to pressure locking. For the flexiblewedge gate valve, the stem thrust needed to overcome pressure locking loads was notably higher than in hydrostatic opening tests at similar pressures, higher by a factor of 1.1 to 1.5 . For the parallel disc valve, the stem thrust requirement was higher by a factor of 2.05 to 2.4 in the pressure locking tests, compared to the corresponding hydrostatic opening tests.

As expected, valve heatup caused the bonnet to pressurize. Pressurization was very rapid after a temperature increase of about $17^{\circ} \mathrm{C}\left(30^{\circ} \mathrm{F}\right)$. In some instances, leakage from the bonnet reduced the tendency for pressure locking; however, leakage varied considerably. The presence of a differential pressure across the discs at the beginning of the heatup tended to minimize or eliminate leakage, making pressure locking more likely to occur. The presence of an air pocket in the valve bonnet did not prevent bonnet pressurization, but it did delay pressurization until a higher temperature was reached. In one instance that included an air pocket and a small leak, increasing the heatup rate increased the valve's propensity for bonnet pressurization during heatup.

Air pockets trapped in the valve bonnet remained after heatup (with pressurization) and cooldown. A small flow through the bonnet, simulating the flow over the disc and through the bonnet during typical operation with a valve open, significantly reduced the size of the air pocket in only three hours.

The thermal binding tests conducted as part of this test program did not produce thermal binding loads great enough to cause a significant difference in the stem thrust needed to unwedge the valves. For the Walworth valve, an increase of about $9 \%$ was noted. For the Anchor/Darling valve, no increase due to thermal binding effects was noted. However, results from earlier full-scale tests of six flexible-wedge gate valves included instances where valves were closed hot and/or pressurized and later opened cold and/or depressurized. These instances provide useful data representing thermal-binding/depressurization conditions. The results allow comparison of ordinary unseating loads to thermal-binding/depressurization 


\section{Summary}

unseating loads. Whereas the ordinary unseating loads for these six valves are typically about $20 \%$ of the previous seating load, the thermal-binding/depressurization unseating loads ranged from about 40 to $120 \%$ of the previous seating load. 


\section{REFERENCES}

NRC Information Notice 92-26, "Pressure Locking of Motor-Operated Flexible Wedge Gate Valves," U.S. Nuclear Regulatory Commission, April 2, 1992.

NRC Information Notice 96-08, "Thermally Induced Pressure Locking of a High Pressure Coolant Injection Gate Valve," U.S. Nuclear Regulatory Commission, February 5, 1996.

NUREG-1275, Operating Experience Feedback Report, Volume 9, Pressure Locking and Thermal Binding of Gate Valves, C. Hsu, U. S. Nuclear Regulatory Commission, March 1993. 


\section{Appendix A}

\section{Tabulated Data Presented in}

U.S. Customary Units of Measurement 


\section{Appendix A}

\section{Tabulated Data Presented in U.S. Customary Units of Measurement}

In the main body of this report, Tables 5 through 11 and Table 13 present test results in SI units of measurement. This appendix presents the same data in U.S. Customary units of measurement. Table numbers are the same in this appendix as in the main body of the report.

Table 5. Walworth gate valve, cold pressure locking test results.

\begin{tabular}{|c|c|c|c|c|c|c|c|c|c|}
\hline $\mathrm{Te}$ & & & $\begin{array}{l}\text { Pressure } \\
\text { (psig) }\end{array}$ & & & Peak & & & lve \\
\hline Number & Type $^{\mathrm{a}}$ & Up & Bonnet & Down & $\begin{array}{c}\text { Temperature } \\
\left({ }^{\circ} \mathrm{F}\right) \\
\end{array}$ & $\begin{array}{c}\text { Thrust } \\
\left(\mathrm{lb}_{\mathrm{f}}\right)\end{array}$ & $\begin{array}{c}\text { Drag } \\
\left(\mathbf{l b}_{\mathrm{f}}\right)\end{array}$ & $\begin{array}{c}\text { Disc } \\
\text { Factor }^{b} \\
\end{array}$ & $\begin{array}{c}\text { Friction } \\
\text { Factor }^{\mathrm{c}} \\
\end{array}$ \\
\hline 226 & S & 1 & 3 & 1 & 74 & 4,353 & 1,275 & - & - \\
\hline 227 & $\mathrm{HD}$ & 1,072 & 1,075 & -4 & 72 & 14,590 & - & 0.569 & 0.594 \\
\hline 228 & HU & -3 & 1,039 & 1,031 & 77 & 14,612 & - & 0.591 & 0.618 \\
\hline 229 & PL & -3 & 495 & -1 & 73 & 13,652 & - & - & - \\
\hline 230 & PL & -3 & 1,065 & -3 & 69 & 21,132 & - & - & - \\
\hline 231 & PL & -3 & 1,127 & 363 & 72 & 18,798 & - & - & - \\
\hline 232 & PL & 318 & 1,056 & -3 & 73 & 18,634 & - & - & - \\
\hline 233 & $\mathbf{S}$ & -1 & 1 & -2 & 70 & 6,065 & 1,270 & - & - \\
\hline 234 & HD & 1,009 & 1,012 & -2 & 71 & 14,177 & - & 0.586 & 0.612 \\
\hline 235 & $\mathrm{HU}$ & -3 & 1,041 & 1,034 & 71 & 14,778 & - & 0.596 & 0.624 \\
\hline 237 & $S$ & -3 & -2 & -4 & 70 & 10,612 & 1,187 & - & - \\
\hline
\end{tabular}

a. Test type: $\mathbf{S}=$ static (no load) opening test, $\mathrm{HU}=$ hydro opening test across upstream seat, $\mathrm{HD}=$ hydro opening test across downstream seat, $\mathrm{PL}=$ pressure lock opening test.

b. Disc factors were calculated from the peak unwedging thrust, using the equation described in AppendixB.

c. Friction factors were calculated from the peak unwedging thrust, using the equation described in Appendix C. 
Appendix A

Table 6. Walworth gate valve, cold pressure locking test results (low friction tests).

\begin{tabular}{|c|c|c|c|c|c|c|c|c|c|}
\hline $\mathrm{Te}$ & & & $\begin{array}{c}\text { Pressure } \\
\text { (psig) }\end{array}$ & & Bonnet & $\begin{array}{c}\text { Peak } \\
\text { Unwedging }\end{array}$ & Packing & & lve \\
\hline Number & Type $^{a}$ & $\mathrm{Up}$ & Bonnet & Down & $\begin{array}{c}\text { Temperature } \\
\left({ }^{\circ} \mathrm{F}\right)\end{array}$ & $\begin{array}{c}\text { Thrust } \\
\left(\mathrm{lb}_{\mathrm{f}}\right)\end{array}$ & $\begin{array}{c}\text { Drag } \\
\left(\mathrm{lb}_{\mathrm{f}}\right)\end{array}$ & $\begin{array}{c}\text { Disc } \\
\text { Factor }^{\mathrm{b}}\end{array}$ & $\begin{array}{l}\text { Friction } \\
\text { Factor }^{c} \\
\end{array}$ \\
\hline 201 & HD & 1,092 & 1,093 & -2 & 72 & 1,693 & - & 0.101 & 0.100 \\
\hline 203 & $\mathrm{HU}$ & 0 & 1,107 & 1,103 & 72 & 1,696 & - & 0.100 & 0.100 \\
\hline 204 & $S$ & 0 & 0 & 0 & 72 & 1,988 & 408 & - & - \\
\hline 205 & $\mathrm{PL}$ & -1 & 222 & -1 & 72 & 3,045 & - & - & - \\
\hline 206 & PL & -1 & 497 & -1 & 72 & 4,217 & - & - & - \\
\hline 207 & PL & -2 & 778 & -2 & 73 & 5,360 & - & - & - \\
\hline 208 & PL & -1 & 1,097 & 0 & 73 & 6,801 & - & - & - \\
\hline 209 & PL & -1 & 1,081 & 301 & 72 & 6,293 & - & - & - \\
\hline 210 & PL & -1 & 1,077 & 587 & 72 & 5,052 & - & - & - \\
\hline 211 & PL & -1 & 1,160 & 912 & 72 & 4,764 & - & - & - \\
\hline 212 & $\mathrm{HU}$ & -1 & 1,130 & 1,125 & 72 & 2,423 & - & 0.127 & 0.123 \\
\hline 213 & PL & 314 & 1,116 & -2 & 72 & 7,268 & - & - & - \\
\hline 214 & $\mathrm{PL}$ & 621 & 1,132 & -1 & 73 & 6,479 & - & - & - \\
\hline 215 & PL & 899 & 1,122 & -2 & 72 & 5,535 & - & - & - \\
\hline 216 & HD & 1,136 & 1,137 & -1 & 72 & 1,948 & - & 0.108 & 0.108 \\
\hline 217 & PL & 614 & 1,126 & 297 & 72 & 5,848 & - & - & - \\
\hline 218 & PL & 319 & 1,082 & 316 & 73 & 6,659 & - & - & - \\
\hline 219 & HD & 1,092 & 1,092 & -1 & 73 & 2,091 & - & 0.116 & 0.116 \\
\hline 221 & $\mathrm{HU}$ & -1 & 1,092 & 1,086 & 72 & 3,151 & - & 0.158 & 0.157 \\
\hline 222 & PL & -1 & 255 & -1 & 72 & 4,083 & - & - & - \\
\hline 223 & PL & -1 & 547 & -1 & 73 & 5,816 & - & - & - \\
\hline 224 & PL & -2 & 829 & -2 & 73 & 7,258 & - & - & - \\
\hline 225 & $\mathrm{PL}$ & -1 & 1,126 & -1 & 72 & 8,888 & - & - & - \\
\hline
\end{tabular}

a. Test type: $\mathrm{S}=$ static (no-load) opening test, $\mathrm{HU}=$ hydro opening test across upstream seat, $\mathrm{HD}=$ hydro opening test across downstream seat, $\mathrm{PL}=$ pressure lock opening test.

b. Disc factors were calculated from the peak unwedging thrust, using the equation described in Appendix B.

c. Friction factors were calculated from the peak unwedging thrust, using the equation described in Appendix C. 
Table 7. Walworth gate valve, thermally induced pressure locking test results.

\begin{tabular}{|c|c|c|c|c|c|c|c|c|c|}
\hline Tes & & & $\begin{array}{c}\text { Pressure } \\
\text { (psig) }\end{array}$ & & & Peak & & & \\
\hline Number & Type $^{\mathrm{a}}$ & Up & Bonnet & Down & $\begin{array}{c}\text { Temperature } \\
\left({ }^{\circ} \mathrm{F}\right) \\
\end{array}$ & $\begin{array}{c}\text { Thrust } \\
\left(\mathrm{lb}_{\mathrm{f}}\right)\end{array}$ & $\begin{array}{l}\text { Drag } \\
\left(\mathrm{lb}_{\mathrm{f}}\right)\end{array}$ & $\begin{array}{c}\text { Disc } \\
\text { Factor }^{b} \\
\end{array}$ & $\begin{array}{l}\text { Friction } \\
\text { Factor }^{c} \\
\end{array}$ \\
\hline 307 & PL & 34 & 1,073 & -2 & 203 & 18,251 & - & - & - \\
\hline 308 & $S$ & 14 & 16 & 12 & 217 & 6,354 & 1,180 & - & - \\
\hline 309 & HD & 1,022 & 1,024 & -2 & 190 & 11,895 & - & 0.489 & 0.507 \\
\hline 310 & HU & 0 & 922 & 916 & 187 & 10,429 & - & 0.474 & 0.491 \\
\hline 312 & $S$ & 200 & 207 & 196 & 71 & 5,866 & 1,383 & - & - \\
\hline 313 & HD & 1,053 & 1,056 & 5 & 69 & 11,226 & - & 0.445 & 0.459 \\
\hline 314 & $\mathrm{HU}$ & 6 & 1,062 & 1,055 & 67 & 12,142 & - & 0.481 & 0.498 \\
\hline 316 & PL & -1 & 1,141 & -3 & 205 & 18,096 & - & - & - \\
\hline 317 & S & 9 & 9 & 8 & 179 & 6,404 & 1,208 & - & - \\
\hline 318 & HD & 1,059 & 1,061 & -4 & 181 & 12,108 & - & 0.480 & 0.498 \\
\hline 319 & HU & -3 & 1,010 & 1,003 & 182 & 12,703 & - & 0.530 & 0.551 \\
\hline 322 & $S$ & 41 & 44 & 57 & 69 & 5,102 & 1,384 & - & - \\
\hline 323 & HD & 1,004 & 1,007 & 44 & 67 & 11,936 & - & 0.514 & 0.534 \\
\hline 324 & HU & 39 & 1,015 & 1,009 & 76 & 12,636 & - & 0.539 & 0.561 \\
\hline 325 & $\mathbf{S}$ & 46 & 49 & 44 & 71 & 3,944 & 1,382 & - & - \\
\hline 326 & HD & 1,097 & 1,100 & -4 & 66 & 14,801 & - & 0.561 & 0.586 \\
\hline 327 & HU & -3 & 1,073 & 1,066 & 70 & 15,256 & - & 0.595 & 0.622 \\
\hline 329 & PL & 35 & 1,105 & -3 & 125 & 17,010 & - & - & - \\
\hline 330 & $S$ & 67 & 42 & 55 & 148 & 5,022 & 1,304 & - & - \\
\hline 331 & HD & 1,080 & 1,083 & -4 & 136 & 14,893 & - & 0.574 & 0.599 \\
\hline 332 & HU & -2 & 1,047 & 1,040 & 133 & 15,242 & - & 0.611 & 0.641 \\
\hline 341 & HU & -1 & 1,119 & 1,114 & 66 & 15,742 & - & 0.593 & 0.621 \\
\hline 342 & $\mathbf{S}$ & 1 & 2 & 2 & 70 & 5,924 & 1,306 & - & - \\
\hline 343 & PL & 2 & 1,050 & 3 & 65 & 19,501 & - & - & - \\
\hline
\end{tabular}

\footnotetext{
a. Test type: $\mathrm{S}=$ static (no-load) opening test, $\mathrm{HU}=$ hydro opening test across upstream seat, $\mathrm{HD}=$ hydro opening test across downstream seat, $\mathrm{PL}=$ pressure lock opening test.

b. Disc factors were calculated from the peak unwedging thrust, using the equation described in Appendix B.

c. Friction factors were calculated from the peak unwedging thrust, using the equation described in Appendix C.
} 


\section{Appendix A}

Table 8. Leak rate data from heatup tests.

\begin{tabular}{cccccc}
\hline $\begin{array}{c}\text { Initial Bonnet } \\
\begin{array}{c}\text { Pressure } \\
(\mathrm{psig})\end{array}\end{array}$ & $\begin{array}{c}\text { Average } \\
\text { Heat Rate } \\
\left({ }^{\circ} \mathrm{F} / \mathrm{hr}\right)\end{array}$ & $\begin{array}{c}\text { Average Leak } \\
\text { Rate from Bonnet } \\
\text { to Downstream } \\
\left(\mathrm{cm}^{3} / \mathrm{min}\right)\end{array}$ & $\begin{array}{c}\text { Range of Bonnet } \\
\text { to Downstream } \\
\text { Leak Rates } \\
\left(\mathrm{cm}^{3} / \mathrm{min}\right)\end{array}$ & $\begin{array}{c}\text { Average Leak Rate } \\
\text { from Upstream to } \\
\text { Maintain } 50 \mathrm{psig} \\
\left(\mathrm{cm}^{3} / \mathrm{min}\right)\end{array}$ & $\begin{array}{c}\text { Range of Upstream } \\
\text { Leak Rates to } \\
\text { Maintain } 50 \mathrm{psig} \\
\left(\mathrm{cm}^{3} / \mathrm{min}\right)\end{array}$ \\
\hline 50 & 45 & 16.2 & 12.5 to 22.2 & - & - \\
600 & $\mathrm{NA}$ & 41.1 & $\mathrm{NA}$ & - & - \\
1200 & $\mathrm{NA}$ & 1.5 & $\mathrm{NA}$ & - & - \\
50 & 66.6 & 1.6 & 1.45 to 1.83 & 2.33 & 1.38 to 3.12 \\
50 & 54.1 & 1.2 & 0.91 to 3.12 & 2.15 & 1.82 to 2.49 \\
50 & 85.2 & 24.2 & 4.97 to 130 & - & - \\
700 & 13.8 & 2.3 & - & & -
\end{tabular}

Table 9. Leak rate data from cold differential pressure tests.

\begin{tabular}{|c|c|}
\hline $\begin{array}{c}\text { Bonnet Pressure Range } \\
\text { (psig) }\end{array}$ & $\begin{array}{c}\text { Leak Rate from Bonnet } \\
\text { to Downstream } \\
\left(\mathrm{cm}^{3} / \mathrm{min}\right)\end{array}$ \\
\hline 1104 to 1326 & 0.216 \\
\hline 504 to 640 & 1.233 \\
\hline 1039 to 1294 & 0.114 \\
\hline 572 to 670 & 0.078 \\
\hline
\end{tabular}


Table 10. Anchor/Darling gate valve, cold pressure locking test results.

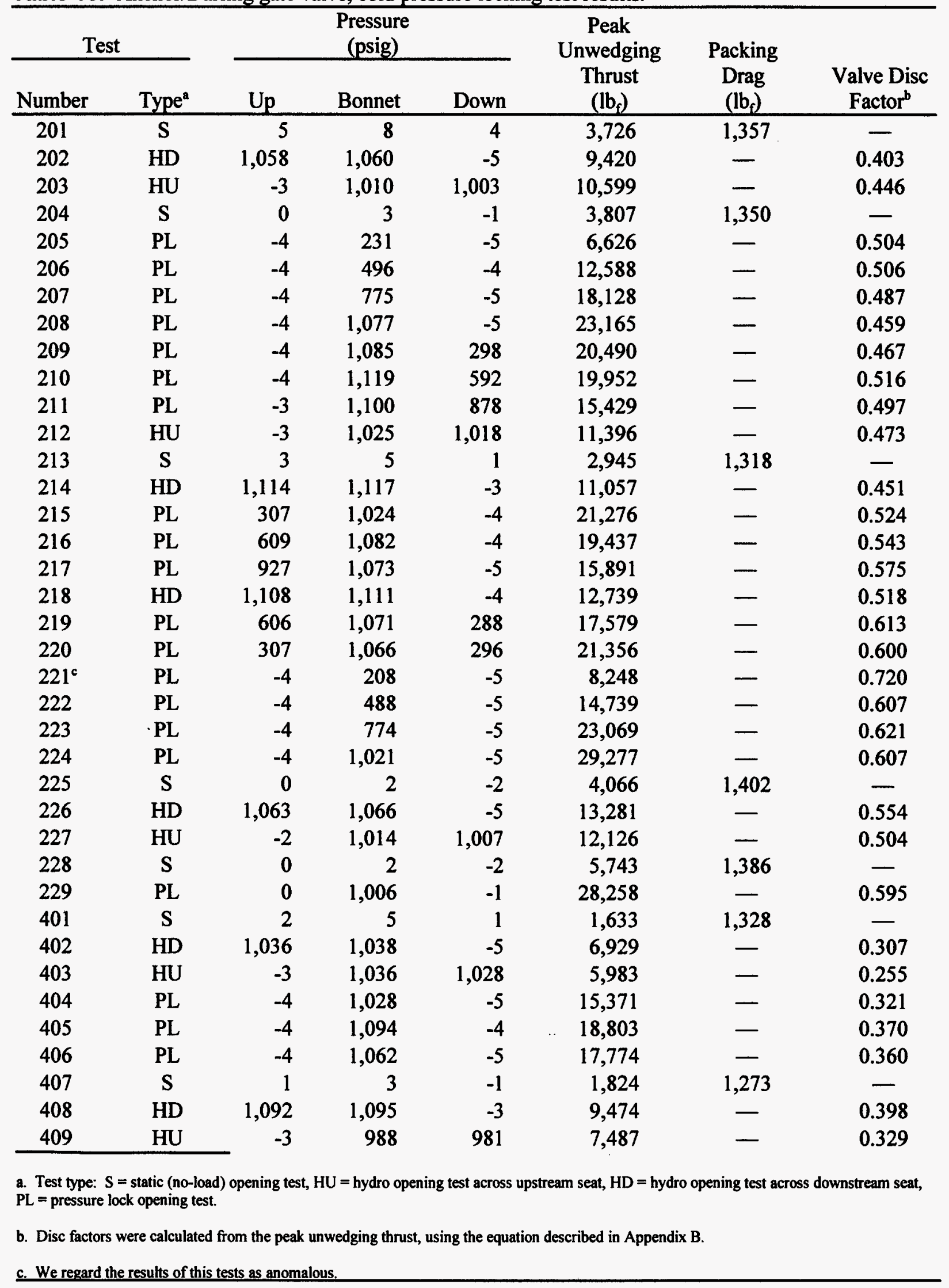


Appendix A

Table 11. Anchor/Darling gate valve, thermally induced pressure locking test results.

\begin{tabular}{|c|c|c|c|c|c|c|c|c|}
\hline & & & $\begin{array}{c}\text { Pressure } \\
\text { (psig) }\end{array}$ & & $\begin{array}{c}\text { Temperature } \\
\left({ }^{\circ} \mathrm{F}\right)\end{array}$ & & & \\
\hline Number & Type & Up & Bonnet & Down & Bonnet & $\left(\mathrm{lb}_{\mathrm{f}}\right)$ & $\left(\mathrm{lb}_{\mathrm{f}}\right)$ & Factor ${ }^{b}$ \\
\hline 301 & S & 189 & 191 & 186 & 72 & 2,425 & 1,383 & - \\
\hline 302 & HD & 1,002 & 1,004 & 45 & 71 & 8,507 & - & 0.400 \\
\hline 303 & HU & 55 & 1,018 & 1,011 & 71 & 10,099 & - & 0.447 \\
\hline 306 & PL & 49 & 1,046 & -6 & - & 26,627 & - & 0.554 \\
\hline 307 & $S$ & 90 & 93 & 88 & 154 & 3,077 & 1,383 & - \\
\hline 308 & HD & 1,090 & 1,092 & 52 & 132 & 10,509 & - & 0.458 \\
\hline 309 & HU & 54 & 992 & 986 & 125 & 10,854 & - & 0.489 \\
\hline 311 & S & 244 & 247 & 242 & 74 & 2,723 & 1,346 & - \\
\hline 312 & HD & 1,089 & 1,092 & 49 & 72 & 10,265 & - & 0.449 \\
\hline 313 & HU & 51 & 1,047 & 1,040 & 72 & 11,737 & - & 0.503 \\
\hline 318 & PL & 48 & 1,025 & -4 & - & 28,596 & - & 0.580 \\
\hline 319 & $S$ & 57 & 60 & 55 & 202 & 3,232 & 1,421 & - \\
\hline 320 & HD & 1,123 & 1,126 & 45 & 184 & 12,231 & - & 0.511 \\
\hline 321 & HU & 59 & 1,018 & 1,010 & 179 & 12,518 & - & 0.551 \\
\hline 323 & $\mathbf{S}$ & 2 & 4 & 0 & 72 & 3,330 & 1,465 & - \\
\hline 324 & HD & 1,050 & 1,053 & 0 & 73 & 11,291 & - & 0.479 \\
\hline 326 & $\mathbf{S}$ & 164 & 168 & 162 & 73 & 2,287 & 1,358 & - \\
\hline 327 & HD & 1,079 & 1,081 & 54 & 72 & 10,475 & - & 0.463 \\
\hline 328 & HU & 52 & 1,095 & 1,088 & 72 & 10,719 & - & 0.443 \\
\hline 331 & PL & 52 & 1,065 & -4 & - & 26,877 & - & 0.550 \\
\hline 332 & $S$ & 140 & 142 & 137 & 153 & 3,057 & 1,423 & - \\
\hline 333 & HD & 1,116 & 1,118 & 48 & 139 & 10,937 & - & 0.463 \\
\hline 334 & HU & 52 & 1,022 & 1,015 & 114 & 11,224 & - & 0.490 \\
\hline 336 & $S$ & 2 & 4 & 0 & 76 & 3,213 & 1,418 & - \\
\hline 337 & HD & 1,102 & 1,105 & 0 & 73 & 12,046 & - & 0.491 \\
\hline 338 & $\mathrm{HU}$ & -3 & 1,137 & 1,130 & 73 & 12,616 & - & 0.474 \\
\hline 339 & $S$ & 347 & 350 & 344 & 75 & 3,848 & 1,389 & - \\
\hline 340 & HD & 1,086 & 1,090 & 50 & 75 & 11,304 & & 0.492 \\
\hline 341 & $\mathrm{HU}$ & 53 & 1,108 & 1,101 & 73 & 11,740 & - & 0.478 \\
\hline 344 & PL & 47 & 1,105 & -4 & - & 28,301 & - & 0.559 \\
\hline 345 & $\mathbf{S}$ & 281 & 284 & 278 & 135 & 4,264 & 1,351 & - \\
\hline
\end{tabular}


Table 11. (continued).

\begin{tabular}{|c|c|c|c|c|c|c|c|c|}
\hline \multicolumn{2}{|c|}{ Test } & \multicolumn{3}{|c|}{$\begin{array}{c}\text { Pressure } \\
\text { (psig) }\end{array}$} & \multirow{2}{*}{$\begin{array}{c}\begin{array}{c}\text { Temperature } \\
\left({ }^{\circ} \mathrm{F}\right)\end{array} \\
\text { Bonnet }\end{array}$} & \multirow{2}{*}{$\begin{array}{c}\text { Peak } \\
\text { Unwedging } \\
\text { Thrust } \\
\left(\mathrm{lb}_{\mathrm{f}}\right) \\
\end{array}$} & \multirow{2}{*}{$\begin{array}{c}\text { Packing } \\
\text { Drag } \\
\left(\mathrm{lb}_{\mathrm{f}}\right)\end{array}$} & \multirow{2}{*}{$\begin{array}{c}\text { Valve Disc } \\
\text { Factor }^{\mathrm{b}}\end{array}$} \\
\hline Number & Type $^{\mathrm{a}}$ & Up & Bonnet & Down & & & & \\
\hline 346 & HD & 1,098 & 1,101 & 46 & 130 & 13,020 & - & 0.557 \\
\hline 347 & $\mathrm{HU}$ & 53 & 1,089 & 1,082 & 113 & 12,357 & - & 0.511 \\
\hline 349 & $S$ & 0 & 1 & -1 & 76 & 3,555 & 1,417 & - \\
\hline 350 & HD & 1,091 & 1,093 & 0 & 75 & 14,184 & - & 0.580 \\
\hline 351 & $\mathrm{HU}$ & -3 & 1,130 & 1,122 & 75 & 12,875 & - & 0.486 \\
\hline 352 & $\mathbf{S}$ & 287 & 292 & 284 & 76 & 1,661 & 1,384 & - \\
\hline 353 & HD & 1,108 & 1,111 & 51 & 75 & 14,234 & - & 0.603 \\
\hline 354 & HU & 51 & 1,094 & 1,087 & 74 & 12,674 & - & 0.519 \\
\hline 361 & PL & 61 & 1,096 & -3 & - & 32,540 & - & 0.647 \\
\hline 362 & $\mathbf{S}$ & 791 & 793 & 787 & 221 & 1,020 & 1,168 & - \\
\hline 363 & HD & 1,124 & 1,127 & 46 & 209 & 10,765 & - & 0.463 \\
\hline 364 & HU & 139 & 1,083 & 1,075 & 208 & 7,348 & - & 0.351 \\
\hline 366 & $S$ & 4 & 6 & 2 & 80 & 2,597 & 1,373 & - \\
\hline 367 & $\mathrm{HD}$ & 1,092 & 1,095 & -4 & 77 & 10,123 & - & 0.420 \\
\hline 368 & HU & -3 & 963 & 956 & 77 & 7,881 & - & 0.348 \\
\hline 369 & $\mathbf{S}$ & 633 & 636 & 629 & 80 & 1,149 & 1,274 & 一 \\
\hline 370 & HD & 1,127 & 1,129 & 51 & 77 & 10,511 & - & 0.449 \\
\hline 371 & HU & 52 & 997 & 990 & 77 & 7,828 & - & 0.360 \\
\hline 375 & PL & 53 & 1,105 & 2 & - & 25,479 & - & 0.501 \\
\hline 377 & $S$ & 1,218 & 1,221 & 1,214 & 204 & -431 & 1,180 & - \\
\hline 378 & HD & 1,090 & 1,093 & 64 & 191 & 8,078 & - & 0.370 \\
\hline 379 & HU & 66 & 969 & 962 & 195 & 7,459 & - & 0.362 \\
\hline 381 & $\mathrm{~S}$ & 11 & 13 & 9 & 76 & 1,626 & 1,351 & - \\
\hline 382 & HD & 1,078 & 1,080 & 4 & 74 & 7,690 & - & 0.330 \\
\hline 383 & HU & -1 & 1,006 & 999 & 74 & 6,584 & - & 0.287 \\
\hline
\end{tabular}


Appendix A

Table 13. GI-87 Phase 2 thermal binding test data.

\begin{tabular}{|c|c|c|c|c|c|c|c|}
\hline \multicolumn{2}{|c|}{$\begin{array}{c}\text { Valve/Test } \\
\text { Number }\end{array}$} & \multirow{2}{*}{$\begin{array}{c}\begin{array}{c}\text { Pressure } \\
\text { Wedging } \\
\text { (psig) }\end{array} \\
11.4\end{array}$} & \multirow{2}{*}{$\begin{array}{c}\begin{array}{c}\text { Temperature } \\
\text { Wedging } \\
\left({ }^{\circ} \mathrm{F}\right)\end{array} \\
42\end{array}$} & \multirow{2}{*}{$\begin{array}{c}\begin{array}{c}\text { Thrust } \\
\text { Wedging } \\
\left(\mathrm{lb}_{f}\right)\end{array} \\
-24,696\end{array}$} & \multirow{2}{*}{$\begin{array}{c}\begin{array}{c}\text { Pressure } \\
\text { Unwedging } \\
\text { (psig) }\end{array} \\
11.4\end{array}$} & \multirow{2}{*}{$\begin{array}{c}\text { Temperature } \\
\text { Unwedging } \\
\left({ }^{\circ} \mathrm{F}\right)\end{array}$} & \multirow{2}{*}{$\begin{array}{c}\begin{array}{c}\text { Thrust } \\
\text { Unwedging } \\
\left(\mathrm{lb}_{\mathrm{f}}\right)\end{array} \\
5,453\end{array}$} \\
\hline Valve 1 & CL2 & & & & & & \\
\hline & $\mathrm{CCl}$ & 0.0 & 57 & $-25,133$ & 9.3 & 58 & 5,645 \\
\hline & $\mathrm{CC} 3$ & 8.8 & 58 & $-25,656$ & 9.8 & 58 & 5,579 \\
\hline & $\mathrm{CC} 7$ & 10.9 & 69 & $-26,506$ & 10.8 & 69 & 5,194 \\
\hline & $\mathrm{CC} 8$ & 10.8 & 69 & $-26,089$ & 10.6 & 76 & 5,542 \\
\hline & $\mathrm{HC} 2$ & 0.0 & 66 & $-26,192$ & 0.0 & 66 & 6,029 \\
\hline & T1S9 & 0.6 & 410 & $-25,475$ & 0.2 & 161 & 16,749 \\
\hline \multirow[t]{6}{*}{ Valve 2} & SU1 & 55.8 & 72 & $-25,800$ & 55.8 & 72 & 4,383 \\
\hline & $\operatorname{CCS} 1$ & 13.4 & 72 & $-23,766$ & 13.4 & 74 & 3,900 \\
\hline & T1S7 & 901.1 & 529 & $-22,769$ & 0.0 & 418 & 24,252 \\
\hline & T6A1S7 & 423.6 & 446 & $-24,380$ & 0.1 & 357 & 15,645 \\
\hline & T6CS7 & 983.0 & 531 & $-24,525$ & 0.0 & 424 & 15,260 \\
\hline & $\mathrm{T} 3 \mathrm{COS} 1$ & 932.9 & 119 & $-25,566$ & 18.0 & 119 & 11,140 \\
\hline \multirow[t]{5}{*}{ Valve 3} & CL4 & 11.7 & 77 & $-16,549$ & 11.7 & 77 & 3,462 \\
\hline & $\mathrm{HCl}$ & 4.7 & 79 & $-16,645$ & 4.7 & 79 & 2,941 \\
\hline & T1AS78 & 864.8 & 525 & $-15,061$ & 0.0 & 448 & 6,541 \\
\hline & T5S78 & $1,060.9$ & 551 & $-15,916$ & 0.0 & 482 & 6,612 \\
\hline & T7S78 & $1,272.0$ & 571 & $-16,043$ & 0.0 & 340 & 10,170 \\
\hline \multirow[t]{2}{*}{ Valve 4} & CCS 1 & 1.2 & 49 & $-35,719$ & 1.1 & 49 & 13,983 \\
\hline & T1S7 & 364.9 & 649 & $-36,091$ & 0.0 & 223 & 35,295 \\
\hline \multirow[t]{3}{*}{ Valve 5} & $\mathrm{CCS} 1$ & 12.3 & 68 & $-37,604$ & 12.3 & 68 & 5,616 \\
\hline & HCSI & 2.4 & 66 & $-37,715$ & 2.4 & 66 & 5,340 \\
\hline & T1AS7 & 923.7 & 528 & $-56,187$ & 7.0 & 498 & 22,361 \\
\hline \multirow[t]{6}{*}{ Valve 6} & SU2 & 0.4 & 65 & $-36,704$ & 0.4 & 65 & 5,488 \\
\hline & $\mathrm{CC} 1$ & 60.2 & 66 & $-37,528$ & 60.2 & 66 & 4,856 \\
\hline & $\mathrm{HCl}$ & 0.0 & 66 & $-38,084$ & 0.0 & 66 & 3,616 \\
\hline & T1S78 & 871.8 & 533 & $-53,385$ & 0.1 & 428 & 30,723 \\
\hline & T1AS7 & $1,204.3$ & 575 & $-53,869$ & 0.0 & 419 & 29,619 \\
\hline & T1BS7 & $1,103.2$ & 563 & $-48,361$ & 2.0 & 404 & 31,963 \\
\hline
\end{tabular}


Appendix B

\section{Disc Factor Equations}




\section{Appendix B}

\section{Disc Factor Equations}

\section{Flexible-wedge Gate Valve}

We used the following equation to calculate the disc factor in opening hydrostatic tests of the flexible-wedge gate valve:

$F_{\text {stem }}=\mu A_{\text {disc }} \Delta P-P_{\text {up }} A_{\text {stem }}+F_{\text {packing }}$

where

$$
\begin{array}{ll}
F_{\text {stem }} & =\text { stem thrust } \\
\mu & =\text { valve disc factor } \\
A_{\text {disc }} & =\frac{1}{4} \pi D_{\text {mean }}^{2} \\
\Delta \mathbf{P} & =\left|P_{\text {up }}-P_{\text {down }}\right| \\
A_{\text {stem }} & =\text { stem area } \\
F_{\text {packing }} & =\text { packing drag } \\
D_{\text {mean }} & =\text { valve mean seat diameter } \\
P_{\text {up }} & =\text { upstream pressure (psig) } \\
P_{\text {down }} & =\text { downstream pressure (psig). }
\end{array}
$$

\section{Parallel Disc Gate Valve}

For hydrostatic and pressure locking tests of the parallel disc gate valve, we used the following equation to calculate the disc factor, with separate values representing the mean seat areas for the upstream and downstream discs:

$$
F_{\text {stem }}=\mu\left[\left(P_{\text {bonnet }}-P_{\text {up }}\right) A_{\text {disc up }}+\left(P_{\text {bonnet }}-P_{\text {down }}\right) A_{\text {disc down }}\right]-P_{\text {bonnet }} A_{\text {stem }}+F_{\text {packing }}
$$

where

$$
\mathrm{P}_{\text {bonnet }}=\text { bonnet pressure (psig). }
$$




\section{Appendix C}

\section{Friction Factor Equation}




\section{Appendix C}

\section{Friction Factor Equation}

We used the following equation to calculate the friction factor for the flexible-wedge valve:

$$
F_{\text {stem }}=F_{\text {packing }}+F_{\text {top }}-F_{\text {bot }}-F_{\text {sr }}+\frac{(f \cos \alpha-\sin \alpha)\left(F_{\text {up }}-F_{\text {dn }}\right)}{(f \sin \alpha+\cos \alpha)}
$$

where

$$
\begin{array}{ll}
F_{\text {stem }} & =\text { stem thrust } \\
F_{\text {packing }} & =\text { packing drag } \\
F_{\text {top }} & =P_{\text {up }} A_{\text {seat }} \text { TAN } \alpha \\
F_{\text {bot }} & =P_{\text {down }} A_{\text {seat }} \text { TAN } \alpha \\
F_{\text {sr }} & =P_{\text {up }} A_{\text {stem }} \\
f & =\text { friction factor } \\
F_{\text {up }} & =P_{\text {up }} A_{\text {seat }} \\
F_{\text {down }} & =P_{\text {down }} A_{\text {seat }} \\
A_{\text {seat }} & =\frac{1}{4} \pi D_{\text {mean }}^{2} \\
A_{\text {stem }} & =\text { stem area } \\
\alpha & =\text { seat angle (degrees) } \\
D_{\text {mean }} & =\text { mean seat diameter } \\
P_{\text {up }} & =\text { upstream pressure (psig) } \\
P_{\text {down }} & =\text { downstream pressure (psig). }
\end{array}
$$




\section{Results of Pressure Locking and Thermal Binding Tests of Gate Valves}

1. REPORT NUMBER

and Addinndum Numbers, II eny.)

NUREG/CR-6611

INEEL/EXT-98/00161

\section{AUTHOR(S)}

K. G. DeWall, J. C. Watkins,

M. G. McKellar, D. Bramwell
3. DATE REPORT PUBLISHED

\begin{tabular}{l|l} 
MONTH & VEAR \\
\hline
\end{tabular}

May

4. FIN OR GRANT NUMEER

W6598

6. TYPE OF REPORT

Technical

7. PERIOD COVERED I/nelusive Oares!

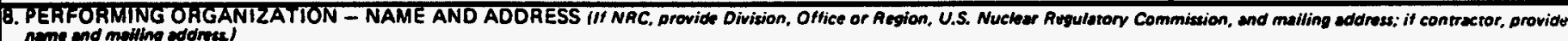

Idaho National Engineering and Environmental Laboratory

Lockheed Martin Idaho Technologies Company

P.O. Box 1625

Idaho Falls, Idaho 83415

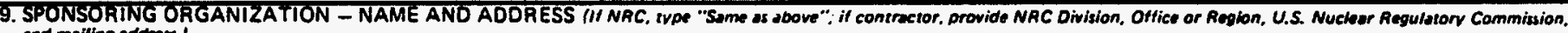
and mailing address.)

Division of Engineering Technology

Office of Nuclear Regulatory Research

U.S. Nuclear Regulatory Commission

Washington, D.C. 20555-0001

10. SUPPLEMENTARY NOTES

G. H. Weidenhamer, NRC Project Manager

11. ABSTRACT 1200 words or wossi

The U.S. Nuclear Regulatory Commission (NRC), Office of Nuclear Regulatory Research, is funding the Idaho National Engineering and Environmental Laboratory (INEEL) in performing research investigating the performance of gate valves subjected to pressure locking and thermal binding conditions. Pressure locking and thermal binding are phenomena that make a closed gate valve difficult to open. If the loads associated with pressure locking or thermal binding are very high, the actuator might not have the capacity to open the valve. We tested a flexible-wedge gate valve and a double-disc gate valve under pressure locking and thermal binding conditions. The results show that these valves are susceptible to pressure locking; however, they are not significantly affected by thermal binding. The results also show that seat leakage affects the bonnet pressurization rate when the valve is subjected to thermally induced pressure locking conditions.

12. KEY WORDS/DESCR!PTORS (List worts or phresess that will essist mesear hers in locating the report.) Key Words

motor-operated valve (MOV), pressure locking, thermal binding

13. AVAILABILLTY STATEMENT
Unlimited
16. SECUAITY CLASSIFICATION
TThis Page!
Unclassified
Irnit ReDOFI
Unclassified
15. NUMBER OF PAGES
16. PAICE




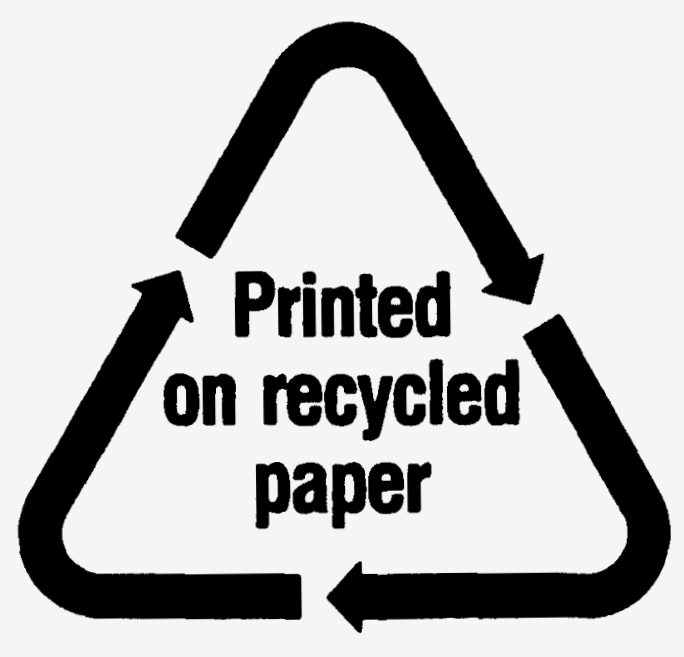

Federal Recycling Program 


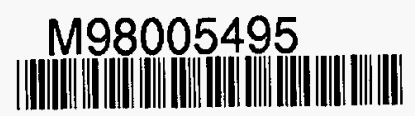

$$
\begin{aligned}
\text { Report Number (14) NURE G/CR }-6611 \\
\text { INEEL/EXT-98/4 }
\end{aligned}
$$

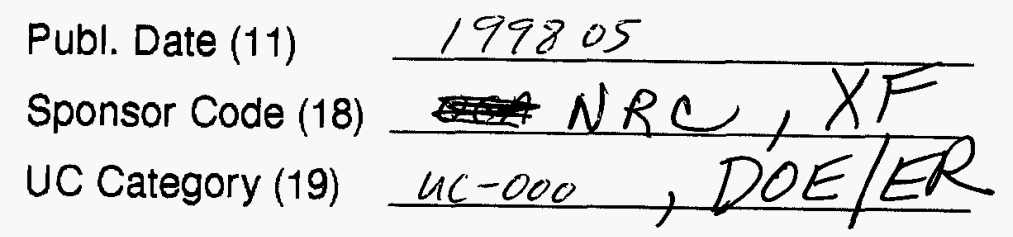

no 1332,15 in foldec 